\title{
Three Essays on the Effect of Pain-of-Payment on Consumers' Financial Decisions
}

\author{
Farnoush Reshadi \\ West Virginia University, fareshadi@mix.wvu.edu
}

Follow this and additional works at: https://researchrepository.wvu.edu/etd

Part of the Business Law, Public Responsibility, and Ethics Commons, and the Marketing Commons

\section{Recommended Citation}

Reshadi, Farnoush, "Three Essays on the Effect of Pain-of-Payment on Consumers' Financial Decisions" (2020). Graduate Theses, Dissertations, and Problem Reports. 7606.

https://researchrepository.wvu.edu/etd/7606

This Dissertation is protected by copyright and/or related rights. It has been brought to you by the The Research Repository @ WVU with permission from the rights-holder(s). You are free to use this Dissertation in any way that is permitted by the copyright and related rights legislation that applies to your use. For other uses you must obtain permission from the rights-holder(s) directly, unless additional rights are indicated by a Creative Commons license in the record and/ or on the work itself. This Dissertation has been accepted for inclusion in WVU Graduate Theses, Dissertations, and Problem Reports collection by an authorized administrator of The Research Repository @ WVU.

For more information, please contact researchrepository@mail.wvu.edu. 
Three Essays on the Effect of Pain-of-Payment on Consumers' Financial Decisions

Farnoush Reshadi

Dissertation submitted to the John Chambers College of Business and Economics at

West Virginia University

in partial fulfillment of the requirements for the degree of

Doctor of Philosophy in

Business Administration-Marketing

M. Paula Fitzgerald, Ph.D., Chair

Vanessa G. Perry, Ph.D.

Jody L. Crosno, Ph.D.

Stephen He, Ph.D.

Laurel A. Cook, Ph.D.

Department of Marketing

Morgantown, West Virginia 2020

Keywords: pain-of-payment, debt repayment, consumer financial decision-making, mental accounting

Copyright 2020 Farnoush Reshadi 


\begin{abstract}
Three Essays on the Effect of Pain-of-Payment on Consumers' Financial Decisions Farnoush Reshadi, Doctoral Candidate, West Virginia University
\end{abstract}

In the past few years, we have witnessed a growing level of consumer debt. Although being in debt increases consumers' stress and reduces their financial well-being, many consumers still take on high levels of debt and hold on to it even when they have financial resources to pay off the debt. Thus, it is of utmost importance to study factors that may influence consumers' debt repayment. In this dissertation, I study consumers' debt repayment behavior through the lens of the double-entry mental accounting theory (Prelec and Loewenstein 1998). This theory argues that consumers' debt repayment behaviors are driven by pain-of-payment-negative emotion evoked when consumers become cognizant of losing their financial resources. In the first essay, I summarize the literature on pain-of-payment (PoP), and offer a new conceptualization that distinguishes between immediate and anticipatory pain of payment. In the second and third essays, I examine when and how consumers' loan repayment behavior is influenced by anticipatory PoP. I argue that expecting high levels of anticipatory PoP associated with future debt repayments influences consumers' likelihood of accelerating debt repayments. I refer to this tendency as the "rip off the Band-Aid" effect. This effect explains the situation when consumers pay off a loan faster than the predetermined loan term due to experiencing high levels of anticipatory PoP. In Essays II and III, I propose a few factors that would influence consumers' tendency to rip off the Band-Aid. The findings of this research make several contributions to the literature on PoP, and also provide directions for public policymakers who seek to design interventions to nudge consumers to pay their debts. 
To Mom, Dad, Mehrnoosh and Amir, for their endless love and support. 


\section{ACKNOWLEDGMENTS}

I would like to extend a most gracious acknowledgment to my advisor, Dr. M. Paula Fitzgerald. I could never thank you enough for the love, support and guidance you have provided me during the past five years. I would also like to acknowledge my dissertation committee members, Dr. Laurel Cook, Dr. Jody Crosno, Dr. Vanessa Perry, and Dr. Stephen He for the time they invested in helping me develop this dissertation. I look forward to continuing to learn from such inspiring, outstanding scholars as I embark on the rest of my academic career. 


\section{Table of Contents}

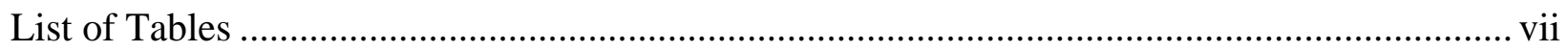

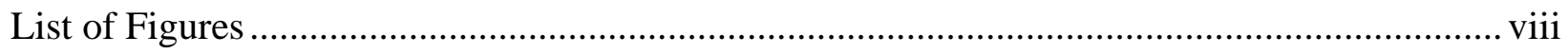

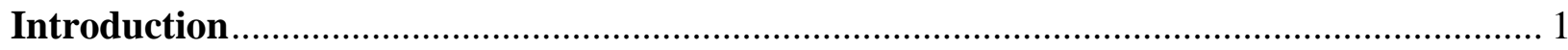

ESSAY I: It Hurts to Spend: A Comprehensive Review and Reconceptualization of Pain-

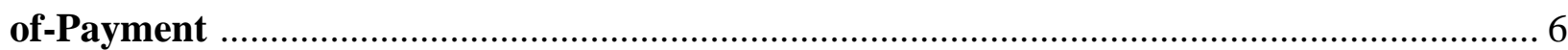

Conceptualization of Pain-of-Payment ..................................................................... 10

Moderators of Pain-of-Payment.............................................................................. 18

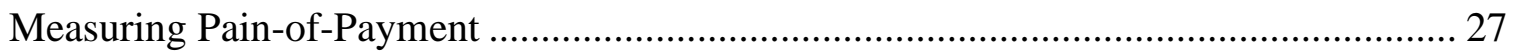

Consequences of Pain-of-Payment ……………………….................................... 36

General Discussion and Future Direction .................................................................... 42

\section{ESSAY II: Ripping Off the Band-Aid: Accelerating Repayment of Socially Unacceptable}

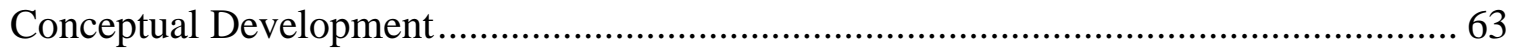

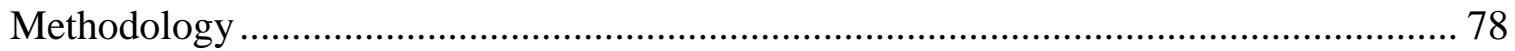

Pretest A- Manipulating Social Approval By Manipulating the Necessity of Borrowing

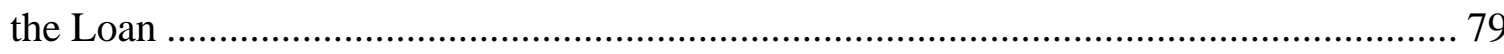

Study 1- Manipulating Social Approval of Loans Using Necessary Vs. Unnecessary

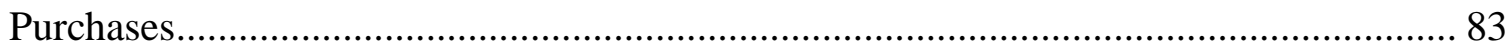

Pretest B- Social Norms Information Provision Manipulation Check.............................. 94

Study 2- Manipulating Social Norms of Debt by Information Provision........................... 98

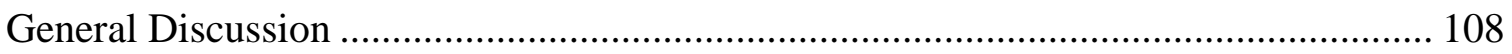

Conclusion And Future Research ......................................................................... 110

ESSAY III: Ripping off the Band-Aid: When and How Perceived Benefits of a Product

Purchased with a Loan Influences Loan Repayment .......................................................... 113

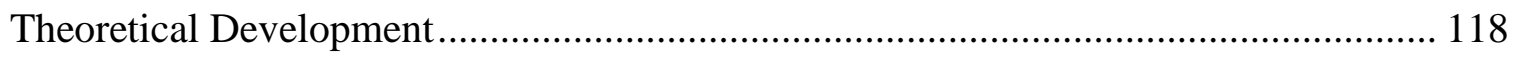

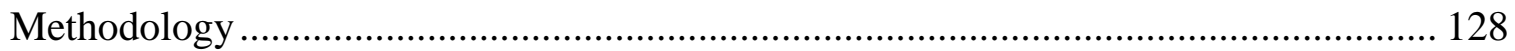

Pretest A- Testing Benefits and Replacement Manipulations .......................................... 129

Study 1- Exploring the Effect of Remaining Benefits on Loan Repayment.................... 134 
Study 2- Exploring the Effect of Remaining Benefits and Replacement Decisions on

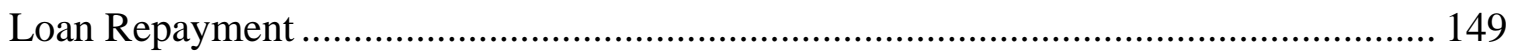

Conclusion and Future Research ......................................................................... 160

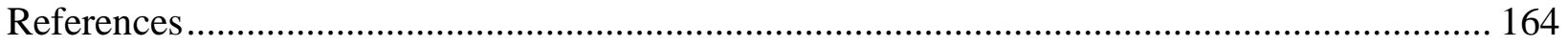

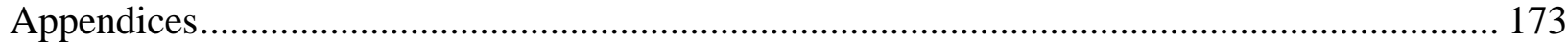




\section{List of Tables}

Table 1- Review of Pain-of-Payment Measures ............................................................. 30

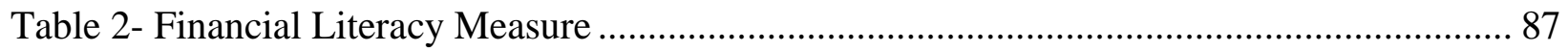

Table 3- Study 1- PLS Model Results, Dependent Variable is Repayment Amount .................. 92

Table 4- Study 1- PLS Model Results, Dependent Variable was Repayment Acceleration ........ 93

Table 5- Study 2- PLS Model Results, Dependent Variable was Repayment Amount.............. 104

Table 6- Study 2- PLS Model Results ......................................................................... 108

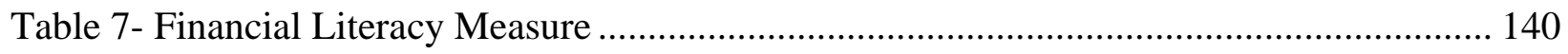

Table 8- Allocation Behavior in the Seven Rounds of the Game............................................ 144 


\section{List of Figures}

Figure 1- Review Framework …………………………………………………………..... 11

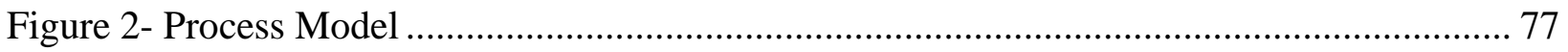

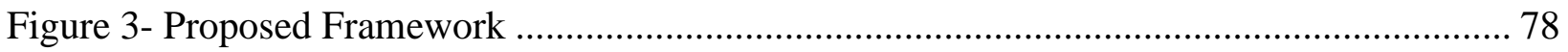

Figure 4- SmartPLS Path Model with Debt Repayment Amount.................................................. 90

Figure 5- SmartPLS Path Model with Debt Repayment Acceleration .......................................... 91

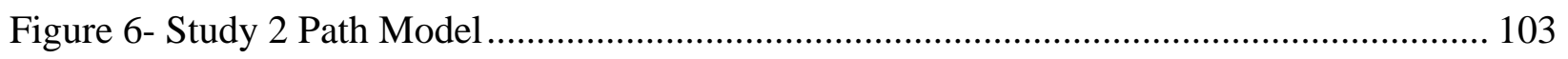

Figure 7- PLS Path with Descriptive Norms ......................................................................... 106

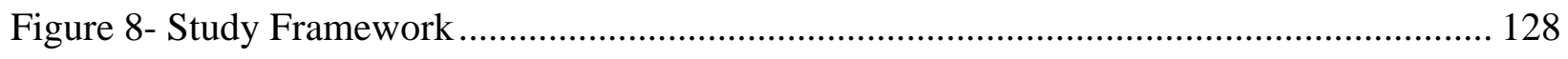

Figure 9- Results of the Benefits Manipulation Check............................................................. 133

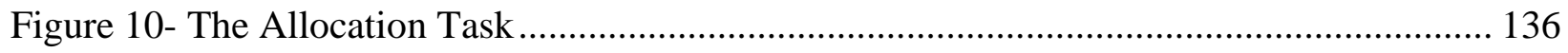

Figure 11- Anticipatory PoP Before and After Playing the Game .......................................... 143

Figure 12- Amount Allocated to the Debt During the Seven Rounds of the Game ................... 145

Figure 13- Amount Allocated to Spending During the Seven Rounds of the Game.................. 145

Figure 14- Amount Saved During the Seven Rounds of the Game .......................................... 146

Figure 15- Amount Paid in Each Experimental Condition .......................................................... 146

Figure 16- Anticipatory Pain-Of-Payment Evoked in the Six Experimental Conditions ............ 154

Figure 17- SPSS PROCESS Model 29 with the Study Variables ............................................. 155

Figure 18- The Average Amount Paid on the Loan in the Six Experimental Conditions.......... 156 


\section{Introduction}

Consumer debt is rising in the United States and other parts of the world. In 2018, American's debt reached a new peak of \$13.21 trillion (Household Debt and Credit Report 2018). Balances on various types of consumer debt including mortgages, auto loans, student loans, and credit card debts have significantly increased in recent years (Household Debt and Credit Report 2018) and this trend seems to be continuing in the future (Komos 2019). The rise of consumer debt is not only limited to the United States. In 2018, the average amount of unsecured consumer debt hit a new peak of $\$ 9,400$ per household in the United Kingdom (Brignall 2019), which was11\% higher than the previous two-year period (Kidd 2019). While the availability of loans in society can increase consumers' quality of life, having high levels of debt can be detrimental to consumers' financial and overall well-being. Indebted consumers lose their financial resources by paying high levels of interest and various fees on their debts (Stango and Zinman 2009). Indeed, Americans paid loan issuers $\$ 113$ billion in credit card interest and fees in 2018 (Gerson 2019). This reduces consumers' available financial slack and hence, their purchase power. In addition, having high levels of debt impacts consumers' health and overall well-being by increasing consumers' stress (Worthington 2006; Tay et al. 2017). Thus, it is of utmost importance to study factors that influence consumers' borrowing and debt repayment behavior.

From an economically rational perspective, consumers' debt repayment decisions must be driven by the economic consequences of not repaying the debt. Consequences include accruing more debt due to the annual interest rate (APR) charged on the balance of the account. However, research has provided ample evidence that a loan's APR is not a strong predictor of 
debt repayment decisions. Previous literature has shown that consumers' debt repayment decisions are driven by factors such as comparing the remaining balances due on multiple credit card debt accounts (Amar et al. 2011; Besharat, Carrillat, and Ladik 2014; Besharat, Varki, and Craig 2015; Brown and Lahey 2015; Gal and Mcshane 2012; Gathergood et al. 2018; Ponce, Seira, and Zamarripa 2014), whether the financial resource allocated to repay consumers' debt was received as a reward or was hard-earned money (Besharat, Carrillat, and Ladik 2014), the hedonic vs. utilitarian nature of the debt (Besharat, Carrillat, and Ladik 2014; Besharat, Varki, and Craig 2015), the minimum required payment amount for credit cards (Hershfield and Roese 2015; Jones, Loibl, and Tennyson 2012; McHugh and Ranyard 2016; Navarro-Martinez et al. 2011; Salisbury 2014; Stewart 2009), the durability of the product (Quispe-Torreblanca et al. 2017), whether the debt was incurred in distant or proximal past (Besharat, Varki, and Craig 2015), and the number of debt accounts (Amar et al. 2011). While previous research provides valuable insights, most of these studies examined debt repayment behavior through the lens of goal and motivation theories (e.g., Amar et al. 2011; Besharat, Carrillat, and Ladik 2014;

Besharat, Varki, and Craig 2015; Brown and Lahey 2015; Gal and Mcshane 2012; Gathergood et al. 2018; Ponce, Seira, and Zamarripa 2014). Studying debt repayment behavior from the lens of other theories can help further our understanding of consumers' behavior in this context. In addition, most of these studies have focused on examining credit card debt repayment and have not examined consumers' behavior in repaying debts that require the consumer to make monthly payments for a certain amount of time such as personal loans. Consumers have different perceptions of credit card loans vs. other sources of loans (Sharma et al. 2018). Finally, previous research has not looked into how the social norms surrounding borrowing and debt repayment, and the perceived benefits of the product/service purchased with the loan influences consumers' 
debt repayment decisions. In this dissertation, I focus on filling these gaps. I study debt repayment decisions through the lens of the double-entry mental accounting theory (Prelec and Loewenstein 1998). This theory argues that consumers' savings and debt repayment decisions are driven by the negative emotion they experience when they become cognizant of losing their financial resources. This emotion is called pain-of-payment and is a psychological reaction to losing money (Zellermayer 1997). This dissertation contributes to the field of consumer financial decision-making by examining the antecedents and consequences of pain of payment in the context of debt repayment.

The first essay is a literature review, examining and summarizing the expansive literature on pain-of-payment. The goal of this essay is to provide a deeper understanding of this emotion, why and when this emotion is evoked, and how this emotion guides and shapes consumer behavior. I summarize the existing literature in a framework to help us improve our understanding of this concept. First, I review the existing research on pain-of-payment, its antecedents, consequences, and measurement. Then, based on the existing evidence, I offer a new conceptualization of pain of payment that distinguishes between immediate pain-ofpayment, experienced immediately after losing financial resources, and anticipatory pain, experienced when becoming aware of a future reduction in financial resources. Finally, I discuss how pain-of-payment can help us further our knowledge of consumer behavior in a wide variety of contexts. I offer several underexplored research questions and multiple avenues for future research.

Essays II and III seek to examine consumers' loan repayment behavior. In particular, I explore factors that influence consumers' decisions to pre-pay or accelerate loan repayment. I argue that expecting high levels of anticipatory pain-of-payment associated with future debt 
repayments influences consumers' likelihood of accelerating debt repayments to pay off the debt faster and avoid experiencing high levels of debt. I refer to this tendency as "rip off the BandAid" effect. This effect explains the situation when consumers decide to pay off a loan faster than the predetermined loan term due to experiencing high levels of anticipatory pain. In Essays II and III, I propose a few factors that would influence consumers' tendency to rip off the BandAid.

Essay II examines consumers' debt repayment behavior by exploring the effect of social norms surrounding debt on repayment decisions. I propose that consumers do not consider all debts as equal. While some debts are perceived to be socially acceptable, others are unacceptable and hard to justify. The goal of this essay is to show that consumers are more likely to rip off the Band-Aid when they perceive a loan as socially unacceptable (vs. acceptable). I argue that making payments for loans that are perceived as socially unacceptable are more aversive and evoke higher levels of anticipatory pain-of-payment compared to socially acceptable debts. To avoid experiencing high levels of pain-of-payment, consumers will be more likely to accelerate debt repayment when they perceive themselves to have high levels of financial self-efficacy. I argue that interventions using normative messages to frame debt as socially unacceptable can increase consumers' debt repayment intentions and help them become debt-free. Findings of this research will provide actionable directions for public policymakers interested in encouraging consumers to repay their debts

The goal of the third essay is to understand how a consumer's decision to rip off the Band-Aid is influenced by her perception of the remaining benefits of the product/service purchased with the loan. I argue that consumers will be more likely to pay off their debts when they feel that the product/service purchased with the loan will not provide any value in the 
future. This effect occurs because making payments on a loan that provides low (vs. high) value to the consumer evokes higher levels of pain of payment. To avoid experiencing this negative affect, consumers will be more likely to rip off the Band-Aid by paying more than the predetermined monthly payments towards the loan. I further propose that this effect depends on whether the consumer intends to replace the product and whether the consumer perceives herself to have the financial self-efficacy to pre-repay the loan.

The three essays will help marketing scholars and public policy makers to learn more about consumers' debt repayment intentions and behavior. Results of this research make various theoretical contributions to the marketing literature and also provides directions for public policymakers who seek to design interventions to nudge consumers to pay their debts. 


\section{ESSAY I:}

\section{It Hurts to Spend: A Comprehensive Review and Reconceptualization of Pain-of-Payment}

Farnoush Reshadi, Doctoral Candidate, West Virginia University 


\begin{abstract}
Consumers must pay for the products and services that they purchase. While consuming products and services are often pleasurable, paying for them evokes a negative psychological emotion called pain-of-payment. Consumers experience pain-of-payment every time they make a payment or when they consider making a payment in the future. Although experiencing pain-ofpayment can significantly influence a wide range of consumers' decisions and behavior, the research on pain-of-payment is limited, and in some cases controversial. In this paper, I conduct a comprehensive review of the literature on pain-of-payment, and propose a new conceptualization of this construct that distinguishes between immediate pain-of-payment-experienced immediately after spending financial resources, and anticipatory pain-of-payment-experienced when considering a future reduction in financial resources. I then discuss the diverse implications of distinguishing between these two types of pain-of-payment. The goal of this literature review is to stimulate research on pain-of-payment to help us improve our understanding of this concept and the effect of experiencing this emotion on various consumer decisions and behavior.

Keywords: pain-of-Payment, anticipatory pain-of-payment, spending, mental accounting
\end{abstract}


Classic economic theory posits that the utility a consumer derives from consumption is defined by the sum of the benefits minus the economic costs of the consumed product or service (e.g., Deaton 1992). However, recent behavioral economic theories have shown that the benefits and costs of a transaction are not merely economic. Research shows a negative affective process associated with spending money, which has a significant influence on consumers' decisions and behavior. This negative affective experience is called "pain-of-payment" (Zellermayer 1997) and is an automatic "psychological reaction to parting with money (p. 9)." Similar to how feelings of shame and guilt can prevent individuals from engaging in unethical behavior, pain-of-payment (PoP) can act as a self-regulatory device that controls consumers' spending and prevents them from overspending (Prelec and Loewenstein 1998). In the previous decades, several studies have explored the effect of pain-of-payment on various consumers' decisions and behaviors such as information search (Shah, Bettman, and Payne 2012), the importance of price information when making a purchase (Sheehan and Van Ittersum 2018), spending (Prelec and Loewenstein 1998; Ariely and Silva 2002; Besharat and Nardini 2018; Sheehan and Van Ittersum 2018), consumption of unhealthy food (Thomas, Desai, and Seenivasan 2011; Bagchi and Block 2011), post-purchase satisfaction and commitment (Shah et al. 2016), attachment to the product purchased (Kamleitner and Erki 2013; Shah et al. 2016), and debt aversion (Greenberg and Hershfield 2016; Prelec and Loewenstein 1998).

The concept of pain-of-payment has mostly been discussed in the mental accounting (Thaler 1980,1985, 2008) and mental budgeting literature (Heath and Soll 1996) to explain how consumers record and keep track of their expenditures and how it affects their purchase decisions. While these studies have provided useful insights, our understanding of the concept of pain-of-payment and the consequences of experiencing this emotion is still limited. Indeed, four 
aspects of previous studies significantly limit our understanding of pain-of-payment. First, the current conceptualization of pain-of-payment only considers an immediate sense of pain associated with spending money. However, research has shown that pain-of-payment is also evoked when consumers anticipate making payments in the future (cf. Bagchi and Block 2011). Previous studies have mostly focused on the immediate and 'real-time' experience of pain and have ignored how anticipatory pain influences consumers' decisions. Second, the literature has not provided a solid explanation for the main cause of experiencing this negative emotion when spending financial resources. Four theories have been used to explain experiencing pain-ofpayment. However, none of these theories has been able to provide a universal explanation for the existence of this emotion. Third, only a few studies have measured pain-of-payment using self-report measures or neurological manifestations of pain. Most research on pain-of-payment has not directly measured this construct. Instead, researchers have used surrogate variables such as the spendthrift-tightwad scale (Rick, Cryder, and Loewenstein 2008) or payment mode (e.g., paying by cash vs. credit card) to measure pain. This is problematic because the evidence on the relationship between these surrogate measures and pain is non-conclusive. The few studies that have tested the effect of these surrogate variables on experiencing pain showed small effect sizes and a weak relationship between these variables and pain-of-payment. Finally, most research on pain-of-payment has explored this emotion when consumers purchase a product and make a onetime payment, and has focused on understanding the aversive impact of this emotion on consumer spending. Research on pain-of-payment has generally ignored situations where consumers make multiple payments to pay for the same product (e.g., when paying for a product with a loan). I believe that experiencing this emotion can influence a wide range of consumer behavior such as debt repayment, tax compliance, donation intentions and borrowing decisions. 
However, research on this topic has been mostly limited to exploring the relationship between an immediate sense of pain and spending decisions. In sum, our current understanding of pain-ofpayment is limited. Hence, the goal of this essay is to conduct a critical review on what is known and unknown about pain-of-payment and identify areas that are left underexplored in the literature. Based on the existing evidence on pain-of-payment, I provide an updated definition of this construct, distinguish between immediate and anticipatory pain, and review the literature that exists on this construct with the goal of stimulating research on this topic in the consumer context.

The current literature review is summarized in a framework, which is shown in Figure 1. The framework consists of three sections. In the first part, which is the heart of the model, I review the current conceptualization of pain-of-payment, how it has been measured and manipulated in the literature, as well as different theories that support and explain how this emotion is evoked and felt, and I provide a new definition of this construct. Next, I explain the situational, personal and consumption-related factors that influence the level of perceived pain by either acting as a buffer against this pain or by increasing the value of money. Third, I review and discuss the ramifications of experiencing this emotion and the effect of this emotion on consumers' decisions and behavior. Finally, I identify important open questions and several avenues for future research.

\section{Conceptualization of Pain-of-Payment}

In this section, I will review and discuss the current conceptualization of pain-of-payment (PoP hereafter) and the theories that explain why this emotion is experienced. I will also provide 
an updated definition of PoP that will encompass all facets of this construct and can be applied to various financial decision-making contexts beyond spending.

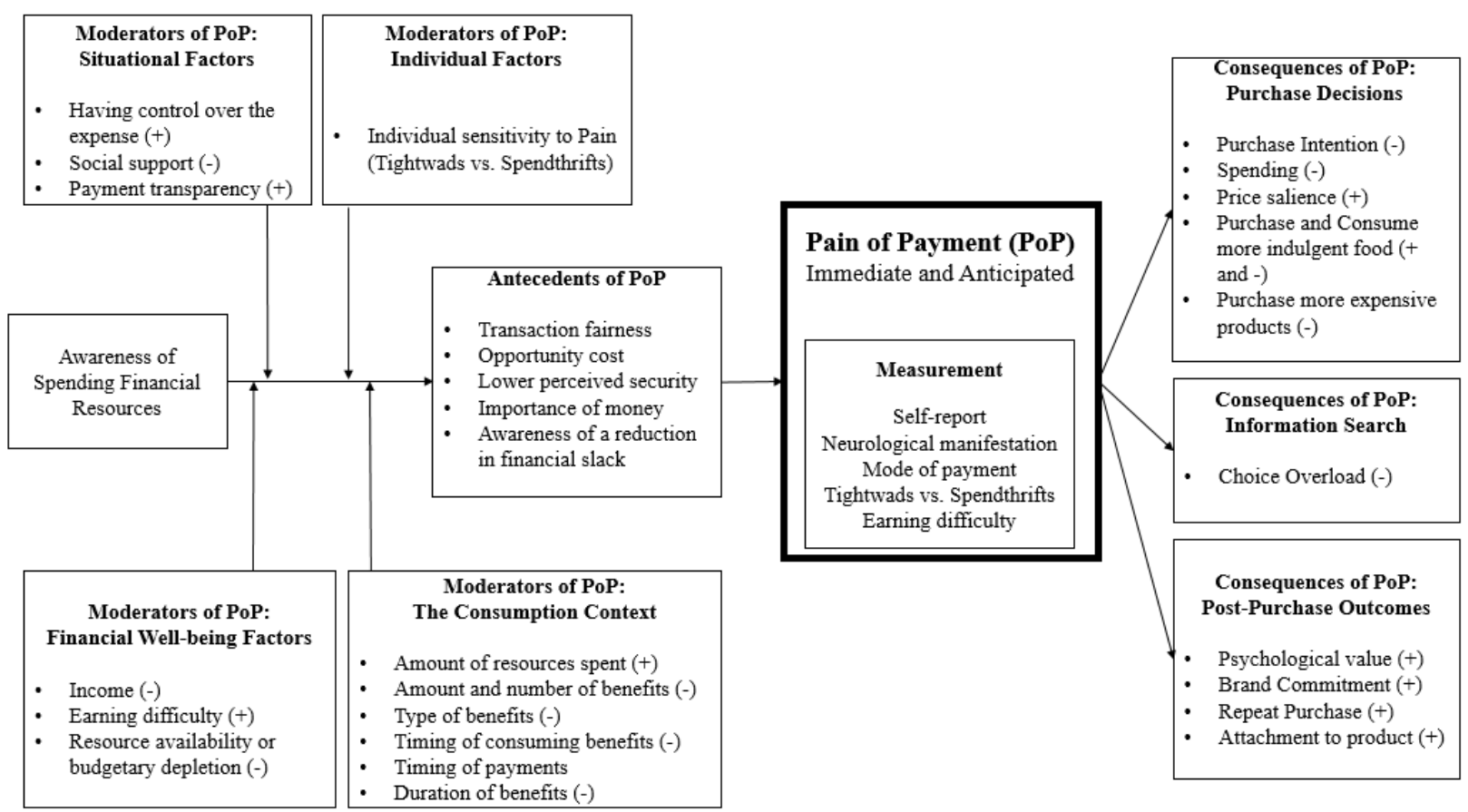

* The signs included for the moderators of PoP indicate the sign of the relationship between each factor and pain. The signs in the consequences of POP indicate the direction of the causal relationship between pain and the outcome.

\section{What is Pain-of-Payment?}

The concept of "pain-of-payment," also referred to as "pain of spending" or the "aversive impact of payment," was first introduced in Zellermayer's (1997) dissertation. Zellermayer (1997) stated that contrary to the classic economic theories, a consumer's purchase decisions are not only influenced by cognitively considering the economic costs and benefits of a purchase. He proposed that consumers experience an "immediate sense of displeasure or pain when making a payment" (p. 2). This sense of pain is a visceral and affective psychological reaction to parting 
with money, and eliminates the need for cognitively contemplating the ramifications of spending such as considering opportunity costs. Zellermayer (1997) conducted several interviews where he asked consumers to explain a transaction that was very hard and painful for them to pay. Using the interviews, Zellermayer (1997) identified several factors that could exacerbate or ease this pain, and proposed that PoP can act as an automatic self-control tool that prevents consumers from overspending. Later research has provided more evidence of the existence of pain-ofpayment. Some research has measured PoP in different situations by asking consumers to report the level of experienced pain (cf. Thomas et al. 2011), uncovering various factors that increase or decrease pain-of-payment and a few consequences of experiencing pain.

Going beyond self-report measures of pain, the literature has provided neurological evidence for the existence of pain-of-payment. In a study, Knutson et al. (2007) asked participants to make purchase decisions regarding several products while their brains were being scanned with functional magnetic resonance imaging (fMRI) devices. Participants first saw a product and viewed its price. They then indicated whether or not they intended to purchase the product. Results indicated that the insula — a region in the brain associated with experiencing physical pain and financial loss (Wager et al. 2013) — was activated when consumers saw the price information. The authors showed that activation was higher for products that were not purchased than those that were purchased, which indicates a negative relationship between pain and purchase behavior. This study provides preliminary correlational evidence of the existence of pain and its dampening impact on spending.

Providing more evidence for the existence of pain and its influence on spending in a controlled setting, Mazar et al. (2017) conducted three experiments. In one experiment they asked participants to view 120 food items, evaluate each item, and make purchase decisions 
while their brains were being scanned with fMRI devices. Half of the participants were asked to pay for the items with cash and the other half were asked to pay by receiving an electric shock. Mazar et al. (2017) hypothesized that if paying by cash is painful, they would find overlapping brain regions involved in making purchase decisions in both conditions. The results confirmed their hypothesis. Paying by cash indeed evokes brain regions related to pain. However, spending only evoked brain regions that process higher-order psychological pain, and was unrelated to the regions related to physical pain. The authors also showed that the level of arousal in the brain increases with the price of the product, indicating that consumers experience higher levels of pain when losing more of their financial resources. In their second experiment, the researchers primed participants either with affective pain, physical pain or no priming. Participants who were primed with affective pain showed lower levels of willingness to purchase than the physical pain or the control condition. This finding provides more support for the existence of physiological pain-of-payment and the influence of this negative visceral reaction on spending and purchase decisions.

\section{Antecedents of Pain-of-Payment}

The literature has provided a few explanations and causes of experiencing pain-ofpayment. These explanations are labeled as antecedents of pain in the model and will be discussed in this section. The first mechanism behind the pain-of-payment can be inferred from Zellermayer's (1997) dissertation, in which he proposed transaction fairness as a variable that could influence the level of experienced pain. A transaction is perceived to be unfair when the purchase "appears to be undeserved or unordinary" (p. 44). For example, when the product or service is too expensive, when the purchase is imposed by the situation vs. one's own will, or when the product does not provide enough benefits to justify payment, payment evokes higher 
levels of pain (p. 24). In an experiment, Zellermayer (1997) asked participants to report the levels of pain they experience when paying various types of bills, and asked them to explain why they thought paying the specific bill was painful. The author then coded the open-ended responses in different categories and ran a regression with pain-of-payment as the dependent variable and these categories as independent variables. Transaction fairness was one of the coding categories that was significantly and highly related to pain $(b=-.625, p<.001)$. Although this research showed a significant influence of fairness on pain, Zellermayer is the only researcher that has looked into transaction fairness as an antecedent of pain-of-payment.

Another possible explanation for experiencing pain is based on the concept of opportunity costs. Frederick et al. (2009) suggest that considering opportunity costs is the root cause of experiencing pain-of-payment. Opportunity costs are the unrealized flow of utility received from alternative options (Buchanan 1969). In other words, opportunity costs refer to the fact that spending money on one purchase means having less to spend on other purchases. Fredrick et al. (2009) proposed that the more consumers consider opportunity costs, the higher the level of experienced pain-of-payment. In one experiment, the authors showed that tightwads, consumers who are highly sensitive to pain-of-payment, are not affected by manipulations that increase the salience of opportunity costs. While this explanation is plausible, research has shown that consumers often do not consider opportunity costs when making purchases (Frederick et al. 2009; Spiller 2011). If pain-of-payment occurs as a reaction to considering opportunity costs, consumers must only experience this emotion when opportunity costs are salient. However, evidence supports the existence of pain-of-payment without making opportunity costs salient (e.g. Sheehan and Van Ittersum 2018). Thus, this theory cannot be a universal explanation of pain-of-payment. 
Another line of research argues that money is a valuable and limited resource, and spending this resource evokes the unpleasant feeling of pain. Zhou and Gao (2008) proposed that money is a source of protection, and security and losing this resource lowers consumers' sense of security. Although Zhou and Gao (2008) did not empirically support this hypothesis, Xu et al. (2012) provided evidence in support of this proposition. The authors proposed that money and social support are two sources of feeling protected and secure. They argued that consumers who have high levels of one of these two resources are not sensitive to a reduction to the other resource. In their experiments, Xu et al. (2012) manipulated social support in three different ways, and showed that consumers who feel highly supported by others have a lower sense of pain when spending. This effect occurs because social support reduces the importance of money as a protection mechanism, which in turn, will dull the pain of losing money. This theory provides another explanation for experiencing pain-of-payment.

In addition to being a source of protection, the resource slack theory argues that money in itself is a valuable and, for most consumers, is a limited financial resource (Zauberman and Lynch 2005). Financial slack is "the perceived surplus of a given resource available to complete a focal task without causing failure to achieve goals associated with competing uses of the same resource" (Zauberman and Lynch 2005, p. 23). Financial slack is not equal to perceived wealth. A consumer can be quite wealthy but low on slack due to liquidity constraints. Based on this theory, Pomerance and Reinholtz (2018) argued that consumers often think that they have a limited amount of financial resources available. Thus, they experience pain when their financial slack is reduced due to spending money. This pain will be lower when consumers expect their financial slack to replenish fast; for example, when they expect to receive their paycheck soon. While this research is still in its early stages, it provides a good theoretical lens to understanding 
the concept of pain-of-payment. Thinking of pain as a psychological reaction to a reduction in financial slack can help explain some of the phenomena explored in the literature, such as experiencing higher levels of pain when budgetary resources are depleted (Sheehan and Van Ittersum 2018; Soster, Gershoff, and Bearden 2014). However, this theory still does not explain why consumers are more likely to purchase and consume unhealthy food when they pay the same amount of money with payment modes that evoke higher levels of pain (Bagchi and Block 2011; Thomas, Desai, and Seenivasan 2010) or why some consumers with the same financial slack expect the pain of repaying a personal loan to grow over time while others expect it to fall (Greenberg and Hershfield 2016). In conclusion, the previous literature has provided a few explanations for the existence of pain-of-payment; however, the mechanism behind experiencing pain-of-payment is still not clear.

\section{A New Definition of Pain-of-Payment}

Extant research has used the concept of experiencing an immediate pain-of-payment to explain various consumer phenomena. While pain-of-payment has been conceptualized in the literature as an immediate affective state experienced at the moment of spending, research on painof-payment suggests these are important elements excluded from this definition. First, contrary to the proposed definition of pain, pain-of-payment can be experienced without making the actual payment and when money has not left the consumer's account. For example, when shopping in a grocery store, consumers reported experiencing pain-of-payment during the shopping experience, before checking out and before making the actual payment (Sheehan and Van Ittersum 2018). This may happen because consumers have already made the final decision to purchase the product and they know that they will purchase that product. However, according to the current definition, consumers experience pain immediately after making payments (Zellermayer 1997, p.2). Second, in some 
situations, consumers may not experience pain-of-payment when they make the actual payments. Ample research on the mode of payment has shown that consumers will experience less pain when they make payments using a credit card vs. cash (e.g. Raghubir and Srivastava 2008). Research has provided a few explanations for this phenomenon. One of the explanations is that credit cards dull the pain-of-payment because they make the payment less transparent (Raghubir and Srivastava 2008). When consumers pay with credit cards, they do not transfer the money to the credit card issuing bank until they pay their monthly statement. Since a consumer's monetary resources do not deplete at the moment of purchase, the consumer will experience less immediate pain at the moment of purchase. This is also the case for automatic payments. A consumer is likely to experience less pain-ofpayment when she pays for a product or service using automatic payments, because she may not be aware that the money has left their account. Hence, in some situations, consumers may not experience pain even when they spend money. Finally, if pain-of-payment occurs due to losing financial resources, pain-of-payment must be experienced when consumers lose financial resources other than cash. Savings, credit, and loans are all different sources of money that can provide a consumer with a sense of security and protection. Hence, pain-of-payment must be experienced when any of these resources are lost, and it should not only be limited to spending cash. Since the current definition of pain does not cover all dimensions of pain-of-payment, I provide a new definition of pain-of-payment that distinguishes between two types of pain. The first type is immediate pain-ofpayment, which I define as "the psychological emotion experienced when a consumer becomes cognizant that she is losing a certain amount of her financial resources." This definition covers the immediate experience of pain. The second type is anticipatory pain-of-payment, which I explain below.

Previous research has shown that consumers' decisions can be affected by the level of pain they expect to experience when thinking about their future expenditure (Greenberg and Hershfield 
2016; Hoelzl, Pollai, and Kamleitner 2009). Greenberg and Hershfield (2016) asked participants to plot the level of anticipatory pain over the first year of an imaginary multi-year loan. They showed that consumers were able to report different patterns of pain when thinking about the loan, finding two patterns in the anticipatory pain among those participants. One group of participants plotted a rising trajectory in which the most pain was anticipated at the latest point in the plot (growing pain). The other group plotted a falling pain trajectory in which the most painful moment was expected to be at the moment of taking out a loan (immediate pain). The authors further showed that these two groups of consumers were different in their level of debt aversion. Participants who expected the pain to grow over time were less likely than the other group to be willing to take out the loan. This suggests that consumers can predict the level of pain they will experience in the future, and this prediction affects their current financial decisions. Thus, it is important to study this aspect of pain that is expected to be experienced in the future. I refer to this aspect of pain as anticipatory pain, and I define it as "the psychological emotion consumers experience when they become cognizant that they will lose a certain amount of their financial resources in future." Importantly, the level of immediate and anticipatory pain depends on the amount of financial resources that are required for the transaction. Overall, consumers will feel higher levels of pain when they lose higher levels of financial resources. In addition to the amount of resources involved, the level of pain depends on various situational, personal and consumption related factors. I will review these factors in the next section.

\section{Moderators of Pain-of-Payment}

Previous literature has uncovered several factors that can lower or exacerbate pain-ofpayment. These factors are labeled as moderators of pain-of-payment in the framework and are categorized into four groups: situational, individual, financial well-being and the consumption 
context. Situational factors are related to the situation under which spending happens. These factors are likely to influence pain by increasing the importance of financial resources to the focal customer (e.g., social support), or by making the reduction in financial resources more salient to the consumer (e.g., payment transparency and mode). Individual factors are trait variables that indicate the sensitivity of individuals to losing financial resources. Financial wellbeing factors are related to the level of the financial status of the individual. These factors are likely to influence the level of experienced pain by increasing the importance of monetary resources to the focal consumer. Finally, the consumption contexts consist of factors related to the transaction that influence pain by influencing the level of perceived transaction fairness. In the next section, I review these factors and explain how they influence the level of experienced pain.

\section{Situational Factors}

Under different circumstances, consumers can experience different levels of pain when spending the same amount from their financial resources (Zellermayer 1997). Extant research found several situations that intensify the experienced pain-of-payment. A consumer will experience higher levels of pain when she perceives low control over an expense (Morris and Huang 2016; Zellermayer 1997). For example, a consumer who spends $\$ 100$ on a product might experience higher levels of pain if the purchase was made voluntarily vs. when it was imposed by the situation. When consumers spend money, they experience pain-of-payment. To reduce this negative affect, consumers contemplate their purchases to find benefits from making that purchase and justify experiencing PoP (Zellermayer 1997). It is easier to justify an expenditure that was incurred by the situation compared to deliberate purchases. Thus, consumers will 
experience lower levels of pain when an expense is imposed by the situation vs. their own will (Morris and Huang 2016).

Another factor that reduces the level of perceived pain is how much a person perceives herself to be socially supported. As explained earlier in the paper, Xu et al. (2014) proposed that money and social support are two interchangeable resources of security and protection. When individuals perceive one of these two resources to be high, they will have less need for the other resource and will assign lower importance to that resource. Hence, individuals will attach a lower value to the same amount of financial resources when they feel socially supported. Thus, the individual will feel less pain-of-payment when spending the same amount of money. The painbuffering effect of social support is greater for hedonic vs. utilitarian purchases, because when money's importance is reduced, it is easier for the consumer to justify making hedonic purchases (Okada 2005; Prelec and Loewenstein 1998).

Payment transparency is another factor that influences the level of perceived pain. According to the definition, pain-of-payment will be experienced when consumers become cognizant of losing resources. Hence, any factor that increases the transparency of losing resources will exacerbate the level of perceived pain. Transparency is the "vividness with which individuals can feel the outflow of money" (Raghubir and Srivastava 2008, p. 204). Soman 2003) proposed that payment transparency depends on the salience of the form of payment, the salience of the amount paid, and the relative timing of transaction and money outflow. Using payment mechanisms such as spending with credit cards (Raghubir and Srivastava 2008) or autopayments that reduce any of these three factors will attenuate the pain-of-payment. I will explain this variable in more detail in the measurement section where I discuss the difference between different modes of payment in pain. 


\section{Individual Factors}

Extant research on physical pain has shown that individuals differ in their sensitivity to physical pain. Patients with the same condition experience different levels of pain due to an individual level of pain tolerance (c.f., Nielsen, Staud, and Price 2009). Analogous to physical pain, research has argued that individuals are different in the level of sensitivity to the psychological pain-of-payment. To capture this individual difference, Rick, Cryder, and Loewenstein (2008) developed a scale, which is called the tightwad-spendthrift scale (TW/ST scale hereafter). Tightwads — "consumers who feel an intense pain of paying," (p. 767) are more affected by the pain-of-payment. By contrast, spendthrifts are less sensitive to this pain and are more likely to spend in the same purchase situation. Rick, Cryder, and Loewenstein (2008) argued that tightwads will be more likely to purchase when the situational factors reduce PoP. For example, they showed that tightwads are more likely to pay a $\$ 5$ shipping fee when it is framed as a “small $\$ 5$ fee” vs. "\$5 fee." While this framing increases tightwads' willingness to spend, it does not affect spendthrifts' actual spending. In addition, when asking for a certain amount of money, tightwads are more likely to ask for the money in higher denomination when they need to exert self-control to curb their spending (Raghubir and Srivastava 2009).

The TW/ST scale is related to, but distinct from price consciousness and frugality. Rick, Cryder, and Loewenstein (2008) showed that the TW/ST scale is moderately correlated (r=-.40; $\mathrm{p}<.05)$ but distinct from price consciousness. Later research also found a low correlation between these two scales ( $r=-.022 ; \mathrm{p}<.05$ in Haws, Bearden and Nenkov 2012). Rick, Cryder, and Loewenstein (2008) also showed that the TW/ST scale is distinct from frugality. Frugality is "a unidimensional consumer lifestyle trait characterized by the degree to which consumers are both restrained in acquiring and in resourcefully using economic goods and services to achieve 
longer-term goals" (p. 769). Research has shown that the two concepts are highly correlated ( $\mathrm{r}=$ .46, p<.001 in Rick, Cryder, and Loewenstein' (2008) work; and r=-.49; $\mathrm{p}<.05$ in Haws, Bearden and Nenkov's (2012) work). However, Rick, Cryder, and Loewenstein (2008) suggested that these two concepts are distinct from each other. They proposed that frugal consumers are different from tightwads, in that frugality is driven by a tendency to save while tightwadism is driven by avoiding spending. They ran an experiment where respondents rated the extent to which they agreed with two sentences: "Saving money is pleasurable for me" and "Spending money is painful for me." Respondents then ranked how much they agreed with items from the TW/ST and the frugality scales. The authors argued that the extent to which people report experiencing pain is independent of the extent to which they reported pleasure of saving ( $\mathrm{r}=.08)$. They also ran two separate regressions to predict each of these two tendencies (pleasure of saving vs. pain of spending) with the TW/ST and the frugality scales. Results indicated that frugality predicts experiencing pleasure of saving $(b=.45, p<.001)$, but it does not have a significant influence on pain of spending. Likewise, the TW/ST scale is a significant predictor of pain of spending $(b=.42, \mathrm{p}<.001)$, but it does not have a significant influence on experiencing pleasure with saving. This finding indicates that individuals' high sensitivity to pain-of-payment is different from a tendency to be frugal and it might influence consumers' decisions differently. Ample evidence supports the existence of an individual difference in pain. The TW/ST scale has been the only attempt to capture this difference. Much research has used this measure as a substitute for directly measuring pain-of-payment. While this measure captures an individual difference between consumers, evidence regarding the validity of this scale is controversial. Previous research has found low effect sizes when testing the relationship between pain-ofpayment and the TW/ST scale. I will review and discuss this research in detail in the 
measurement section. In addition, when measuring pain by scanning consumers' brains in a purchase situation, Mazar et al. (2016) did not find any difference between the level of PoP between tightwads and spendthrifts. Finally, Rick, Cryder, and Loewenstein (2008) did not explore the antecedents of this sensitivity to PoP, and did not identify the factors that cause this difference in pain sensitivity between tightwads and spendthrifts. Hence, it is unclear whether this scale is indeed capturing individuals' sensitivity to pain.

\section{Financial Well-Being Factors}

Another set of variables that influence the level of experienced pain is financial wellbeing factors. This category includes any factor that influences the importance of money as a resource. Money is considered a limited resource for many consumers; spending from this limited resource evokes psychological pain (Pomerance and Reinholtz 2018; Prelec and Loewenstein 1998). Any factor that influences the marginal utility of money or the availability of this resource (Prelec and Loewenstein 1998) can increase the importance of this resource and the level of experienced pain. For example, individuals feel higher levels of pain when they earn lower income or when money is difficult to earn (Bagchi and Block 2011; Soster, Gershoff, and Bearden 2014). Bagchi and Block (2011) asked participants to imagine they worked at a job that left them exhausted vs. at a job where they needed to spend little effort. Participants who worked at a demanding job reported higher levels of pain when spending money. Soster, Gershoff, and Bearden (2014) also conducted a similar study and showed a positive relationship between earning difficulty and pain-of-payment.

Another factor that can influence the level of experienced pain is the amount of available budget. Spending is more painful when the budget is depleted or is about to deplete (Sheehan and Van Ittersum 2018; Soster, Gershoff, and Bearden 2014). When consumers spend their 
budget, the level of experienced pain depends on what percentage of their budget has been depleted. In their experiments, Soster, Gershoff, and Bearden (2014) showed that spending the same amount of money will cause more pain when a consumer's budget is depleted. They asked participants to imagine that they have withdrawn $\$ 130$ from the bank for their weekly budget and have spent some of this money on necessities. Participants were either told that they have $\$ 10$ or $\$ 88$ left in their budget. All respondents were asked to imagine that they want to purchase a $\$ 10$ movie ticket. This purchase would deplete the budget of the first group of participants and would leave $\$ 78$ in the budget for participants in the second condition. Participants in the spend-to-zero condition were significantly more aversive to spending, indicating that consumers will feel higher pain when their budget is depleted after spending. Confirming these findings, Sheehan et al. (2018) showed that consumers' level of experienced pain evolves during a shopping trip as the consumer's budget is depleted. They showed that for non-budget shoppers, the pain-ofpayment is higher at the end of the shopping trip when budgets are becoming depleted. In sum, this evidence indicates that pain-of-payment is more intense when money becomes scarce.

\section{The Consumption Context}

The last moderator of pain-of-payment in the framework is the consumption context. Several consumption-related factors influence the level of experienced PoP. First, the amount of financial resources spent in that transaction influences the level of evoked pain. As the amount of financial resources spent increases, the consumers will experience higher levels of pain. Shah et al. (2016) showed that consumers experience higher levels of pain when they spent a higher amount of money. The second consumption related factor is the perceived fairness of the transaction. Zellermayer (1997) proposed that the level of perceived pain depends on perceived transaction utility or fairness. In his experiment, he asked participants to indicate why they felt 
pain when paying for different bills. A content analysis revealed that the main factor influencing pain was transaction fairness.

One factor influencing transaction fairness is the perceived benefits of the product. Four different aspects of benefits influence the level of pain: 1) amount or the number of benefits, 2) type of benefits (e.g., hedonic vs. utilitarian), 3) timing of benefits, and 4) the duration of benefits. A consumer experiences lower levels of pain-of-payment when she receives high levels or the high number of benefits from a product, or when she expects the product to provide high levels of benefits in the future (Prelec and Loewenstein 1998). When the product is purchased and consumed at the same moment, the purchase decision is simply defined by comparing the pain experienced by paying for the product and the benefits received at the moment of consumption. If the product provides high levels of benefits, a consumer will feel less pain when paying for that product, and will be more likely to make the purchase (Prelec and Loewenstein 1998). In this situation, the perceived benefits of the product can buffer the pain experienced when paying for it.

The type of benefits received can influence the level of experienced pain in two ways. First, hedonic benefits can reduce the level of evoked pain. Bagchi and Block (2011) showed that consumers are more likely to purchase indulgent products when the pain-of-payment derived from payment mode is high. According to Bagchi and Block (2011), when a consumer pays for a product with cash (vs. credit), she experiences higher levels of pain-of-payment. To reduce this negative affect evoked by making the payment, the consumer is more likely to purchase unhealthy (vs. healthy) products that provide immediate hedonic benefits and lower the negative feeling of pain. Hence, consumers will purchase more unhealthy products when paying by payment modes that evoke higher levels of pain. Second, the type of benefit received from a 
product can interact with payment timing to influence the level of perceived pain. According to Prelec and Lowenstein (1998), paying for a hedonic product after consumption is more painful than paying for them before consuming the product. On the contrary for a utilitarian product, paying for the product evokes higher pain when payment occurs before consumption.

Based on the literature on mental accounting, Prelec and Loewenstein (1998) proposed the theory of "double-entry mental accounting," which suggests that consumers tend to open a mental account for each purchase they make and they track the benefits and costs of that purchase using this mental account. Tracking this "double-entry mental account" will help consumers to evaluate a purchase by comparing the costs and benefits received from that purchase over time. The utility derived from the purchase depends on the degree of coupling between payment and consumption - "how much consumption calls to mind thoughts of payment, and vice versa" (Prelec and Loewenstein 1998, p. 4). Prelec and Loewenstein (1998) argued that consumers prefer to align payments with consumption because when paying for a product, payments will feel painful if they do not evoke thought of consumption. According to Prelec and Loewenstein (1998), consumers engage in a behavior called "prospective accounting," in which they prefer to pay now and consume later. When an individual consumes a product that has been paid off, she consumes the product without experiencing the pain-ofpayment. In this situation, consumption "will be enjoyed as if it were free" (p. 9). This preference for pre-payment is stronger for products for which the benefits are consumed in one consumption episode. For example, consumers are more likely to pre-pay vs. post-pay for a vacation vs. a washer-dryer, because the benefits of the vacation are consumed in one episode. Paying for a vacation after taking the vacation will be painful, because consumers cannot associate the payments with any benefits. In sum, Prelec and Loewenstein (1998) proposed that 
consumers prefer to align the benefits of a product with payments, because thinking about the benefits received from a product can attenuate pain-of-payment.

While the double-mental accounting theory provides useful insights, these propositions have not been empirically tested. Some researchers have examined the payment-benefit alignment hypothesis - the tendency to align benefits with payments to reduce pain (Auh, Shih, and Yoon 2008; Patrick and Park 2006). Auh, Shih and Yoon (2008) showed that consumers indeed "prefer financing schemes that match the pattern of benefits and payments in each period" (p. 292). However, this research has neither measured pain nor has it explored this construct as the mechanism behind a tendency to align benefits with payments. Hence, future research is warranted to explore the relationship between the four aspects of perceived benefit, pain-ofpayment and consumers' behavior.

\section{Measuring Pain-of-Payment}

In previous sections, I reviewed the concept of pain-of-payment shown in the heart of the proposed framework and explained the factors that exacerbate or lower pain, which is shown in the left half of the model. In this section, I will review how pain-of-payment has been measured in the literature.

Pain-of-payment has mostly been measured in the literature by self-report measures. Only two studies have measured pain by scanning consumer's brains. In addition, most researchers have not directly measured pain-of-payment. Instead, they have used mode of payment, the tightwad-spendthrift scale or payment difficulty as proxies for measuring pain. While these surrogate measures have been widely used in the previous literature to measure pain, evidence of the validity of these measures as indicators of pain-of-payment is not conclusive. In this section, 
I review all of these measures and discuss the controversial evidence on how these measures affect pain.

Many researchers who have measured pain have done so by asking consumers to indicate how much pain they felt when paying for a specific product (cf. Rick, Cryder, and Loewenstein (2008), Thomas et al. (2011), Bagchi and Block (2011), study 3; Xu et al. (2015)). Rick, Cryder, and Loewenstein (2008) measured consumers' level of pain by asking them to indicate how much they agree with "spending money is painful for me" and indicate "how painful it was for you to pay for [the product]" on a seven-point scale. They averaged the two items to measure pain. The most cited scale was introduced by Thomas et al. (2011) who measured pain by asking consumers: "How did you feel about spending money on this shopping trip?" Participants indicated their responses on a 5-point nonverbal faces pain scale from a sad smiley [O] to a happy face [ن]. In addition, respondents were shown a list of negative feelings and were asked to check all words that described their feelings at the moment. The list included these words: "Irritated, Restricted, Annoyed, Powerless, Controlled, Suffocated, Inhibited, and None of the above." For each participant researchers counted the number of words that were checked. Many researchers studying pain-of-payment have adopted this measure or have patterned their pain measure after Thomas et al.'s (2011) pain scale.

Although previous studies on pain have mostly used a self-report measure of pain, two studies have measured pain-of-payment using its neurological manifestations. Knutson et (al. 2007) and Mazar et al. (2017) used fMRI equipment to scan consumers' brains while making a purchase decision. They identified certain regions of the brain that are activated due to pain-ofpayment and provided a neurological measure of this construct. 
Many researchers have not directly measured pain-of-payment and have tested their theories by using other constructs as proxies to measure pain. Table 1 provides a review of such studies. For example, Bagchi and Block (2011) used two different proxies to measure pain. In their first study, they used imputed cost as a proxy for pain and they measured this construct by asking consumers to indicate, "How expensive they felt the purchased product was" on a sevenpoint scale. They assumed that purchases that appear as more expensive are more painful. In the second study, they used spending difficulty to measure pain. Bagchi and Block (2011) argued that consumers will experience higher levels of pain when having spending difficulty. Hence, the authors measured pain by asking respondents to indicate, "How difficult it was to spend money in the café," and if they felt they had a lot less money after the purchase (using a seven-point Likert scale from "disagree" to "agree"). Three widely used substitutes to measure pain-ofpayment are the payment mode, payment timing, and the tightwad-spendthrift scale. Due to the popularity of these measures, I will discuss the accuracy of these proxies in measuring pain.

\section{Using Payment Mode to Measure Pain}

Many researchers that discuss pain-of-payment have tested their theories by comparing the variation in certain consumers' behavior when they make payments with different modes of payment. Mode of payment, also called the form of payment in the literature, is the mechanism that consumers use to make their payments (Raghubir and Srivastava 2008). The literature has introduced different modes of payment such as paying with cash, general bank credit card, debit card, check, and store credit card. Researchers have argued that some forms of payments are more painful than others. In particular, many researchers have assumed that paying the same amount of money is more painful when paid with cash vs. bank credit cards. Hence, to test the causal relationship between pain-of-payment and a consumer behavior phenomenon such as 
spending, many studies have explored how that behavior changes when consumers pay with cash vs. a credit card. Frequently, these studies have assumed that this measure directly captures the pain and have not used direct measures of pain such as self-reported pain scale discussed earlier. Although the mode of payment has been widely used as a surrogate variable to measure pain, the evidence on the pain difference between the credit card and cash payments is contradictory.

Table 1- Review of Pain-of-Payment Measures

\begin{tabular}{|c|c|c|}
\hline Pain Measure & Description & References \\
\hline Self-report & $\begin{array}{l}\text { Asking participants to rate their level of pain } \\
\text { using single or multiple-item scales. } \\
\text { Sample measure: } \\
\text { - How much pain do you feel right now due to } \\
\text { paying for [the product]? (1- Not at all, 7- } \\
\text { Very much } \\
\text { - Smiley face to report on pain } \\
\text { - List of negative words } \\
\text { - How expensive they felt the purchased } \\
\text { product was? (1-Not at all, 7-Very expensive) }\end{array}$ & $\begin{array}{l}\text { Thomas, Desai, and Seenivasan } \\
\text { (2011); Bagchi and Block (2011); } \\
\text { Xu et al. (2012); Kamleitner and } \\
\text { Erki (2013); Besharat and Nardini } \\
\text { (2018); Sarofim, Chatterjee, and } \\
\text { Rose (2018); Lee et al. (2019) }\end{array}$ \\
\hline $\begin{array}{l}\text { Neurological } \\
\text { Manifestations }\end{array}$ & Recording brain activities using fMRI scans & $\begin{array}{l}\text { Knutson et al. (2007); Mazar et al. } \\
\text { (2017); Banker et al. (2017) }\end{array}$ \\
\hline Mode of payment & $\begin{array}{l}\text { Using a credit card as a less painful method and } \\
\text { cash as a more painful method. Compare using } \\
\text { credit card vs. cash in the target behavior to show } \\
\text { how pain influences that behavior without } \\
\text { directly measuring pain. }\end{array}$ & $\begin{array}{l}\text { Thomas, Desai, and Seenivasan } \\
\text { (2011); Bagchi and Block (2011); } \\
\text { Chatterjee and Rose (2012); Shah } \\
\text { et al. (2016); Shah, Bettman, and } \\
\text { Payne (2014); Lee et al. (2019) }\end{array}$ \\
\hline Tightwad/Spendthrift & $\begin{array}{l}\text { Using the tightwad-spendthrift scale to report on } \\
\text { the level of sensitivity to pain and then look at the } \\
\text { difference between tightwads and spendthrifts in } \\
\text { a certain behavior to show how pain influences } \\
\text { that behavior without directly measuring pain. }\end{array}$ & $\begin{array}{l}\text { Rick, Small, and Finkel (2011); } \\
\text { Haws, Bearden, and Nenkov } \\
\text { (2012); Hsee et al. (2014); Berman } \\
\text { et al. (2015); Reyna and Wilhelms } \\
\text { (2017); Lee et al. (2019) }\end{array}$ \\
\hline Earning Difficulty & $\begin{array}{l}\text { Manipulate pain by manipulating earning } \\
\text { difficulty } \\
\text { - } \quad \begin{array}{l}\text { Money was earned by working in a } \\
\text { demanding and exhausting vs. easy and } \\
\text { rejuvenating job }\end{array} \\
\text { - } \quad \begin{array}{l}\text { Money was received as a windfall or } \\
\text { hard-earned money }\end{array}\end{array}$ & $\begin{array}{l}\text { Bagchi and Block (2011); Soster, } \\
\text { Gershoff, and Bearden (2014) }\end{array}$ \\
\hline
\end{tabular}


In their seminal paper on mental accounting, Prelec and Loewenstein (1991) proposed that the level of experienced pain-of-payment is different when consumers pay with card vs. cash. The pain difference is due to a lack of transparency when making credit card payments. When paying with credit cards, the actual depletion of financial resources does not happen at the time of purchase. This 'decoupling' of consumption and payment attenuates the immediate pain experienced when making a purchase. One can argue that the consumer will be aware of this depletion at the end of the month when the billing statement is issued. However, according to Prelec and Loewenstein (1998), the billing statement will show a consumer's purchases in an aggregate, thus reducing the chance that the consumer associates that payment with any specific purchase. While this proposition is plausible, the authors did not test the mediation effect of pain in the relationship between mode of payment and spending.

Building on Prelec and Loewenstein (1991), some researchers have tested the difference between payment modes in transparency and how this difference influences consumer spending (e.g. Soman 2001; Raghubir and Srivastava 2008). While they showed significant spending differences when paying with different payment modes, these authors also did not measure and test the mediating role of pain-of-payment.

The paper that has been most highly cited as the evidence of pain difference between cash and credit card is that by Raghubir and Srivastava (2008). Also building on Prelec and Loewenstein (1991), Raghubir and Srivastava (2008) proposed that payment modes that provide higher transparency are more painful and hence will reduce consumers' spending. In four experiments, they tested different modes of payments (e.g. cash, credit card, and gift certificate) that vary on their level of transparency, showing that higher payment transparency leads to lower spending. While the mode of payment significantly affected spending, the authors did not 
measure pain-of-payment or any other variable that measures pain-of-payment. They also did not directly test the mediation effect of pain. Hence, Raghubir and Srivastava's (2008) work cannot be used as evidence of experiencing different levels of pain when using different payment modes.

Studies that have explicitly measured pain and the pain difference between different payment modes, provide contradictory results. The first test of pain as a mediator was conducted in Thomas et al.'s (2011) work. As a part of their study, Thomas et al. (2011) measured selfreported pain and showed that consumers perceive higher levels of pain when they pay with cash vs. credit cards. Bagchi and Block (2011) also measured pain and showed significant higher levels of pain is evoked when spending with cash vs. a credit card. While both of these works provide evidence of significant pain differences between different modes of payments (mostly cash vs. credit card), some research has shown a non-significant relationship between payment mode and pain. In an attempt to understand the relationship between pain and psychological ownership of a product, Kamleitner and Erki (2013) manipulated pain by using cash vs. credit card payment. Kamleitner and Erki (2013) asked 208 customers leaving an apparel store to complete a questionnaire. Participants had to choose an item that they purchased in-store and answer questions about the mode of payment and psychological ownership. Results indicated that there is a difference between pain-of-payment when paying with cash vs. credit, but this pain does not influence psychological ownership. To test their theory in a more controlled setting, Kamleitner and Erki (2013) ran an experiment where they manipulated the mode of payment and measured pain and psychological ownership. The results of this study indicated no pain difference between paying with cash vs. card (p. 66). To understand the relationship between payment mode and recall of purchase amount, Gafeeva, Hoelzl, and Roschk (2018) measured 
pain as a control variable; however, they did not find a significant difference in self-reported pain between cash vs. card payments (p. 67). Finally, due to the contradictory evidence of the effect of payment mode on pain in the literature, Banker et al. (2017) used fMRI equipment to scan consumers' brains while making shopping decisions. In a simulation task, they asked participants to browse products on a website, choose products that they liked, and finally pay out of their own pocket either using cash or credit card. Products were either available to purchase with cash or credit. Results from the scans indicated that different parts of the brain are activated when paying with cash vs. credit card, but these regions are not related to pain regions in the brain. Their findings indicate that consumers use different criteria when purchasing with cash vs. credit but this difference is not related to the experienced pain-of-payment.

In sum, considerable empirical research shows that using different modes of payment leads to different levels of consumer spending. In particular, paying with credit cards vs. cash increases consumers' spending (c.f., Inman, Winer, and Ferraro 2009; Raghubir and Srivastava 2008). However, we still do not know whether this spending difference is due to experienced pain-of-payment or other factors explored in the literature such as payment transparency.

\section{Using the Tightwad/Spendthrift Scale to Measure Pain}

The Tightwad/Spendthrift Scale (TW/ST) scale is another popular surrogate for measuring pain-of-payment $(\mathrm{PoP})$ in the literature. Many researchers have used this scale as a substitute for measuring pain (cf. Hsee et al. 2014; Reyna and Wilhelms 2017). This inference makes sense if tightwads and spendthrifts are truly different in the level of experienced pain and this construct is the only difference between tightwads and spendthrifts. However, evidence on this difference is non-conclusive. 
In their experiment, Rick et al. (2008) asked participants who filled out the tightwadspendthrift scale questionnaire to indicate how much they agreed with this statement: "spending money is painful for me." They ran a regression with self-reported pain as the dependent variable and S/TW scale as the independent variable. Their results showed that the S/TW scale only explains $18 \%$ of the variance in self-reported pain-of-payment, indicating that this scale explains only a small portion of experienced pain. This suggests that these two measures do not have construct validity and should not be used to indicate the same construct. In their second experiment, Rick et al (2008) measured the S/TW scale and showed that spendthrifts and tightwads are significantly different in how much pain they feel to pay for a pleasurable relaxing massage $\left(\mathrm{M}_{\mathrm{TW}}=4.60, \mathrm{M}_{\mathrm{ST}}=3.87\right)$. While the evidence from this study suggests that pain-ofpayment is partially determined by the S/TW scale, the measured pain-of-payment might only be related to purchasing a relaxing massage (experiential product) and cannot be generalized to overall experienced pain-of-payment.

Lee et al. (2019) also tested the effect of the S/TW scale on pain. Lee et. al. (2019) conducted four experiments to understand whether and why small probabilistic price promotions (cf. $1 \%$ chance it's free) increase sales more than fixed price promotions (e.g., $1 \%$ off). Using various pain measures, they showed that probabilistic discounts reduce pain-of-payment more than fixed promotions. A reduced pain-of-payment will increase consumers' willingness to purchase, especially when they pay with credit cards as opposed to cash. In a fourth experiment, they measured pain-of-payment using Thomas et. Al.'s (2011) measure, and ran a regression to predict pain using the TW/ST scale, promotion type $(0=$ fixed and $1=$ probabilistic price promotion) and the interaction. Lee et.al (2019) found that the TW/ST scale $(\beta=.50, \mathrm{p}<.001)$, price promotion $(\beta=.853 \mathrm{p}<.01)$ and their interaction $(\beta=.55, \mathrm{p}<.05)$ are significantly related to 
pain-of-payment. This research provides some evidence that the S/TW scale is related to pain. However, this measure can only partially predict pain-of-payment.

Another difference between spendthrifts and tightwads is how much consumers neglect expenses when predicting their future available financial resources (Berman et al. 2015). To predict one's future financial slack, consumers must compare their future income and expenses. Bermen et al. (2015) showed that, when consumers estimate their future available slack, they often underweight future expenses and tend to overestimate their future financial resources. The authors argued that tightwads are less likely to have this 'expense neglect' bias because they pay more attention to expenses than spendthrifts. In their ninth experiment, the researchers ran a regression to predict financial slack change based on changes in expenses, changes in income, and their interaction with the TW/ST scale. Results showed a significant interaction between the TW-S scale and change in expenses $(\beta=.013, \mathrm{SE}=.006 ; \mathrm{t}(994)=2.13, \mathrm{p}=.034)$, indicating that tightwads are slightly more likely to neglect future expenses in estimating their future available financial slack. In sum, optimism in estimating future slack can be another variable distinguishing tightwads from spendthrifs other than sensitivity to pain.

To the best of my knowledge, Rick et al.'s (2008) and Lee et al.'s (2019) works are the only studies that empirically tested the difference in experienced pain between tightwads and spendthrifts. Overall, there is not enough evidence that indicates the difference between tightwads and spendthrifts in spending is solely caused by the individual difference in sensitivity to pain. Indeed, in an fMRI study to measure a neurological manifestation of pain, Mazar et al. (2010) tested the moderation effect of TW/ST scale on the effect of pain and spending, and they did not find any moderating effect. If tightwads experience more pain when spending money, they should be more willing to spend when they use someone else's money as opposed to their 
own. However, Trump, Finkelstein, and Connell (2015) did not find this effect. In conclusion, the difference between tightwads and spendthrifts may occur due to other reasons such as sensitivity to opportunity costs. It is clear that researchers should not use this scale as a substitute for measuring pain.

\section{Using Earning Difficulty to Measure Pain-of-Payment}

The difficulty with which money is earned is another surrogate variable for measuring pain-of-payment in the literature. Bagchi and Block (2011) manipulated earning difficulty by telling participants that they received a salary from a job that was very demanding and exhausting vs. a job that required little effort and was rejuvenating. Participants who were told to imagine higher earning-difficulty experienced significantly higher levels of pain. Soster, Gershoff, and Bearden (2014) also conducted a similar study confirming this relationship. In sum, evidence from these two studies supports the effectiveness of this manipulation in measuring pain.

To conclude, evidence on using the TW/ST scale and payment mode as substitutes for measuring pain-of-payment is not recommended due to a lack of construct validity. Future research is required to test the relationship between these variables and PoP and uncover the nature of these relationships.

\section{Consequences of Pain-of-Payment}

In the previous sections, I reviewed the conceptualization, measurement, and moderators of pain-of-payment (PoP). In the current section, I will explain the consequences of experiencing this negative emotion. The consequences of POP are shown in the right-half of the proposed 
framework and are divided into three categories: purchase decisions, information search, and post-purchase outcomes. I will explain each category in detail.

\section{Purchase Decisions}

Seminal research on pain-of-payment has argued that the main consequence of experiencing pain-of-payment is self-regulation when spending (Zellermayer 1997; Prelec and Loewenstein 1998; Ariely and Silva 2002). When making decisions, consumers must think about the ramification of spending (for example, by considering opportunity costs) and avoid spending by exerting self-control when those consequences are not desirable. However, many consumers fail to do this. In the absence of a deliberate contemplation of spending consequences, pain-ofpayment acts as an automatic affective tool that will prevent consumers from overspending (Zellermayer 1997). Analogous to how shame and guilt shape moral decisions, pain-of-payment provides a mechanism to control spending by emotionally signaling the sacrifice that one is making for that purchase (Prelec and Loewenstein 1998). In other words, consumers will avoid spending if it is too painful to spend money (Rick 2018).

Indeed, several studies have shown that the unpleasant experience of PoP can reduce consumers' intention to purchase and spending behavior. In an experiment, Ariely and Silva (2002) manipulate pain-of-payment using different payment mechanisms and they showed that the different levels of pain-of-payment experienced through different payment schemes can influence consumers' spending. Ariely and Silva (2002) conducted an experiment in which they asked participants to purchase different articles to read in the lab. The authors showed that consumers will buy and read fewer articles when they are required to pay for each article as they view it (pay-as-you-go method) vs. when they make a one-time purchase to read as many articles as they want (subscription payment method). Ariely and Silva (2002) argued that this effect 
occurs because paying with a pay-as-you-go method is more painful than paying with a subscription method of payment. This work provides preliminary evidence for the relationship between pain-of-payment and controlling spending; however, the authors did not directly measure pain-of-payment or any antecedents of pain. Later research explored this relationship by studying the relationship between PoP and spending. These studies, which are explained below, showed that pain-of-payment indeed reduces intentions to spend providing some evidence on the self-regulatory characteristic of PoP (Bagchi and Block 2011; Rick, Cryder, and Loewenstein 2008; Thomas, Desai, and Seenivasan 2011).

In addition to the immediate pain-of-payment, there is some evidence that anticipatory pain-of-payment can also influence consumers' spending decisions. Greenberg and Hershfield (2016) demonstrated that anticipatory pain experienced when taking out a loan and making loan payments can influence consumers' debt aversion. The authors asked participants to plot the level of anticipatory pain over the first year of an imaginary multi-year loan. They found two patterns in the anticipatory pain among those participants. One group of participants plotted a rising trajectory in which the most pain was anticipatory at the latest point in the plot (growing pain). The other group plotted a falling pain trajectory in which, the most painful moment was expected to be at the moment of taking out a loan (immediate pain). The authors further showed that these two groups of consumers were different in their level of debt aversion. Participants who expected the pain to grow over time were less likely to show a willingness to take out the loan.

Pain-of-payment can also reduce spending by increasing the salience of price information. Sheehan et al. (2018) demonstrated that at higher levels of pain, price information will be more salient to consumers. They asked participants to indicate how much their purchase 
decisions were influenced by price as opposed to quality information, and showed that consumers' decisions are more influenced by price information when they experience higher levels of pain. The authors showed that high levels of pain will then influence consumers' purchase intention. This research was the first empirical study that showed PoP reduces spending by increasing consumers' attention to price information.

In addition to controlling spending, pain-of-payment can reduce impulsive purchases such as purchasing unhealthy food (Bagchi and Block 2011; Thomas, Desai, and Seenivasan 2011). Thomas et al. (2011) proposed that experiencing pain-of-payment when paying with cash (vs. credit card) prevents consumers' impulsive purchases of unhealthy food products. They argued that purchasing vice products such as unhealthy food are influenced by impulsive responses whereas purchasing virtue products is more deliberative. When consumers' decisions are impulsive, they are more affected by the negative experience of pain because consumers do not have the chance to regulate this negative emotion by justifying their purchase (e.g., Kross, Ayduk, and Mischel 2005). In this situation, consumers' impulsive purchases of vice products will be curbed by the pain experienced from paying for those products. Since paying with cash evokes higher levels of pain than credit cards, paying with cash reduces consumers' purchases of vice products by reducing experienced pain-of-payment. However, purchasing virtue products is not affected by the levels of experienced pain because even when the pain levels are high, consumers can deliberately and easily justify their purchase of virtue products and reduce the negative influence of pain on spending. In four experiments, the authors showed that consumers indeed make more unhealthy purchases when paying with a credit card vs. cash, and this relationship is mediated by the level of pain experienced when spending. This effect is stronger for tightwads, who are more susceptible to pain. 
Thomas et al. (2010) provide evidence that pain-of-payment reduces unhealthy food purchases. However, their research has only explored a situation where consumers purchase products for future consumption. Baghchi and Block (2011) explored the same relationship but they tested this relationship in a context where purchase and consumption occur at the same time. Contrary to Thomas et al. (2013), Bagchi and Block (2011) showed that experiencing pain-ofpayment increases the consumption of unhealthy food. Across three lab studies and one field study, they showed that when the pain of paying is higher, consumers are more likely to consume unhealthy food because consumption of indulgent food dulls the pain of spending. Although the direction of the relationship between pain and consumption of vice products is not clear in this literature, both research teams show that pain-of-payment significantly influences consumers' decisions to purchase unhealthy food products, via a cognitive (justification) or affective paths (hedonism).

Previous research has provided evidence that pain-of-payment can prevent excessive spending. While lower spending is beneficial to some consumers, it can be harmful to others. Reduced spending can result in hyperopia for consumers who are overly sensitive to this pain (Kivetz and Simonson 2002). If the pain is too intense, consumers may not spend money when spending is beneficial to them (Zellermayer 1997). Tightwads, who are more sensitive to painof-payment, often spend less than they would like to spend (Rick, Cryder, and Loewenstein 2008). Similar to overspending, underspending can lead to lower consumer well-being and hence must be studied by researchers.

\section{Information Search}

Pain-of-payment can also influence consumers' information search behavior by reducing the level of choice overload (Shah, Bettman, and Payne 2012). The number of alternatives in a 
consumer's consideration set influences their purchase decisions in an inverted U-shape pattern. First, as the number of alternatives increases, a consumer's purchase intention increases. When the number of alternatives becomes too large to process, the consumer experiences choice overload, which in turn will reduce her purchase intention and post-purchase satisfaction. Shah, Bettman, and Payne (2012) tested the effect of pain-of-payment on choice overload. They showed that lowering the pain-of-payment through manipulating the payment mode (credit/debit card vs. cash) moderates the effect of choice overload. In particular, they found that consumers are less likely to experience choice overload as the number of alternatives increases when they pay with a credit card as opposed to cash. Their work provides evidence that pain-of-payment does not only influence purchase intention through increasing self-control but it can be used to explain a wider set of phenomena through other mediators.

\section{Post-Purchase Outcomes}

Pain-of-payment can also influence post-purchase outcomes. Soster, Gershoff, and Bearden (2014) explored the effect of spending when budgets are depleted on pain-of-payment and satisfaction. They proposed that the level of pain experienced when spending is higher when a consumer's budget is depleted. When a consumer purchases a product that depletes her budget to zero, compared to when the purchase does not deplete the entire budget, she will feel higher levels of pain. This pain will then attenuate her satisfaction with the product purchased. Furthermore, Shah et al. (2016) proposed that pain-of-payment increases a consumer's connection to the product and her commitment to the brand. They argued that when a purchase is made with more painful modes of payment such as cash, a consumer will justify the pain by increasing her post-transaction connection to the product and the brand. As a result, a consumer who buys a product with a more painful mode of payment becomes more emotionally attached to 
the product, more committed to the brand and has a higher likelihood to make repeat purchases from that brand. This work shows that pain-of-payment not only effects purchase decisions but it can influence a consumer's post-purchase behavior such as satisfaction with the product, attachment to the product, brand commitment, and patronage.

\section{General Discussion and Future Direction}

Pain-of-payment $(\mathrm{PoP})$ is an automatic psychological reaction that consumers experience when they become aware of losing a certain amount of their financial resources. This comprehensive review of the literature on PoP has uncovered the existence of two types of PoP: immediate and anticipatory. Previous research has offered evidence of the existence of these two types of PoP and their effect on a variety of contexts such as choice overload, purchase intention, spending decisions, consumption of unhealthy food and post-purchase decisions. In the previous sections, I reviewed and discussed the existing literature on pain-of-payment (PoP) based on the proposed conceptual framework. The literature review revealed that our understanding of pain-ofpayment is limited, and in some cases, unclear. In this section, I will explain several aspects of the current studies that limit our understanding of pain-of-payment and I will provide avenues for future research. To be consistent with the framework, this section is divided into conceptualization, measurement, moderators, and consequences of PoP. Each section explains the limitations of research in each of these four aspects, and provides open questions that need to be answered to have a better understanding of this phenomenon.

\section{Conceptualization}

As noted earlier, we have only limited understanding of immediate and anticipatory painof-payment. Previous studies have only conceptualized and explored immediate pain-of-payment and they did not distinguish between immediate and anticipatory pain. Immediate PoP was 
conceptualized in Zellermayer's (1997) and Prelec and Loewenstein's (1998) work, and is defined as an automatic affective reaction experienced immediately after losing financial resources such as making payments. I defined anticipatory pain as the level of pain experienced when becoming cognizant of a future loss in the financial slack. In this case, the actual financial depletion or payment occurs in the future, but the pain is experienced at the moment of awareness. Although research has not distinguished between these two aspects of pain, research has indeed measured and tested anticipatory pain instead of immediate pain. For example, Sheehan et al. (2018) sought to understand how experiencing pain-of-payment influences purchase intentions. In their experiments, they asked participants, in the lab or in a grocery store, to report the level of pain they experience as they put products in their shopping bag. They measured pain-of-payment as the respondent was selecting an item in the store and before making the final payment. This measurement of pain is indeed measuring anticipatory pain instead of an immediate pain experienced after making payments. This study, as well as other evidence, supports the existence of anticipatory pain and its influence on consumers' purchase decisions. Hence, distinguishing between immediate and anticipatory pain can help researchers explain phenomena that have not yet been explored in this literature. In particular, anticipatory pain can play an important role in consumers' decisions in situations where payments occur after consumption. For example, the concept of pain-of-payment has not been studied in the context of debt repayment. We do not know how immediate and anticipatory pain of making a series of payments influence consumers' debt repayment decisions such as delinquency, accelerating payments, or paying off debt and becoming debt-free. Hence, a better understanding of immediate and anticipatory pain offers important insights to marketers, public policymakers and consumers who seek to learn more about their own behavior in various contexts. 
To increase our understanding of pain-of-payment, future research should be conducted to understand how consumers with different demographics and cultural values experience this emotion. Mazar et al. (2017) reported that pain-of-payment was influenced by the participant's gender. Women experienced higher levels of pain-of-payment thanmen. In addition to demographics, cultural norms can also influence how consumers experience this pain. Early research on physical pain has shown that consumers in groups that have certain common traits experience pain similarly (Zborowski, 1969). Analogous to physical pain, the psychological painof-payments may be influenced by different cultures. In an experiment, Kamleiner and Erki (2013) asked participants to report their levels of pain when paying with cash vs. by credit card. Their findings were different based on the sample. While non-Asian students reported higher levels of pain when spending cash vs. credit cards, Asian students did not report any pain difference between the two modes of payments. This experiment provides preliminary support that culture may influence the way consumers experience pain. Hence, future research must study how a consumer's culture and demographic variables other than financial well-being factors such as income, influence how they experience pain-of-payment.

Another limitation of the research on pain-of-payment is that most of these studies have only explored consumption situations in which 1) consumption and payments occur in one episode and 2) either consumption or payments occur at the same time (cf. Bagchi and Block 2011) or consumption occurs after making payments (cf. Thomas et al. 2011). However, consumers often pay for their purchases with financing schemes or loans that require them to make multiple monthly payments across a certain period of time. Personal loans, mortgages, student loans and financing purchases such as BestBuy's six-month zero-interest financing program are examples of these loans. To the best of our knowledge, only Greenberg and 
Hershfield's (2016) work has studied pain-of-payment in the context of loans. They explored how consumers expect their pain to varying during the term of an imaginary personal loan, and how this anticipation influences consumers' intentions to take out the loan. While this research provides valuable insights, it is the only research that has studied PoP in the context of loans. Studying immediate and anticipatory pain-of-payment can help us have a better understanding of consumers' debt behavior to design better interventions to nudge them into a positive direction.

Another limitation of the current research on pain-of-payment is the lack of a universal theory that can explain the existence of pain. Only a few studies in the literature have explored the antecedents and causes of experiencing PoP. While those theories offer valuable insights, none of them can offer a universal explanation to justify the findings in the literature. In addition, some of these theories (e.g., the transaction fairness explanation of PoP) are under-explored and it is unclear how these theories influence PoP. Hence, future research must try to take advantage of other consumer behavior theories to understand this phenomenon. One possible direction is to test transaction fairness as the cause of experiencing pain-of-payment. This theory was only tested in Zellermayer's (1997) dissertation, and was shown to have a significant effect on PoP. Future research can be conducted to realize what aspects of a transaction leads to a perception of fairness, how this fairness influences pain and what factors influence the strength of this effect.

\section{Measurement}

As outlined in Table 1, much of the previous research on PoP did not directly measure this construct. Instead, researchers used the tightwad-spendthrift scale (TW/S) or payment mode (cash vs. credit) as a substitute to measuring pain. It is unclear whether that research will be replicated when the direct measures of PoP are used. Future research must use the self-report measures of pain or the neurological manifestations of pain to measure this emotion. In addition, 
future research can use other tools to measure PoP. For example, other biological devices such as galvanic skin responses or heart rate monitors can be used to measure neurological manifestations of pain. Also, research on PoP can use the available software that can assist with automated text-analysis (Humphreys and Wang 2018) to measure PoP. Since pain-of-payment is an affective reaction to losing financial resources, researchers can ask consumers to express the emotions they experienced when they became aware of a reduction in their financial slack in open-ended responses. They then can use automatic text-analysis tools such as LIWC (Pennebaker et al. 2015) to extract negative or positive affect from consumers' sentiments. This measurement can provide further evidence on the experienced PoP.

\section{Moderators}

Research has uncovered some factors that influence the level of experienced pain-ofpayment, which are called pain moderators in the framework. Individual sensitivity to pain is one factor that influences the level of pain. As discussed above, the current conceptualization and measurement of sensitivity to pain (TW/ST scale) are controversial. Some research that used this scale did not find any correlation between this scale and pain. In addition, this scale only partially explains the pain-of-payment. Also, research has not explored why consumers show such differences in their sensitivity to pain. Future research must study this individual sensitivity more closely and try to find the root cause of this pain sensitivity difference between consumers.

Another under-explored moderator of pain is the perceived benefits of the product or service purchased. Earlier, I explained how the perceived benefits of a product influences painof-payment. Four factors were identified that can influence the level of evoked pain: amount and number of benefits, type of benefits, duration of benefits and timing of receiving those benefits. Research on how these four factors influence the level of pain is limited. In their research, Prelec 
and Loewenstein (1998) explained that making payments can remind the consumer of the benefits received from the product and vice versa. They suggested that consumers tend to align payments with benefits because making payments for a purchase that has no remaining benefits causes higher levels of pain. Hence, consumers prefer to pre-pay for a hedonic purchase such as a vacation since the benefits of the vacation do not remain after the vacation is over. While this research provides useful insights, no study has tested how benefits received from a product can influence PoP. Future research must try to understand how and when these four aspects of perceived benefits influence pain.

\section{Consequences}

Experiencing Pain-of-Payment can influence a wide range of consumer behavior. The proposed framework explained some consequences of PoP studied in the literature. However, most research on PoP has focused on understanding consumers' spending intentions. These studies have often used the mental accounting (Thaler 1985, 2008, 1980) and mental budgeting theories (Heath and Soll 1996) to understand how consumers behave when they pay for their purchases with different modes of payment (mostly cash vs. credit). Only recently has this emotion has been used to study choice overload (cf. Shah, Bettman, and Payne 2012) and some types of postpurchase behavior (cf. Shah et al. 2016). Although previous research has provided some understanding of pain-of-payment, I believe that the construct of pain-of-payment can be used to study a broader range of consumer behavior and decision-making phenomena. PoP is tightly coupled to consumers' purchase decisions and post-purchase behavior. Every time that a consumer purchases a product or service or considers making a purchase, she may experience pain-of-payment. This emotion will then influence her information search, purchase, and postpurchase decisions. Thus, consumer behavior research that studies consumers' purchase 
intentions, willingness to pay, and post-purchase behavior such as satisfaction and commitment can benefit from having a better understanding of pain-of-payment. In this section, I point out a few under-explored research avenues that can be influenced by PoP, as well as areas that can be further studied. I also outline questions that have not been answered in the literature to provide direction for future research.

A growing stream of research that can benefit from studying pain-of-payment is the research on word of mouth (WOM). As noted earlier, experiencing pain-of-payment can increase consumers' post-transaction commitment to the product and the brand (Shah et al. 2016). Another post-purchase behavior that can be influenced by PoP is how consumers share their product or service experiences with others. In recent years, the internet and the advancement of technology have changed the way consumers share their experiences with others. Online review websites such as Yelp, and Amazon's reviews as well as social media websites have enabled consumers to share higher volumes of WOM at a faster pace. Many consumers read these reviews before they make a purchase. Research has shown that the volume and valence of these reviews significantly influence consumers' short-term and long-term judgments (Fitzgerald 2017), decisions to purchase and the company's sales (Floyd et al. 2014; Zhu and Zhang 2010). Hence, it is important to study the factors that will influence consumers' intentions to engage in online WOM and the valence of the reviews that they post on those websites. The pain-ofpayment can influence consumers' motivation to disperse WOM and the valence of their message. Intuitively consumers who are less satisfied with products will write more negative reviews. One possible prediction is inferred from the relationship between transaction fairness and PoP. When transaction fairness is low, consumers will experience higher levels of pain, 
which may increase their intentions to disperse negative WOM. Future research is required to look at the strength and direction of the relationship between POP, WOM intentions and valence.

Another research area that can benefit from studying pain-of-payment is consumers' debt repayment decisions such as delinquency, avoidance, borrowing intentions, and debt prepayment. As noted earlier, pain-of-payment has not been studied in the context of debt repayment. Studying pain-of-payment in the context of debt and loans can help marketers and public policymakers in their attempt to solve the current consumer debt problem in the United States and other countries. Currently, in the U.S. many consumers have high levels of debt. In 2018, American's debt reached a new peak of \$13.21 trillion (Household Debt and Credit Report 2018). In the first quarter of 2018, "balances climbed 0.6 percent on mortgages, 0.7 percent on auto loans, and 2.1 percent on student loans" (Household Debt and Credit Report 2018). At this rate, consumer credit/debt has become a normal way of living (Peñaloza and Barnhart 2011) and often a problem in the United States. Higher consumer debt not only affects consumers financially, but also increases their level of stress (Worthington 2006) and reduces their subjective well-being (Tay et al. 2017). Understanding how pain-of-payment influences debt repayment decisions can help with the current debt situation.

Several avenues of research related to consumer's debt behavior can be pursued. First, future research is required to understand how consumers experience pain when they pay for products or services with loans, especially when the product's benefits are already consumed. Many American consumers have credit card debts. On average, American credit card debtholders owe $\$ 6,929$ on their credit cards (Tsosie and Issa 2019). Due to the decoupling of the credit card payments and the product purchased (Prelec and Loewenstein 1998), consumers cannot assign these payments to any specific product benefits; and hence, they will experience 
high levels of pain when repaying their credit card debts. It is important to understand how the pain experienced when making payments and how the anticipatory pain of future payments influence consumers' debt repayment decisions such as delinquency or paying-off the debt. One possible prediction can be made based on the coping literature (Folkman and Lazarus 1988), which explains consumers' coping strategies in reaction to stressful stimuli such as pain. According to the coping literature, consumers often engage in two types of coping: problemfocused and emotion-focused. Problem-focused coping occurs when the consumer is motivated to remove the stressor such as accelerating making payments to avoid pain (Folkman and Lazarus 1988, p. 467). Emotion-focused coping occurs when the consumer tries to reduce the emotional response to the stressor by avoiding or neglecting it altogether. Using emotion-focused coping, the consumer may avoid making payments to reduce the pain experienced. Depending on which one of these two strategies consumers use, they may accelerate or decelerate debt repayment. In addition, future research can try to understand whether there is a difference in how consumers experience pain when paying debt off all at once vs. in multiple episodes.

Moreover, studying pain-of-payment can help the new stream of literature on how consumers manage their multiple debts when having limited financial resources (cf. Amar et al. 2011). Indebted consumers often have multiple debts but only limited financial resources to repay their debts. Rationally, when paying back multiple debt accounts with the same consequences, consumers must allocate their available financial resources to pay off the account with the highest interest rate. However, research has shown that consumers often deviate from this economically-optimal strategy when repaying debts and their repayment decisions are not solely driven by the accounts' interest rates. Previous research has shown that consumers generally use a heuristic when repaying their debts. A commonly-used heuristic is the debt- 
snowball strategy, in which consumers start with paying off the debt that has the lowest balance and then pay their available money to the next lowest balance until they pay-off their whole debt (Amar et al. 2011; Besharat, Carrillat, and Ladik 2014; Besharat, Varki, and Craig 2015; Brown and Lahey 2015; Gal and Mcshane 2012; Ponce, Seira, and Zamarripa 2014). Another debt repayment heuristic that consumers use is to divide their available budget between all debts relative to the balance of each debt account (Gathergood et al. 2018). These studies provide some insights into consumers' debt repayment strategies. However, these researchers have mostly studied debt repayment using the economic characteristics of debt accounts. Most of these researchers have asked respondents to prioritize repaying debt accounts based on the accounts' balances and interest rates. To the best of my knowledge, no research has looked at how consumers' emotions towards each debt account influence their repayment decisions. In particular, no research has tested the impact of experiencing immediate and anticipatory pain on consumers' debt repayment strategies. I believe that studying pain-of-payment can help improve our understanding of consumers' debt repayment decisions. Future research is required to discover whether consumers give higher priority to repaying debts that evoke higher levels of pain-of-payment. In addition, does a repayment strategy in which consumers always prioritize paying the most painful debt increase consumers motivation to clear all of their debt accounts and to become debt-free?

Another phenomenon that can be explained by pain-of-payment is the denomination effect (Raghubir and Srivastava 2009). The denomination effect posits that consumers are less likely to spend the same amount of money when it is represented by a single large denomination (e.g. one $\$ 50$ bill) vs. many smaller denominations (e.g. five $\$ 10$ bills). A possible explanation for this phenomenon is that when money is in the form of a large bill, spending it will be more 
salient to the consumer, leading to increased anticipation of pain. Since spending a large bill is more painful than spending several smaller bills, a consumer will be less likely to spend the large bill.

In addition to debt repayment, pain-of-payment can be used to study different public policy issues such as citizen's satisfaction and payment of taxes. Research has shown that allowing citizens to allocate the tax they pay across different budgets provided by the billing party increases the perceived benefits associated with tax payment, citizens' satisfaction of paying taxes, and their compliance (Lamberton 2013). This effect can be explained by pain-ofpayment. As noted earlier, the amount of perceived benefits of purchase reduces pain-ofpayment, which will in turn increase spending. When benefits from taxes are unclear, citizens will experience high levels of pain and will be less willing to pay taxes. However, when the benefits of paying taxes are made more salient by allowing citizens to allocate their tax to different budgets, this pain will be reduced and citizens will be more likely to pay taxes and feel better about it. Future research can manipulate other pain moderators, such as the transparency of payment (cf. by showing a list of how the focal citizen's taxes has been allocated to different budgets), payment timing (e.g., by adjusting tax payments so that citizens will not receive a rebate vs. overpayingto receive a high rebate), and payment mode (paying taxes with credit cards vs. automatic income deduction) to reduce pain experienced when paying taxes and increase compliance.

Finally, pain-of-payment can help marketing and public policymakers in designing better interventions to increase consumers' overall well-being. For example, research has shown that many patients forgo care due to high healthcare prices. Interventions that increase the salience of benefits received from a visit would increase consumers' motivation to seek care when needed. 
In addition, designing interventions that increase the pain of paying interest rates can increase consumers' motivation to pay off their credit card debts. Amar et al. (2011) studied how indebted consumers with multiple debts prioritize paying their debts when having limited financial resources. They found that consumers often do not follow an economically-optimal strategy and they do not prioritize paying the debt with the highest interest rate. However, they showed that making the interest rate more salient will draw consumers' attention to the interest rate, and will nudge consumers to prioritize debts based on the interest rate. As noted earlier, one factor that increases pain is the transparency and salience of payments. Making the interest rate of each debt more salient may increase the pain of paying that interest rate, especially since that interest rate cannot be tied back to any product benefits. Thus, interventions that increase the transparency of interest rates could increase consumers' intentions to repay the debt. For example, in the U.S., the Credit CARD Act of 2009 has mandated lenders to include a specific table on credit card statements to disclose information about the debt, duration of payments if the balance is paid in one and three years, and the total money paid if the balance is paid either in one or three years. Previous research has shown that the current design does not have a strong effect on consumers' decisions to pay off the debt (Salisbury 2014). Based on pain-of-payment research, adding a section to this table that makes the interest rate and the amount of interest rate more concrete and salient can increase consumers' motivation to pay off their balance in full each month.

To conclude, the current literature review uncovered what is done and what needs to be done to increase our understanding of pain-of-payment. In addition, this research has identified several literature streams that will benefit from having a deeper understanding of this topic. Painof-payment can help us study various consumer behavior phenomena. It can also help public policy decision-makers to design interventions to nudge consumers into making better financial 
decisions. However, our current understanding of this construct is limited. Future research must be conducted to dig deeper into this phenomenon and improve our understanding of pain-ofpayment. 


\title{
ESSAY II:
}

\section{Ripping Off the Band-Aid: Accelerating Repayment of Socially Unacceptable Debts}

\author{
Farnoush Reshadi, Doctoral Candidate, West Virginia University
}




\begin{abstract}
Consumer debt is rising in the United States and other parts of the world. Researchers and public policy experts have studied various individual and situational factors that motivate consumers to repay their debts. One important factor that has not been studied in the context of debt repayment is the social norms surrounding debts. In this essay, I look at the relationship between social norms and consumer debt repayment. I propose that consumers do not consider all debts as equal. While some debts are perceived to be socially acceptable in society, others are unacceptable and hard to justify. I argue that making payments for debts that are perceived as socially unacceptable is more aversive and painful than paying socially acceptable debts. I propose that consumers accelerate debt repayment for socially unacceptable debts to avoid high levels of anticipatory pain-of-payment. However, this effect depends on consumers' financial self-efficacy. I argue that using interventions that frame debt as socially unacceptable can be effective in encouraging certain consumers to repay their debts. Marketing and public policymakers who are interested in encouraging consumers to repay their debts can use the results of this research to increase consumers' debt repayment. Keywords: debt repayment, pain-of-payment, social norms
\end{abstract}


Consumer debt is rising in the United States and other parts of the world. In 2018, American's debt reached a new peak of \$13.21 trillion (Household Debt and Credit Report 2018). Balances on various types of consumer debt including mortgages, auto loans, student loans, and credit card debts have significantly increased in recent years (Household Debt and Credit Report 2018) and this trend seems likely to continue in the future (Komos 2019). The rise of consumer debt is not limited to the United States. In 2018, the average amount of unsecured consumer debt has hit a new peak of $\$ 9,400$ per household in the United Kingdom (Brignall 2019), which is $11 \%$ higher than the previous two-year period (Kidd 2019). While the availability of loans in society can increase consumers' quality of life, having high levels of debt can be detrimental to consumers' financial and overall well-being. Indebted consumers lose their financial resources by paying high levels of interest and various fees on their debts (Stango and Zinman 2009). Indeed, Americans paid loan issuers $\$ 113$ billion in credit card interest and fees in 2018 (Gerson 2019). This reduces consumers' available financial slack; and hence, their purchase power. In addition, having high levels of debt impacts consumers' health and overall well-being by increasing consumers' stress (Worthington 2006; Tay et al. 2017). Hence, it is of utmost importance to study factors that influence consumers' borrowing and debt repayment behavior.

Researchers and public policymakers have studied various factors that influence consumers' borrowing and debt repayment behavior. Most of the previous work in this area has focused on studying why consumers overspend and borrow in the first place. For example, previous studies have explored the effect of financial literacy and education (Fernandes, Lynch, and Netemeyer 2014), fear of missing out (Tully and Sharma 2018), financial scarcity (Cook and Sadeghein 2018), attitude towards debt (Wertenbroch, Soman, and Nunes 2001), self-control 
(Wertenbroch, Soman, and Nunes 2001) and use of various payment modes such as paying with credit cards vs. cash (Soman and Cheema 2002; Thomas, Desai, and Seenivasan 2011) on consumers' intentions to over-borrow. However, research that focuses on discovering ways to encourage and help consumers to pay their current debt is still underdeveloped.

While understanding the factors that lead consumers to borrow money is important in reducing indebtedness, many consumers are already deeply in debt and it is very important to discover ways to help them repay their current debts. To that end, behavioral researchers have recently started to explore how consumers perceive debt and what factors influence their debt repayment intentions and behavior (Amar et al. 2011; Gal and Mcshane 2012; Sussman and Shafir 2012; Besharat, Carrillat, and Ladik 2014; Besharat, Varki, and Craig 2015; Brown and Lahey 2015; Hershfield and Roese 2015; Kettle and Blanchard 2016). Previous research has mostly focused on how consumers repay their debts based on the economic factors associated with consumers' debt accounts such as the number of debt accounts a consumer owes (Amar et al. 2011; Gal and Mcshane 2012; Kettle and Blanchard 2016), balances on those accounts (Amar et al. 2011; Besharat, Carrillat, and Ladik 2014; Gal and Mcshane 2012; Kettle and Blanchard 2016), the annual interest rates (APR) charged on those loans (Amar et al. 2011), hedonic vs. utilitarian nature of the product purchased using debt (Besharat, Carrillat, and Ladik 2014; Besharat, Varki, and Craig 2015), whether the debt was incurred in distant or proximal past (Besharat, Varki, and Craig 2015), and the minimum payment amount charged on credit cards (Hershfield and Roese 2015; Jones, Loibl, and Tennyson 2012; McHugh and Ranyard 2016; Navarro-Martinez et al. 2011; Salisbury 2014; Stewart 2009). Additionally, most of these studies examined debt repayment behavior through the lens of goal and motivation theories (cf. Amar et al. 2011; Besharat, Carrillat, and Ladik 2014; Besharat, Varki, and Craig 2015; Brown and 
Lahey 2015; Gal and Mcshane 2012; Gathergood et al. 2018; Ponce, Seira, and Zamarripa 2014). Studying debt repayment behavior from the lens of other theories can help further our understanding of consumers' behavior in this context.

Furthermore, most of these studies have focused on examining credit card debt repayment and have not examined consumers' behavior in repaying other types of debt such as personal loans and auto loans in which payments are due over a long period of time. Indeed, research has shown that consumers have different perceptions of credit card loans vs. other types of loans (Sharma et al. 2018).

Finally, one important factor that has not been studied in this context is the social norms prescribing what types of debt are socially appropriate and common. Extant research has shown that social norms significantly influence consumers' behavior in a range of contexts. While social norms have been widely studied in other areas, they have not been studied in the context of consumer debt repayment. Therefore, the goal of the current study is to understand how consumers' perceptions of social norms prescribing appropriate borrowing behavior influence their debt repayment behavior.

Social norms are "rules and standards of behavior understood by members of a group and that guide and/or constrain social behavior without the force of laws" (Cialdini and Trost 1998, p. 152). Social norms are often generated in society at the collective level. However, individuals may have their own interpretation of the collective norms. An individual's perception of the existing norms is called "perceived norms" (Lapinski and Rimal 2005, p. 129). Perceived social norms are important determinants of consumers' attitudes and behavior (Fishbein and Ajzen 1975). Previous research has shown that social norms guide consumers' behavior in various contexts (cf. Reno, Cialdini, and Kallgren 1993; Goldstein, Cialdini, and Griskevicius 2008; 
Schultz et al. 2007). I argue that similar to other contexts, certain social norms exist that prescribe appropriate and common borrowing behavior. One such norm is the set of norms prescribing appropriate and 'good' reasons for borrowing. A myriad of financial consultants, financial advising institutions, internet resources and society as a whole, contribute to the creation and communication of such norms. While some financial advisors, such as Dave Ramsey, label all debts as bad and advise consumers to stay away from any form of debt, many financial advisors and internet resources divide debt types into "good" and "bad" debts (c.f., Roos 2018). These advisors encourage consumers to take out as many good debts as they want and stay away from bad debts as much as possible. For example, Debt.org, Investopedia.com, NerdWallet.com, Forbes.com, and Equifax have dedicated a page on their websites to explain what entails good and bad debts; how to use good debts and how to say away from bad debts. Labeling debt as good and bad by the society's financial advisors leads to creating such norm in the society and in consumers' minds. Consumers who are exposed to this good vs. bad debt distinction may think that not all debts are created equal and may treat debts differently based on this perception. Indeed, in a financial education document to empower consumers, the Consumer Financial Protection Bureau (CFPB) explains that consumers sometimes do make this distinction and cautions consumers that making this distinction may lead to making suboptimal financial decisions (Consumer Financial Protection Bureau 2014). To show further evidence of the existence of such norms in consumers' minds, Reshadi and Cook (2017) asked 65 Americans to categorize various types of debts as good vs. bad. Ninety-six percent of Amazon Mechanical Turk respondents categorized mortgages as good debt, while $98 \%$ categorized payday loans as bad debt. If consumers perceive various debt types differently, they may behave differently when it comes to borrowing and repayment of various types of loans. Generally, financial advisors 
recommend consumers borrow good debts and stay away from bad debts. This prescription from advisors results in forming social norms that suggest how socially approved it is to borrow for a specific purpose. Contrary to good debts, bad debts are debts that are borrowed for purposes that are considered socially unacceptable; and hence, consumers often avoid borrowing for such purposes. While labeling debt as bad may deter consumers from borrowing for that purpose, it is unclear how making this distinction influences consumers' debt repayment behavior. Do consumers behave differently when repaying good vs. bad debts? Does knowing that one owes money for a socially unapproved purpose (a bad debt) influence one's debt repayment behavior? Using the literature on mental accounting theory (Thaler 1980; Thaler 1985; Prelec and Loewenstein 1998) and pain-of-payment (Zellermayer 1997), I argue that a consumers' perception of norms prescribing appropriate and inappropriate reasons for borrowing influences how they repay their bets by influencing the level of experienced pain-of-payment when making debt repayments. Pain-of-payment (PoP) is a negative, affective, psychological reaction to spending money (Mazar et al. 2017; Quispe-Torreblanca et al. 2019; Zellermayer 1997). Consumers experience PoP whenever they spend money or anticipate spending money in the future (Sheehan and Van Ittersum 2018). Research has shown that the level of experienced painof-payment depends on various factors such as the amount of money spent (Zellermayer 1997b), mode of payment (Raghubir and Srivastava 2008), transaction fairness and the level of received benefits in return for the money spent (Zellermayer 1997b). I argue that it is harder for a consumer to justify having a bad debt than good debt. Hence, a consumer feels more pain-ofpayment when making payments for a debt that she perceives as socially unacceptable (vs. acceptable). Higher levels of experienced pain-of-payment will, in turn, influence consumers' debt repayment behavior. In particular, I predict that higher levels of experienced and 
anticipatory pain-of-payment associated with making multiple payments towards a loan increases consumers' intention to accelerate repayment of a specific debt (a phenomenon that I call ripping off the Band-Aid effect). However, I suggest that this effect is dependent upon the level of consumers' financial self-efficacy-- a consumer's belief in her ability to engage in positive financial behavior that would lead to acquiring the money required to repay the debt.

Consumer indebtedness has become a serious problem in the United States and other parts of the world. Governments and public policymakers have designed various policies and financial education initiatives to help consumers repay their debts. For example, the Credit Card Act of 2009 in the U.S. mandates credit card issuers to provide a table summarizing information about consumers' debt including minimum required amount, years that it will take to pay off the card balance and the total amount of interest paid if they only pay the minimum payment amount every month, the amount that they need to pay every month to pay off the balance in three years (Credit Card Accountability Responsibility and Disclosure Act of 2009, 123 STAT. 1736, $11^{\text {th }}$ Congress, 2009). Previous research has shown that the information provided in this table is not effective in reducing consumers' debt (Salisbury 2014) and it even may reduce the amount of money that the consumer had intended to pay towards this credit card before reading this table (Stewart 2009). In addition, research has shown that financial literacy education programs and interventions that aim to help consumers repay their debts do not explain much variance in making positive financial decisions (Fernandes, Lynch, and Netemeyer 2014). The current research introduces social norms as a new tool that can be used to nudge consumers into repaying their debts. I show that using normative messages on credit card and loan statements or sending normative messages via emails or texts to indebted consumers may increase their debt repayment intentions. 
In addition to public policy, this research contributes to the literature in several ways. First, this research explores the influence of pain-of-payment on consumers' debt repayment intentions. Previous literature has only explored the influence of pain-of-payment on consumers' consumption decisions, spending, product ownership and brand relationships. The current research is the first research that looks into how experiencing pain-of-payment influences consumers' debt repayment intentions. Second, this research introduces ease of justification as an antecedent to experiencing PoP, a variable that has not been explored in the PoP literature. Finally, in Essay 1, I offered a new conceptualization of pain-of-payment and introduced a new type of PoP (anticipatory) that was not previously coined in the literature. In this study, I show that anticipatory PoP can significantly influence consumers' debt repayment decisions when they perceive themselves to have high levels of financial self-efficacy.

In the following sections, I first review the literature on PoP and social norms and develop my hypotheses. Then I explain the methodology I used to test my idea and explain the results. I finally discuss the findings, limitations, and provide suggestions for future research and will conclude.

\section{Conceptual Development}

\section{Social Norms and Debt Repayment}

Social norms are unwritten codes of acceptable conduct within a group, society or culture (Cialdini 2001; Lapinski and Rimal 2005; Goldstein, Cialdini, and Griskevicius 2008). Social norms are created in groups or societies, at the collective level, as standards of correct conduct and they serve as individuals' guide for appropriate behavior when those individuals are not in the society or the group setting (Sherif and Sherif 1953, p. 202). While norms are created at the 
collective level, individuals in a group may have their own interpretation of the collective norms. An individual's perception of the existing norms is called "perceived norms" (Lapinski and Rimal 2005, p. 129). Perceived norms represent an individual's perception of what others do and/or what they should do in different situations (Cialdini and Goldstein 2004). Individuals often use perceived norms as guides to their behavior (Cialdini 2001) and this perception, not the actual social norm existing at the collective level, influences consumers' behavior. A myriad of experimental research (cf. Verhallen et al. 2018; Allcott 2011; Burger and Shelton 2011), as well as lab and field studies (cf. Goldstein, Cialdini, and Griskevicius 2008; Aarts and Dijksterhuis 2003), have shown that individuals' attitudes and behaviors are partly shaped by their cognitions and beliefs about the behavior of their social group (for a review, see Cialdini \& Trost 1998). When consumers perceive a behavior as common and approved among their social group, they try to align their behavior with that norm (Otto et al. 2019). This compliance to group norms occurs when 1) consumers perceive the behavior to be beneficial, 2) when they have a strong affiliation with the reference group, and 3) when they perceive the behavior as central to their self-concept (Real and Rimal 2003).

In general, there are two types of social norms that influence consumers' behavior: descriptive and injunctive norms (Cialdini and Goldstein 2004). Descriptive norms articulate what others do and what is the common behavior among the group members. These norms describe what others are actually doing without specifying the appropriate behavior (Goldstein, Cialdini, and Griskevicius 2008; Reno, Cialdini, and Kallgren 1993). For example, if a consumer believes that $90 \%$ of Americans borrow money to pay for a car, then borrowing money for purchasing a car is perceived as more descriptively normative than paying with cash. Injunctive norms are those that dictate what is acceptable or unacceptable within the group. These norms 
prescribe what is approved or disapproved by the group and what behavior is considered ethical (Haruvy, Ariely, and Gneezy 2017). For example, if a consumer believes that most people think one should or ought to borrow money to purchase a car, then borrowing money for purchasing a car is perceived as more injunctively normative than paying with cash. In sum, descriptive norms relate to what is common and injunctive norms relate to what is socially acceptable among the group members.

Previous research on social norms has shown that activation of descriptive and injunctive norms can significantly influence consumers' behavior. Communicating descriptive norms and injunctive norms to consumers or drawing their attention to these norms can significantly change their behavior in the direction that those norms prescribe. For example, Goldstein, Cialdini, and Griskevicius (2008) showed that communicating descriptive social norms regarding hotel guests' reuse of hotel towels will increase consumers' reuse of towels. Normative appeals were more successful than appeals that communicated environmental concerns to increase consumers' reuse of hotel towels. Additionally, research has shown that communicating descriptive social norms can increase consumers' energy conservation (Allcott 2011; Schultz et al. 2007), decrease littering in a public setting (Reno, Cialdini, and Kallgren 1993), decrease students' alcohol consumption (Real and Rimal 2003), and increase consumption of more healthy food (Burger and Shelton 2011; Otto et al. 2019). While the effect of social norms on consumers' behavior has been examined in many different contexts, research on how social norms influence consumers' debt repayment behavior is lacking. Thus, in this essay, I will focus on understanding the influence of injunctive norms on consumers' debt repayment. In particular, I will focus on how consumers' perceptions of injunctive norms and communicating such norms influence consumers' intentions to accelerate their debt repayment to rip off the Band-Aid. While most 
research aimed at designing interventions to nudge consumers in the right direction has focused on descriptive norms, research on social norms shows that injunctive norms have a stronger influence on consumers' behavior than descriptive norms (Reno, Cialdini, and Kallgren 1993). Thus, in this essay, I focus on understanding the influence of injunctive norms on debt repayment behavior.

Many consumers are generally debt-averse by nature and consider all types of debt as socially unapproved (Brown et al. 2015; Walters et al. 2016). In addition, some religions, such as Islam, consider debt as unacceptable and deem avoiding debt repayment as injustice (Bursztyn et al. 2015). However, the recent trends in borrowing around the world suggest high debt usage. Many consumers have high levels of debt and many others carry significant balances on their credit cards. Peñaloza and Barnhart (2011) found that borrowing and holding debt has become more common and the "normal way of living" in American society. Borrowing is becoming more common, more approved and the "norm" among American consumers.

Although, in general, society norms prescribe that debt has become more socially acceptable and common, not all debts are considered normal and socially approved and not all consumers agree on what types of debts are socially approved. While collective social norms existing at the group or society level may prescribe some types of debts as socially unacceptable, consumers' perceptions of social norms surrounding debts vary across debt types and consumers. Debt incurred by purchasing a car may be considered as socially approved for consumers living in small cities, where cars are considered as necessities, but auto loans may be perceived as socially unapproved for consumers living in New York City, where cars are considered luxury purchases. This perception can also differ across consumers based on factors such as demographics, levels of financial well-being, and financial knowledge. Consumers with lower 
incomes might have a different perception regarding how socially acceptable it is to take out an auto loan compared to consumers with higher levels of income. Additionally, some consumers, such as some Muslims, perceive all types of debt as unacceptable (Walters et al. 2016), while others think that debt is becoming more normal in society and it is acceptable and common to borrow for certain purposes (Peñaloza and Barnhart 2011). Hence, I argue that while social norms of appropriate debt types exist at the collective level, consumers' perceptions of debt norms vary across consumers and debt types. Even in the same society with compatible social norms, consumers' perceptions of debt norms differ.

To show this variability in consumers' perceptions, Reshadi and Cook (2017) conducted a pre-test where they asked participants to categorize various types of debts according to their perception of social approval of those debts. Participants reported different levels of social approval for debts. Respondents generally rated payday loans (98\%) as socially unacceptable and mortgages as socially acceptable (96\%) loans. However, the level of social acceptability of debts for other types of debts (e.g., credit card debt owed due to everyday purchases, auto loans, student loans, and medical debt) varied across consumers. While the collective norm is that some forms of debt are acceptable or unacceptable, what influences a consumer's debt repayment behavior is her perception of such norms. Perceived norms of appropriate debt types can influence consumers' financial decisions such as debt repayment behavior.

I argue that consumers are generally more likely to repay debts that they consider as socially unacceptable vs. acceptable. This effect occurs because it is harder to justify having a socially unacceptable (vs. acceptable) debt. Making repayments for a debt that is hard to justify evokes high levels of negative affect — referred to as pain-of-payment. Higher experienced and 
anticipatory pain-of-payment will, in turn, increase a consumers' motivation to rip off the BandAid by accelerating debt repayments of socially unacceptable debts.

\section{Pain-of-Payment}

Research on mental accounting (Prelec and Loewenstein 1998) proposes that consumers experience negative affect when they spend money. This negative psychological experience is called "pain-of-payment" and is a psychological reaction to losing money (Mazar et al. 2017). Pain-of-payment is not experienced physically, but research using fMRI tools has shown that consumers psychologically experience pain-of-payment when they pay for the products and services that they purchase (Mazar et al. 2017). Similar to physical pain tolerance, consumers differ on the level of sensitivity to pain-of-payment. While tightwads are highly sensitive to painof-payment, spendthrifts are not that sensitive and experience lower levels of pain-of-payment when spending an equal amount of money (Rick, Cryder, and Loewenstein 2008).

Previous literature has conceptualized pain-of-payment as an emotion that is evoked immediately after making a payment. For example, consumers who make monthly payments on a personal loan experience pain-of-payment immediately after making each payment. However, experimental research exists that shows consumers can also experience this pain when thinking about a payment that they have to make in the future. Sheehan and Van Ittersum (2018) measured the level of consumers' self-reported pain-of-payment in a grocery store before consumers checked out. These authors showed that this pain-of-payment influences consumers' purchase behavior in the store. Based on this evidence, in essay 1 , I proposed a new conceptualization of pain-of-payment that distinguishes between immediate and anticipatory pain-of-payment. Immediate pain-of-payment is the level of pain evoked immediately after a consumer loses money. Anticipatory pain-of-payment is evoked when consumers contemplate a 
future payment that they must make some time in the future. For a payment to evoke anticipatory pain, the payment must be finalized and certain. Thinking about an uncertain future payment that is not booked in the consumers' mental account; thus, it does not evoke pain. The main distinction between immediate and anticipatory PoP is that in the former, money is immediately deducted from the consumer's financial slack; in the latter, the money will be deducted from the slack sometime in the future.

Pain-of-payment can work as a self-regulatory tool for consumers. Similar to how feelings of shame and guilt can prevent individuals from engaging in unethical behavior, pain-ofpayment can act as a self-regulatory device that controls consumers' spending (Prelec and Loewenstein 1998). Several studies have explored the effect of pain-of-payment on various consumers' decisions and behavior such as information search (Shah, Bettman, and Payne 2012), the importance of price information when making a purchase (Sheehan and Van Ittersum 2018), spending (Prelec and Loewenstein 1998; Ariely and Silva 2002; Besharat and Nardini 2018; Sheehan and Van Ittersum 2018), consumption of unhealthy food (Thomas, Desai, and Seenivasan 2011; Bagchi and Block 2011), post-purchase satisfaction and commitment (Shah et al. 2016), attachment to the purchased product (Kamleitner and Erki 2013; Shah et al. 2016), and debt aversion (Greenberg and Hershfield 2016; Prelec and Loewenstein 1998). However, previous research has not examined how this negative emotion influences consumers' debt repayment behavior. The only work that has tapped into this relationship was Prelec and Loewenstein’s (1998) “double-entry mental accounting” theory.

Based on the literature on mental accounting (Thaler 1985, 2008, 1980), Prelec and Loewenstein (1998) proposed that consumers tend to open a mental account for each purchase they make and then track the benefits and costs of that purchase using this mental account. 
Tracking this double-entry (costs and benefits) mental account helps consumers evaluate a purchase by comparing the costs and benefits received from that purchase over time.

The purpose of tracking is to maximize the pleasure of consuming received benefits and to minimize the pain associated with the costs incurred. One behavior that consumers engage in to maximize pleasure and minimize pain is a tendency to align payments with consumption. Prelec and Loewenstein (1998) explained that there is a coupling between payments and consumption such that consuming a product purchased evokes thought of payments and vice versa. Hence, every time a consumer makes a payment for a purchase she made, she thinks about the benefits that she received in return for that cost. Since it is very painful to pay for a product that does not provide benefits anymore, consumers tend to prefer to finish the payments of a product before the benefits are over. For example, consumers tend to prefer to pre-pay vs. postpay for a vacation because it is more painful to pay for a vacation after the vacation is taken and the are no further benefits provided. This tendency, which is called "prospective accounting," proposes that consumers only care about the future costs and benefits of a product (QuispeTorreblanca et al. 2019, p. 5394). Quispe-Torreblanca et al. (2019) argued that when an individual consumes a product that has been paid off, she consumes the product without experiencing the pain-of-payment. In this situation, consumption "will be enjoyed as if it were free" (Prelec and Loewenstein 1998, p. 9). Hence, they predict that consumers are generally debt-averse and prefer to pay before consumption.

While Prelec and Loewenstein (1998) argued that consumers are generally debt-averse, they also proposed that this tendency may be different for durable products, for which the benefits received from consumption last over a long period of time. For example, consumers are more likely to post-pay vs. pre-pay for a durable product such as a washer-dryer because the 
benefits of the washer-dryer last for a long time. In sum, Prelec and Loewenstein (1998)

proposed that consumers prefer to align the benefits of a product with payments because thinking about the benefits received from a product can attenuate pain-of-payment evoked by making those payments.

In addition to payment timing, in their seminal article, Prelec and Lowenstein (1998) proposed that anticipation of experiencing pain also influences consumers' decision to pre-pay a loan. Specifically, they proposed that consumers decide to pre-pay a loan when they expect to experience high levels of pain-of-payment and low levels of benefits in the future. In other words, when a product's benefits are over, consumers cannot associate the pain-of-payment with any benefits and their overall utility derived from the transaction will be negative. The authors argued that in such situations, the consumers are very likely to pre-pay or pay-off the loan to reduce the level of anticipatory pain-of-payment evoked by the thought of making future payments. Indeed in their recent article, Quispe-Torreblanca et al. (2017) showed that consumers are more likely to repay debts that were incurred by purchasing non-durable products vs. durable products.

While this proposition is plausible, researchers have not experimentally tested this hypothesis or the boundary conditions of this effect. No research has looked into the relationship between the pain-of-payment and consumers' debt repayment behavior. The double-mental accounting theory suggests that when making multiple payments for a product (e.g., a loan), experiencing high levels of anticipatory pain-of-payment influences consumers' tendency to repay the debts. While Prelec and Loewenstein (1998) argued that this debt payment acceleration only happens for durable products, we argue that debt pre-payment can happen whenever consumers experience high levels of anticipatory pain-of-payment regardless of the reason pain- 
of-payment was evoked. I call this effect the "Rip off the Band-Aid" effect and I argue that any factor that increases consumers' anticipatory pain-of-payment while making debt repayments (e.g., knowing that your debt was socially unapproved) can lead to ripping off the Band-Aid.

\section{Pain-of-Payment and Social Norms}

Pain-of-payment is evoked every time a consumer loses a certain amount of her financial resources. The level of experienced PoP is strongly dependent on the amount of money paid (Prelec and Loewenstein 1998; Shah et al. 2016; Zellermayer 1997b). In addition to the amount of money paid, the level of PoP can be buffered by various factors such as perceived transaction fairness (Zellermayer 1997a), payment transparency--"the vividness with which individuals can feel the outflow of money" (Raghubir and Srivastava 2008, p. 204), whether spending was voluntary or imposed by the situation (Morris and Huang 2016), the transparency of payments (Gourville and Soman 1998; Prelec and Loewenstein 1998), the amount of benefits received from the product (Prelec and Loewenstein 1998), whether payment is due before or after consumption (Prelec and Loewenstein 1998), the importance of money (Xu et al. 2012), the payment mode such as paying by credit card vs. cash (Bagchi and Block 2011; Thomas, Desai, and Seenivasan 2011), and the durability of the product (Quispe-Torreblanca et al. 2017).

One under-explored factor that is likely to buffer PoP is the focal consumer's perception of injunctive norms that prescribe what types of debts are considered acceptable or unacceptable. Consumers' perceptions of these injunctive norms may influence the level of evoked PoP and their debt repayment behavior. Not all purchases that consumers make are perceived as socially approved and a 'good' purchase. For example, in Reshadi and Cook's (2017) pre-test participants rated using credit cards to purchase a discretionary item as less acceptable and more painful than purchasing a necessary item at an equal price. I argue that when consumers know 
that they have borrowed a loan to make a purchase that is socially unapproved and against the society's norms of appropriate borrowing, the consumer will experience higher levels of pain-ofpayment when paying for that product.

I argue that experienced pain-of-payment is higher for purchases that are socially unacceptable and uncommon because it is harder to justify having a loan due to a socially unapproved vs. approved reason. Zellermayer (1997) showed preliminary evidence of this proposition. In a survey, he asked participants to explain why certain types of bills are painful to pay in an open-ended question. One of the themes discovered in the data was the social acceptability of the expense. Consumers stated that they would experience higher levels of painof-payment if they are aware that the purchase, they made is not compatible with the collective society's norms. Zellermayer (1997) did not further explore the effect of social norms on the pain-of-payment. I argue that this effect occurs because it is harder to justify payments for purchases that are socially unacceptable.

Consumers often need to justify their purchase decisions to themselves; their ability to justify an expense influences their decisions (Shafir, Simonson, and Tversky 1993). When a consumer has a hard time justifying an expense, she will experience higher levels of pain-ofpayment. Indeed, extant research on hedonic vs. utilitarian products has shown that it is harder for consumers to justify purchasing hedonic products (Okada 2005). I argue that this effect occurs because consumers experience higher anticipatory pain-of-payment when they consider spending money on hedonic vs. utilitarian products at an equal price. This pain-of-payment will then act as a self-regulatory device (Prelec and Loewenstein 1998; Bagchi and Block 2011; Thomas, Desai, and Seenivasan 2011) and will reduce consumers' likelihood of making hedonic purchases. 
Similar to making a purchase, I argue that ease of justification influences consumers' anticipatory pain when making debt repayments. When consumers have a debt that was incurred due to a socially unacceptable and/or uncommon purchase, it is harder to justify having such debt. In this situation, consumers are not able to justify to themselves why they have borrowed this money and why they are holding onto this debt. The low justifiability of holding on to the debt will then increase consumers' experienced and anticipatory PoP. The increased level of pain-of-payment will then lead to consumers' tendency to rip-off the Band-Aid by accelerating debt repayment. Two hypotheses follow from this argument:

H1- Making payments for socially unapproved (vs. approved) debts evoke higher levels of immediate and anticipatory pain-of-payment.

H2- The effect of social approval of debt on immediate and anticipatory pain-of-payment is mediated by the ease of justification.

\section{Anticipatory Pain-of-Payment and Ripping Off the Band-Aid}

Researchers have argued that consumers' debt repayment decisions depend upon the level of anticipatory pain-of-payment. When consumers purchase a product with a loan, they experience the pain-of-payment each time that they pay the loan installments. In their doublemental accounting theory, Prelec and Loewenstein (1998) argued that consumers' debt repayment decisions depend on a comparison between how much pain-of-payment they feel at the moment if they pay off the debt (immediate pain) and how much pain-of-payment they anticipate experiencing in the future when they consider making future payment. If the level of anticipatory pain-of-payment is higher than the pain evoked by paying off the debt, consumers will decide to pay off the debt to avoid feeling pain in the future and enjoy consuming the product without having to make future payments. 
In addition, Greenberg and Hershfield (2016) showed that anticipatory pain-of-payment will grow during the term of a one-year loan and will reduce consumers' intentions to take out a loan. The authors asked participants to imagine that they are contemplating taking out a personal loan. Participants were asked to draw a graph depicting how they expect their level of pain-ofpayment to change during the terms of the loan. The graphs showed two patterns of anticipatory pain-of-payment: growing pain and declining pain trajectories. In another experiment, Greenberg and Hershfield (2016) showed that participants who expect anticipatory pain to grow over the lifetime of the loan were more reluctant to take out the loan than participants who expected anticipatory pain to decline over time. This research also supports the proposal that there is a positive relationship between anticipatory pain-of-payment and repayment intentions. Analogous to these studies, I suggest that anticipating high levels of pain-of-payment evoked by future debt repayments increases consumers' motivations to rip-off the Band-Aid. However, I argue that the likelihood of ripping off the Band-Aid depends on a consumer's belief in her ability to take the necessary actions to come up with monetary and non-monetary resources to pre-pay her debt.

Following previous research, I propose that expecting to experience high levels of painof-payment regarding future payments towards a loan will increase consumers' likelihood to rip off the Band-Aid. However, previous research has failed to consider how consumers' ability to pay off the debt influences this effect. The aversive impact of anticipatory pain-of-payment motivates consumers to consider paying off their debt. However, consumers will only do so if they have the available resources to perform this task. To pre-pay a debt or rip off the Band-Aid altogether, a consumer needs to have the required financial resources to pay off the debt, or to have the ability to obtain the required monetary resources by reducing her current spending and/or increasing her earnings. Even if the consumer does not have the available financial 
resources to pay towards the loan, the consumer can take action to save money or earn more money to pay towards the loan.

This is specifically evident in the behavior of consumers who follow the American financial advisor, Dave Ramsey. Dave Ramsey advises consumers on various financial matters such as debt repayment. He has created a multiple-step technique in which indebted consumers decide to live with the minimum amount of financial resources to save money and repay their debts. He encourages consumers to cut any unnecessary expenses (e.g., dining out) to save money and put that money towards their debts. According to Dave Ramsey, four million Americans have taken this approach and have repaid their debts. Thus, I propose that paying off debt as a result of anticipating high levels of PoP depends on the consumer's assessment of her self-efficacy to come up with necessary financial and non-financial resources to find the required money to pay off the debt.

Previous literature (Lown 2011) refers to this ability as "financial self-efficacy." Selfefficacy is an individual's perceptions of her ability to activate the resources, motivations, and actions required to accomplish a specific task (Gist and Mitchell 1992). Whether a consumer engages in a particular behavior, depends on how much she believes she can be successful in performing that task (Bandura 1986). Financial self-efficacy is a form of self-efficacy that is relevant to a consumer's belief in her ability to perform positive financial behavior such as debt repayment (Lown 2011). Financial self-efficacy covers various aspects of self-efficacy related to making positive financial decisions such as ability and motivation to perform positive financial behavior as well as the individual's estimation of her available resources (Lown 2011). Consumers are more likely to engage in positive financial behavior when they perceive higher levels of financial self-efficacy (Perry and Morris 2005; Danes and Haberman 2007; Lown 
2011). Thus, I propose that the level of financial self-efficacy moderates the relationship between anticipatory pain and repayment intentions.

H3- Higher levels of anticipatory pain-of-payment increase debt repayment intentions when consumers perceive high (vs. low) levels of financial self-efficacy.

Figure 2 shows a process model of my hypotheses and Figure 3 shows an overview of my proposed model. In two studies, I test these hypotheses. The following section explains the methodology that I used and the findings of this research.

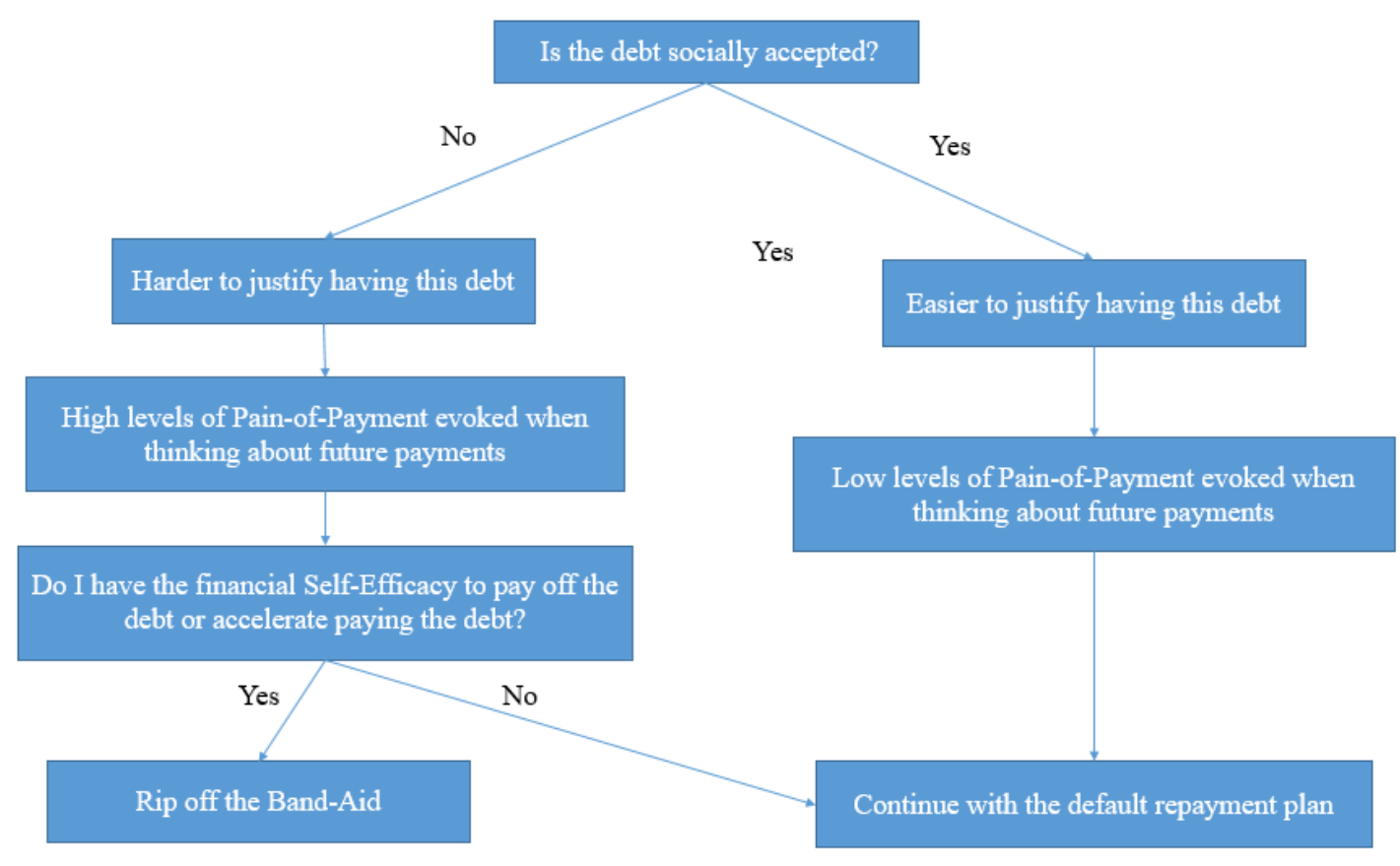

Figure 2- Process Model 


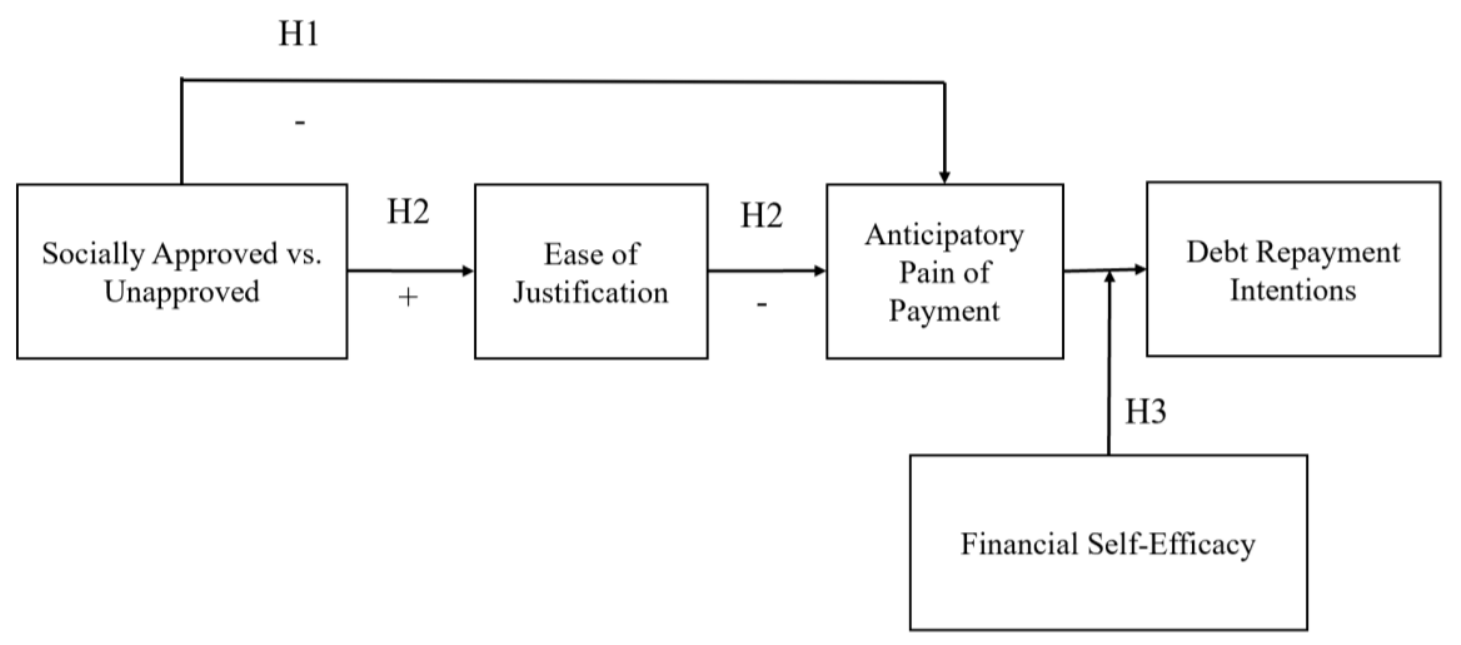

Figure 3- Proposed Framework

\section{Methodology}

\section{Overview of Studies}

Across two studies, I tested the proposed hypotheses. In the first study, I manipulated the social approval of debt by manipulating the purpose of taking out the loan. Assuming that debts borrowed to purchase a necessary product/service are more socially approved than debts borrowed to purchase an unnecessary product/service, I manipulated the purpose of taking out an auto loan as necessary vs. unnecessary. Then I examined whether consumers' debt repayment behavior depends on whether their purchase was socially approved or not (e.g., necessary or unnecessary). I also manipulated the annual interest rate charged on the loan to test whether perceptions of social norms can explain any variance in debt repayment over and above the annual interest rate charged on the loan. To make sure that the necessary vs. unnecessary manipulation works and it adequately manipulates the perceptions of injunctive social norms surrounding debts, I ran a separate pretest study, which is explained in the next section. 
In study 2, I manipulated the social approval of the debt types by providing numerical information on how common a specific type of debt is in society. A second pretest (pretest B) was conducted to make sure that the manipulation works before running the full study. The following sections explain the design, procedure, and results of these studies.

\section{Pretest A- Manipulating Social Approval by Manipulating the Necessity of \\ Borrowing the Loan}

\section{Participants and Design}

The purpose of this study was to test the necessary vs. unnecessary manipulation. The study had two conditions (Loan purpose: necessary vs. unnecessary purchase) and used a scenario-based experimental design ${ }^{1}$. Participants were randomly assigned to one of the two conditions. Forty-eight U.S. respondents were recruited from Amazon Mechanical Turk (MTurk). In exchange for their time, participants were paid $\$ 0.70$. Three questions were added to the survey to check if participants were paying attention to the scenario. Six participants who failed at least one of the attention checks were excluded from the study, leaving 42 participants $\left(50 \%\right.$ female, $\left.M_{\text {age }}=40, M_{\text {income }}=\$ 56,786\right)$.

\section{Procedure}

Participants were randomly assigned to one of the two experimental conditions. After reading the consent form, participants read a scenario in which they were told to imagine that five months ago they took out a loan to purchase a car. Participants in the necessary condition were told that they purchased the car because their previous car did not work well, was creating

\footnotetext{
${ }^{1}$ Materials and details of the pretest are available in Appendix A.
} 
serious problems for them, and it was not safe to drive that car anymore (broken car condition). Participants in the unnecessary condition read that they purchased the car because their previous car had a few dents, did not look new and lustrous anymore, and they did not like driving this car (old-looking condition). Participants were then asked to imagine that they searched for a used car and they found a used car that they liked at a dealership they trusted. Participants were then told that they purchased the car from the dealership using a 4-year loan with a $6 \%$ annual interest rate to purchase the car. To make sure that participants understood the loan terms, they then saw a table summarizing the loan terms (see Appendix A for the design). Participants were finally told to imagine that today; they made the fifth payment towards this loan.

After reading the scenario, participants answered questions about the necessity of the purchase, injunctive and descriptive norms, manipulation checks, the realism of the scenario, and attention checks. Participants were then asked how expensive they thought 1) the car and 2) the annual interest rate charged on the loan were. Both of these perceptions were measured using a 7-point semantic differential scales (cheap:expensive). On average participants thought that the car was not expensive $(M=3.64)$. Participants also rated the interest rate as an average rate $(M=$ 4.50). Finally, participants answered demographic questions, were thanked and paid.

\section{Measures}

Necessity

Necessity perceptions were measured with five different items. Three items measured necessity with three seven-point semantic differential scale (inessential:essential, unnecessary:necessary, not at all important:important). The order of presenting the items was randomized in the survey. The fourth and fifth questions asked participants how much they thought buying the car was necessary and unavoidable on a 7-point Likert-type scale. A factor 
analysis of the five items measuring the necessity of the purchase revealed that all items load on one factor $(\alpha=.953)$. All items were averaged to form a necessary index.

\section{Injunctive norms}

Injunctive norms were measured with four items patterned after Taylor et al. (2011). Participants were asked to rate how much they thought 1) their family and close friends, 2) other people, and 3) Americans, in general, would approve of their decision to take out the described loan on a seven-point Likert-Type scale (1=Completely disapprove, $7=$ Completely approve $)$. The last item asked participants to rate whether this debt is a good or bad debt on a seven-point semantic differential scale (bad debt: good debt). The order of presenting the items was randomized in the survey. All four items loaded on one factor and the scale was reliable $(\alpha=.89)$. The average of the four items was calculated to form an injunctive norm measure.

\section{Descriptive norms}

Descriptive norms were measured with three items. Participants were asked how common, typical, and normal it is for someone to take out a loan for the reason explained in the scenario on three seven-point Likert-type scales ( $1=$ Not at all, $7=$ Very much). The order of presenting the items was randomized in the survey. All items loaded on one factor and the scale was reliable $(\alpha=.941)$. The three items were averaged to form a descriptive norms scale.

\section{Results}

\section{Attention checks and realism}

In four different multiple-choice questions, participants were asked to choose the purpose of purchasing the car, the price of the car, the number of monthly payments of the loan and the level of the interest rate. Respectively, 98\%, 100\%, 98\%, 95.2\% of participants correctly answered these questions. I asked participants to rate how realistic the scenario was on a scale 
from 1-7 (1=Not at all, $7=$ Very much). On average, participants thought that the scenario was very realistic $(M=6.1)$.

\section{Manipulation Checks}

The necessity of purchase. As predicted, the necessary car purchase situation was perceived to be more necessary than the unnecessary condition $(F(1,40)=34.5$, $p<.001$; Adjusted $\left.\mathrm{R}^{2}=.45, \mathrm{M}_{\text {necessary }}=5.45, \mathrm{M}_{\text {unnecessary }}=2.58\right)$.

Injunctive norms. An analysis of variance (ANOVA) showed that borrowing the loan to purchase the car in the necessary car purchase situation (broken car) was perceived to be more socially approved $\left(\mathrm{F}(1,39)=49.74, \mathrm{p}<.001 ;\right.$ Adjusted $\left.\mathrm{R}^{2}=.54, \mathrm{M}_{\text {necessary }}=5.96, \mathrm{M}_{\text {unnecessary }}=3.31\right)$ than borrowing the loan to purchase a car in the unnecessary car purchase situation (old-looking car).

Descriptive norms. An analysis of variance (ANOVA) showed that borrowing the loan to purchase the car in the necessary car purchase situation (broken car) was perceived to be more typical in the society $\left(\mathrm{F}(1,40)=17.59, \mathrm{p}<.001 ;\right.$ Adjusted $\mathrm{R}^{2}=.29, \mathrm{M}_{\text {necessary }}=6.5$, $M_{\text {unnecessary }}=5.07$ ) than borrowing the loan to purchase a car in the unnecessary car purchase situation (old-looking car).

\section{Discussion}

The manipulation designed in this scenario-based experimental design was successful. The two conditions significantly and strongly differed from each other in terms of consumers' perceptions of social norms prescribing appropriate and common debt types and the extent to which it was necessary to borrow for this purpose. Study 1 uses this manipulation to test the hypothesis proposed in this study. 


\section{Study 1- Manipulating Social Approval of Loans Using Necessary Vs. Unnecessary Purchases}

The purpose of this study was: 1) to manipulate the social norms of the debt by manipulating the necessity of taking out the loan, and 2) to manipulate the interest rate charged on the loan to show that social norms can explain variance in consumers' debt repayment intentions over and above APR.

\section{Participants and design}

The study was a 2 (Loan purpose: necessary vs. unnecessary purchase) $* 2$ (Interest rate: $4 \%$ vs. $10 \%$ ) factorial design. The scenario and the loan purpose manipulation were the same as those used in the pretest above. However, to manipulate the interest rate, half of the participants were told that the APR on their debt was $4 \%$ and the other half were told that the APR was $10 \%$. These numbers were chosen based on the average auto loan APR rate in the U.S. to represent low vs. high-interest rates.

Two hundred and seven U.S. respondents were recruited from Amazon Mechanical Turk. Participants were paid \$1 in exchange for their time. An open-ended question was asked at the beginning of the study to detect robots on MTurk. One open-ended question was asked at the end of the survey to measure consumers' understanding of the purpose of the study. In addition, two open-ended questions were asked throughout the survey to ask participants about their opinions and emotions. These four open-ended questions were used to detect if any of the responses were given by a robot instead of a human being. Participants who did not write a relevant answer with correct English grammar in all four boxes were labeled as robots and were deleted from the data. In total, 65 respondents were flagged as bots and were deleted from the data. I am confident that these 65 respondents were robots since these participants had suspicious IP addresses. The IP 
addresses recorded for these respondents were consecutive, showing that they were submitted from the same network of computers (e.g., 172.1.523.1, 172.1.523.2, etc.). In addition, four questions were added to the survey to check if participants were paying attention to the scenario. Participants who failed more than one of the attention checks were excluded from the analysis.

Overall, eleven participants were excluded, leaving 131 participants $\left(\mathrm{M}_{\mathrm{ag}} \mathrm{e}=37.5, \mathrm{M}_{\mathrm{income}}=48088\right.$, $55 \%$ female).

\section{Procedure}

Participants were randomly assigned to one of the four experimental conditions. Participants read the same scenario used in the pretest. They then answered questions about the level of immediate and anticipatory pain, debt repayment intentions, necessity, descriptive and injunctive norms, memory checks, perceptions of the car, the loan and the interest rate charged on the loan, financial self-efficacy, tightwad vs. spendthrift tendency, financial literacy and debt aversion. Participants were then asked to answer a few questions about their current debt portfolio (level of mortgage, student loan, credit card debt and any other debt that they have and their FICO score). Participants then answered demographic questions, wrote their perception of the purpose of the study, were thanked and paid.

\section{Measures}

\section{Manipulation Checks}

Perceptions of injunctive $(\alpha=.885)$ and descriptive norms $(\alpha=.949)$ were measured as described in the pretest. Averages were calculated to form scales for these three variables.

\section{Mediators}

Ease of justification was measured with three items. Participants were asked to rate how easy it is for them to justify having this loan to other people, their family members and their 
close friends on a 7-point semantic differential scale from "extremely Easy" to "extremely Difficult." All items loaded on the same factor and the scale was reliable $(\alpha=.947)$. The average of the three items was calculated to create an ease of justification scale.

Anticipatory pain-of-payment was measured similarly to the immediate pain-of-payment. All items were worded such that they were asking about the level of pain evoked when thinking about the future 43 payments instead of the current payment. All five items loaded on one factor and the scale was reliable $(\alpha=.951)$. The average of five items was calculated to create an anticipatory pain scale.

\section{Moderator}

Financial self-efficacy items were adopted from Lown's (2011) scale. The four items that had the highest factor loadings in Lown's (2011) study were used to measure this variable. Participants were asked to rate how much they agree/disagree with four statements measuring financial self-efficacy perceptions on a 7-point scale (sample items include "It is easy for me to stick to my spending plan when unexpected expenses arise," and "It is easy to make progress toward my financial goals"). All four items loaded on one factor and the scale was reliable $(\alpha=$.856). The four items were averaged to form a financial self-efficacy scale.

\section{Dependent Variable}

Three different questions were used to measure consumers' intentions to repay their debts:

1) In an open-ended question, participants were asked to imagine that they have won $\$ 800$ in the lottery the previous night. Participants were asked to indicate how much of this $\$ 800$, they were willing to pay towards this debt. Participants typed in a number between $\$ 0$ and $\$ 800$. Hereafter, this measure will be called the debt repayment amount. 
2) On a 7-point point Likert-type scale, participants were asked how fast they want to repay this debt $(1=$ Not fast, $7=$ Very fast $)$. Hereafter, this measure will be called the debt acceleration measure.

3) Participants were asked to imagine that they have an extra $\$ 1000$ cash on hand. Participants indicated whether they preferred to save this money or put it towards the debt in a multiple-choice question with two options: save vs. pay towards the debt. This variable, debt repayment choice hereafter, was coded as $1=$ pay towards the debt and $0=$ save the money.

\section{Control Variables}

Debt aversion, individuals' sensitivity to the pain-of-payment and financial literacy were measured and controlled for in this study. Debt aversion is an individuals' tendency to consider all types of debt negatively. This variable may influence consumers' debt repayment behavior. To make sure that this variable does not influence our results, debt aversion was measured using three items adapted from Callender and Jackson (2005). Respondents were asked to rate how much they agree or disagree with three statements ("You should always save up first before buying something," "Owing money is basically wrong," and "There is no excuse for borrowing money") on a 7-point scale. Exploratory factor analysis indicated that all three items loaded on the same factor. However, the first item had low factor loading and the scale was not reliable. Thus, the first item was dropped from the scale and the average of the second and third items ( $\mathrm{r}$ $=.62$ ) was calculated to create a debt-aversion scale.

Previous research has shown that consumers differ in the level of sensitivity to the painof-payment. This sensitivity influences the level of pain evoked by thinking about future payments. To control for this trait variable, individuals' sensitivity to the pain-of-payment was measured using the tightwad vs. spendthrift scale. All items were adopted from Rick, Cryder, 
and Loewenstein (2008). An exploratory factor analysis was conducted on the four items. All items loaded on one factor; however, one item had low factor loading and item-total correlation and the scale was not reliable. To improve the reliability of the scale, the item with low itemtotal correlation was dropped from the scale and the average of the three items was calculated to create an index of sensitivity to POP $(\alpha=.827)$.

Finally, the effect of social approval on pain-of-payment and debt repayment depends on how much consumers know about debt, interest, and compounding. Hence, consumers' level of financial literacy may influence the rip-off of the Band-Aid effect. To measure financial literacy, participants were asked five questions. Three questions were adopted from Lusardi and Tufano (2011). These three items measured financial literacy related to debt. Two questions, which measured participants' understanding of the time value of money and compound interests were adopted from (Cook and Sadeghein 2018). All items are listed in Table 2. The number of correct answers given to these five questions was calculated for each participant to form a financial literacy scale $(M=2.63)$.

Table 2- Financial Literacy Measure

\begin{tabular}{|l|l|l|}
\hline Question & Options & Source \\
\hline $\begin{array}{l}\text { Cheryl owes } \$ 1,000 \text { on her bank } \\
\text { overdraft and the interest rate she }\end{array}$ & $\bullet \quad \$ 850$ & Lusardi and \\
$\begin{array}{l}\text { is charged is 15\% per year. If she } \\
\text { didn't pay anything off, at this }\end{array}$ & $\bullet \quad \$ 1,000$ & \\
$\begin{array}{l}\text { interest rate, how much money } \\
\text { would she owe on her overdraft } \\
\text { after one year?' }\end{array}$ & $\bullet \quad$ I do not know \\
\hline $\begin{array}{l}\text { Sarah owes } \$ 1,000 \text { on her credit } \\
\text { card and the interest rate she is } \\
\text { charged is } 20 \% \text { per year }\end{array}$ & $\bullet$ Less than 5 years & \\
$\begin{array}{l}\text { compounded annually. If she } \\
\text { didn't pay anything off, at this } \\
\text { interest rate, how many years } \\
\text { would it take for the amount she } \\
\text { owes to double? }\end{array}$ & $\bullet$ More than 10 years & \\
\hline
\end{tabular}




\begin{tabular}{|c|c|c|}
\hline $\begin{array}{l}\text { David has a credit card debt of } \\
\$ 3,000 \text { at an Annual Percentage } \\
\text { Rate of } 12 \% \text { (or } 1 \% \text { per month). } \\
\text { He makes payments of } \$ 30 \text { per } \\
\text { month and does not gain any } \\
\text { charges or additional spending on } \\
\text { the card. How long will it take } \\
\text { him to pay off this debt?' }\end{array}$ & $\begin{array}{l}\text { - } \text { Less than } 5 \text { years } \\
\text { - Between } 5 \text { and } 10 \text { years } \\
\text { - More than } 10 \text { years } \\
\text { - None of the above, he will continue to be } \\
\text { in debt } \\
\text { - Do not know }\end{array}$ & $\begin{array}{l}\text { Lusardi and } \\
\text { Tufano (2011) }\end{array}$ \\
\hline $\begin{array}{l}\text { Which of the following do you } \\
\text { think would worth more in two } \\
\text { years? }\end{array}$ & $\begin{array}{l}\text { - } \$ 100 \text { received today, and then put in a } \\
\text { savings account at an interest rate of } 10 \% \text {, } \\
\text { compounded annually } \\
\text { - } \$ 120 \text { received two years from today } \\
\text { - They would be worth the same amount } \\
\text { - I am not sure }\end{array}$ & $\begin{array}{l}\text { Cook and } \\
\text { Sadeghein } \\
(2018)\end{array}$ \\
\hline $\begin{array}{l}\text { Assume a friend inherits } \$ 10,000 \\
\text { today and his sibling inherits } \\
\$ 10,000 \text { three years from } \\
\text { now. Who is richer because of the } \\
\text { inheritance? }\end{array}$ & $\begin{array}{ll}\text { - } & \text { My friend } \\
\text { - } & \text { His sibling } \\
\text { - } & \text { They are equally rich } \\
\text { - } & \text { I'm not sure }\end{array}$ & $\begin{array}{l}\text { Cook and } \\
\text { Sadeghein } \\
(2018)\end{array}$ \\
\hline
\end{tabular}

\section{Results}

\section{Manipulation Checks}

The necessity and interest rate manipulations were successful. The necessity

manipulation check was measured using pretested items discussed above. Participants rated how necessary, essential and unavoidable it was to borrow the loan for the described purpose $(\alpha=.943)$. The average of the three items was calculated to create a necessity scale. An ANOVA revealed that a loan borrowed to purchase a car was perceived as more necessary when the participants' current car is broken vs. it is functional but does not look lustrous $(\mathrm{F}(1,129)=$ $197.1, \mathrm{p}<.001$, Adjusted $\left.\mathrm{R}^{2}=.61 ; \mathrm{M}_{\text {necessary }}=5.85, \mathrm{M}_{\text {unnecessary }}=2.28\right)$.

The interest rate manipulation check was measured with two items. Participants were asked to rate how high and expensive the interest rate charged on the loan was $(r=.94)$. The average of the two items was calculated to form the manipulation check. An ANOVA revealed 
that there is a significant difference in expensiveness between the two low (4\%) and high (10\%) interest rate conditions $\left(\mathrm{F}(1,129)=88.96, \mathrm{p}<.001\right.$, Adjusted $\mathrm{R}^{2}=.40 ; \mathrm{M}_{\text {highApr }}=5.99, \mathrm{M}_{\text {LowAp }} \mathrm{r}=$ 3.23).

The influence of debt type and the interest rate on pain-of-payment.

Hypothesis 1 predicted that debts that are perceived as socially unapproved evoke higher levels of immediate and anticipatory pain-of-payment. Hypothesis 2 predicted that this effect is driven by consumers' perceptions of how easy it is to justify having this debt. I tested both of these hypotheses by running a mediated moderation model (with the three control variables in the model) using the PROCESS SPSS macro (model 7, Hayes 2012). In all analyses, debt type was coded such that the socially approved debt was coded as " 1 " and the socially unapproved debt was coded as " 0. ." Interest was coded as " 1 " if the participant was in the high-interest rate $(10 \%)$ condition and was coded as " 0 " if the participant was in the low-interest condition (4\%). Results indicate that debt type significantly influences the ease of justification $(b=1.6, S E=.29$, $\mathrm{p}<.001,95 \% \mathrm{CI}[2.19,1.01])$ and the ease of justification significantly influences anticipatory pain-of-payment $(b=-.46, \mathrm{SE}=.09, \mathrm{p}<.001,95 \% \mathrm{CI}[-.28,-.65])$. However, there is no direct relationship between debt type and anticipatory pain, which indicates that the relationship between social approval and pain-of-payment is completely mediated by the ease of justification. The interest rate charged on the debt and the interaction of debt type and interest rate had no significant influence on ease of justification. Debt-aversion significantly influenced the ease of justification $(b=-.38, \mathrm{SE}=.10, \mathrm{p}<.001,95 \% \mathrm{CI}[-.16,-.59])$; however, it was not significantly related to anticipatory pain. Financial literacy and individual sensitivity to pain did not significantly influence either ease of justification or pain-of-payment. Debt type and the three control variables account for $24 \%$ of the variance in ease of justification $\left(\mathrm{R}^{2}=24 \%\right)$. Ease of 
justification accounted for $19 \%$ of the variance in pain-of-payment $\left(\mathrm{R}^{2}=19 \%\right)$. The results provide support for both $\mathrm{H} 1$ and $\mathrm{H} 2$.

The influence of pain-of-payment on repayment and the moderation of financial self-efficacy

Hypothesis 3 predicted that higher levels of anticipatory pain-of-payments would lead to a tendency to accelerate debt repayments and this relationship depends on consumers' perceived financial self-efficacy. To measure debt repayment, three different debt repayment measures were used. I used SmartPLS (Ringle, Wende, and Becker 2015) to test these hypotheses. I created three separate models in SmartPLS for each of the three measures. All models contained the independent variable (debt type), mediators (ease of justification and anticipatory pain) and control variables (financial literacy, debt-aversion, and tightwad-spendthrift trait). Figures 4, 5, and 6, show the path of the three models and the results are explained below.

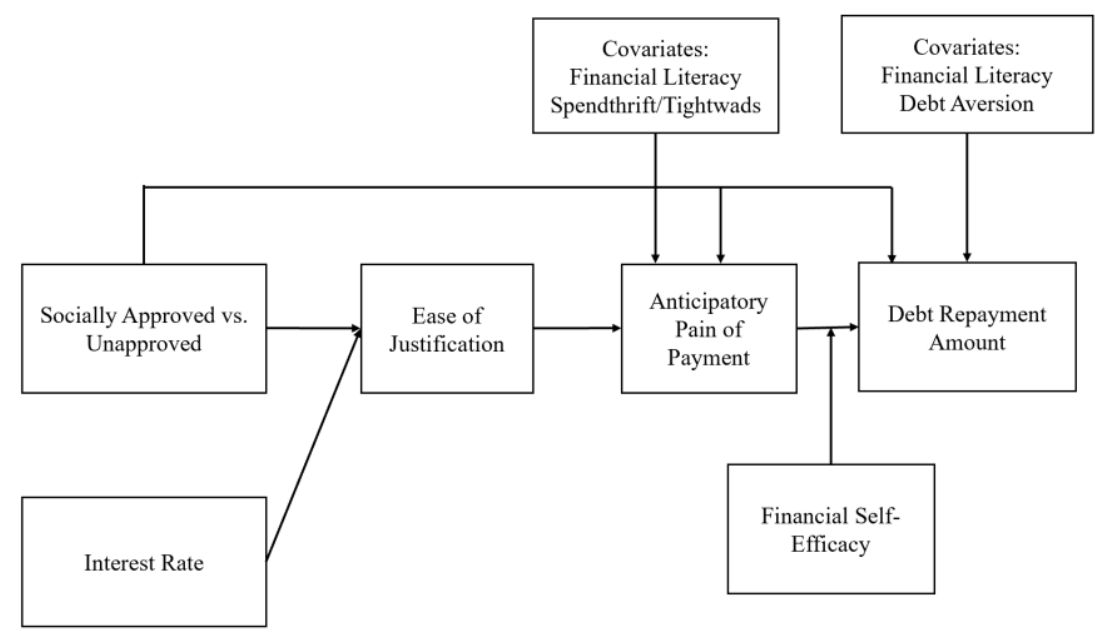

Figure 4- SmartPLS Path Model with Debt Repayment Amount 


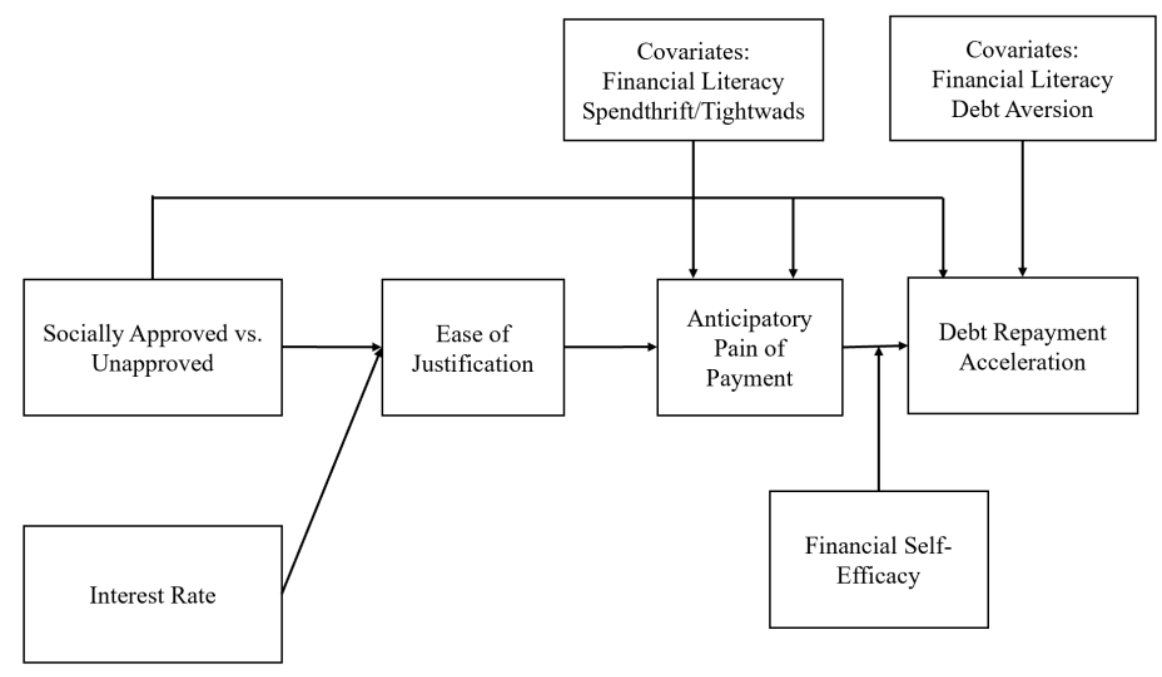

Figure 5- SmartPLS Path Model with Debt Repayment Acceleration

Debt repayment amount. The debt repayment amount was used as the dependent variable in the model. Results from the PLS model indicated that the influence of pain-of-payment on debt repayment amount was significant $(b=0.186, \mathrm{p}<.05)$. However, there is no relationship between financial self-efficacy or the interaction of efficacy and anticipatory pain on the amount of repayment. Financial literacy did not have any significant effect on debt repayment. Debt aversion was marginally related to debt repayment $(b=0.185, p<.1)$. To further understand the interaction between pain-of-payment and self-efficacy on repayment amount, I ran a moderation effect with the control variables using model 1 of SPSS PROCESS macro (Hayes 2012). Further analysis of this interaction using a Johnson-Neyman estimation of significance regions (via PROCESS [Hayes 2012] and including all three covariates) shows that at moderate levels of financial self-efficacy, the pain-of-payment is significantly related to the debt repayment amount. Specifically, anticipatory pain-of-payment significantly increased the debt repayment amount if the participants' financial literacy was between 2.9 (5\% below) and 5 (46\% above). R-squares 
for ease of justification, anticipatory pain-of-payment and debt repayment were 16.9\%, 21.8\%, and $8.9 \%$ respectively. Table 32 summarizes these results.

Table 3-Study 1- PLS Model Results, Dependent Variable is Repayment Amount

\begin{tabular}{|l|c|c|c|c|c|}
\hline Path & $\begin{array}{c}\text { Hypothesi } \\
\text { S }\end{array}$ & B & SD & t-value & p-value \\
\hline Debt Type -> Anticipatory Pain & H1 & 0.123 & 0.086 & 1.429 & 0.154 \\
\hline Debt Type -> Ease of Justification & $\mathrm{H} 2$ & 0.401 & 0.074 & 5.426 & $<.001$ \\
\hline Ease of Justification -> Anticipatory Pain & $\mathrm{H} 2$ & -0.445 & 0.083 & 5.328 & $<.001$ \\
\hline $\begin{array}{l}\text { Anticipatory Pain -> Debt Repayment } \\
\text { Amount }\end{array}$ & & 0.186 & 0.093 & 2.006 & $<.05$ \\
\hline $\begin{array}{l}\text { Anticipatory X Financial Self-efficacy -> } \\
\text { Debt Repayment Amount }\end{array}$ & $\mathrm{H} 3$ & -0.086 & 0.098 & 0.878 & 0.381 \\
\hline Debt Aversion -> Debt Repayment Amount & & 0.185 & 0.1 & 1.844 & 0.066 \\
\hline $\begin{array}{l}\text { Debt Type -> Debt Repayment Amount } \\
\text { Financial Literacy -> Anticipatory Pain }\end{array}$ & & -0.048 & 0.088 & 0.551 & 0.582 \\
\hline $\begin{array}{l}\text { Financial Literacy -> Debt Repayment } \\
\text { Amount }\end{array}$ & & -0.037 & 0.077 & 0.483 & 0.63 \\
\hline $\begin{array}{l}\text { Financial Self-Efficacy_-> Debt Repayment } \\
\text { Amount }\end{array}$ & & -0.001 & 0.092 & 0.005 & 0.996 \\
\hline $\begin{array}{l}\text { Interest rate -> Ease of Justification } \\
\text { Interest rate X debt-type -> Ease of }\end{array}$ & -0.071 & 0.078 & 0.91 & 0.363 \\
\hline $\begin{array}{l}\text { Justification } \\
\text { Spendthrifts vs. Tightwads -> Anticipatory } \\
\text { Pain }\end{array}$ & & -0.019 & 0.076 & 0.253 & 0.8 \\
\hline
\end{tabular}

Debt repayment acceleration. Debt repayment acceleration measured how fast consumers intend to get rid of the debt--consumers' intentions to rip off the Band-Aid. The PLS analysis indicated that there is no relationship between anticipatory pain-of-payment or the interaction of anticipatory pain with self-efficacy on the amount of repayment. However, self-efficacy was significantly related to consumers' debt repayment intentions $(b=.29, p<.001)$. Adjusted Rsquares for ease of justification, anticipatory pain-of-payment and debt repayment were 16.5\%, $21.8 \%$, and $16.7 \%$ respectively. Table 4 summarizes these results. 
Table 4- Study 1- PLS Model Results, Dependent Variable was Repayment Acceleration

\begin{tabular}{|l|c|c|c|c|c|}
\hline Path & Hypothesis & B & SD & t-value & p-value \\
\hline Debt Type -> Anticipatory Pain & H1 & 0.122 & 0.08 & 1.525 & 0.128 \\
\hline Debt Type -> Ease of Justification & H2 & 0.406 & 0.078 & 5.208 & $<.001$ \\
\hline Ease of Justification -> Anticipatory Pain & H2 & -0.445 & 0.084 & 5.262 & $<.001$ \\
\hline $\begin{array}{l}\text { Anticipatory X Financial Self-efficacy -> } \\
\text { Debt Repayment Acceleration }\end{array}$ & H3 & -0.046 & 0.078 & 0.585 & 0.559 \\
\hline $\begin{array}{l}\text { Debt Aversion -> Debt Repayment } \\
\text { Acceleration }\end{array}$ & & 0.271 & 0.088 & 3.095 & 0.002 \\
\hline $\begin{array}{l}\text { Debt Type -> Debt Repayment Acceleration } \\
\text { Anticipatory Pain -> Debt Repayment }\end{array}$ & & -0.015 & 0.079 & 0.189 & 0.851 \\
\hline $\begin{array}{l}\text { Acceleration } \\
\text { Financial Literacy -> Anticipatory Pain }\end{array}$ & & 0.021 & 0.078 & 0.272 & 0.786 \\
\hline $\begin{array}{l}\text { Financial Literacy -> Debt Repayment } \\
\text { Acceleration }\end{array}$ & & -0.038 & 0.08 & 0.472 & 0.637 \\
\hline $\begin{array}{l}\text { Financial Self-Efficacy -> Debt Repayment } \\
\text { Acceleration }\end{array}$ & & 0.297 & 0.092 & 0.076 & 0.94 \\
\hline $\begin{array}{l}\text { Interest -> Ease of Justification } \\
\text { Interest X Debt Type -> Ease of Justification }\end{array}$ & & -0.028 & 0.08 & 0.348 & 0.728 \\
\hline $\begin{array}{l}\text { Spendthrifts vs. Tightwads -> Anticipatory } \\
\text { Pain }\end{array}$ & & -0.173 & 0.182 & 0.951 & 0.342 \\
\hline
\end{tabular}

Debt repayment choice. Debt repayment choice measured participants' tendency to allocate their money to pre-pay this debt vs. put it in their savings. To test the relationship between pain, self-efficacy and debt repayment choice, I ran a logistic regression with repayment choice as the dependent variable. Financial self-efficacy, the pain-of-payment, their interaction and control variables were entered as the independent variables. PoP was not related to debt repayment choice. The effect of financial self-efficacy on repayment choice was marginally significant $(B=-0.80, S E=.45, p<.1, \operatorname{Exp}(B)=.448)$. Participants with higher financial selfefficacy were twice less likely to use the money to repay the debt as opposed to save it. Debt aversion was also marginally related to the choice variable $(B=-0.27, S E=.15, p<.1, \operatorname{Exp}(B)=$ .76). Individual sensitivity to pain and financial literacy were unrelated to participants' choice. 


\section{Discussion}

Study 1 showed that when a consumer perceives her debt as socially unapproved, she will experience higher levels of pain-of-payment when contemplating future debt repayments. This happens because it is harder for the focal consumers to justify having this debt. Additionally, I predicted that high levels of pain-of-payment will, in turn, influence debt repayment intentions for consumers with high perceived financial self-efficacy. I found some evidence supporting this hypothesis in this study. Study 2 was conducted to replicate these findings. Before conducting study 2 , I ran a pretest to design and test the manipulations. The following section explains the procedure, design, and results of the pretest.

\section{Pretest B- Social Norms Information Provision Manipulation Check}

\section{Participants and Design}

The purpose of this study was to test the interest rate and the socially acceptable vs. unacceptable manipulations. The study had a 2 (Social approval: 90\% percent of Americans borrow for this purpose vs. 10\%) *2 (Interest rate: $6 \%$ vs. $12 \%$ ) factorial scenario-based design ${ }^{2}$. In addition, because the manipulation was specifically about American consumers, I made sure to only recruit participants from the United States on MTurk.

Seventy-five U.S. respondents were recruited from Amazon Mechanical Turk (MTurk). In exchange for their time, participants were paid $\$ 1$. Three questions were added to the survey to check if participants were paying attention to the scenario. Seven participants who failed at

\footnotetext{
${ }^{2}$ Materials and details of the pretest are available in Appendix B.
} 
least one of the attention checks were excluded from the study, leaving 69 participants (38\% female, $\left.\mathrm{M}_{\mathrm{age}}=39, \mathrm{M}_{\text {income }}=\$ 51,855\right)$.

\section{Procedure}

Participants were randomly assigned to one of the four experimental conditions. After reading the consent form, participants read a scenario in which they were told to imagine that three months ago they took out a loan to purchase a new 8K HD TV, priced at $\$ 5,400$.

Participants were asked to imagine that they bought this TV from a store in their neighborhood. The store offered a 36-months financing loan option with a $12 \%$ (or 6\%) annual interest rate to purchase digital products, which the participant used to purchase the TV. Participants then saw a table that summarized the loan terms including the amount $(\$ 5,400)$, number of payments $(36)$, interest rate (6\% or $12 \%)$, monthly payment amount (\$164 vs. \$179) and the total interest paid by the end of the loan (\$504 vs. $\$ 1044)$. To help participants better imagine being in this situation, participants were asked to enter "I agree" in a box as an indication of signing the contract. Participants were then told to imagine three months had passed since they borrowed the loan and purchased the TV. Participants imagined that they were planning to make the fourth payment towards this loan. Before making the payment, they saw an article from a fictitious government agency (Association of Consumers and Bankers) which showed the social approval manipulation. Participants in the socially-approved loan condition read:

90\% of Americans use some type of loans when purchasing digital products, according to recent research by the Association of Consumers and Bankers. In other words, it is very common for an American consumer to use financing options such as in-store financing, to buy digital products. 
For the socially-unapproved loan condition, participants read the same paragraphs except they were told that $10 \%$ of Americans use loans when purchasing digital products and that it is uncommon for an American to use these types of loans. Participants were told that after reading the article, they logged in the store's website and paid the fourth monthly payment on the loan. After reading the scenario, participants answered questions about ease of justification, the necessity of borrowing the loan, injunctive norms, manipulation checks, perceptions of the TV (how expensive it was), and attention checks. Participants then answered demographic questions and their perception of the purpose of the study. They were then thanked and paid.

After reading the scenario, participants answered questions about the necessity of borrowing money for the purchase, injunctive and descriptive norms, manipulation checks, perceptions of the TV (liking and perceived costs), and attention checks. Participants then answered demographic questions, were thanked and paid.

\section{Measures}

\section{Injunctive norms}

Injunctive norms were measured with three items. Participants were first asked to rate how much they agree with three statements on a 7 -point scale $(1=$ strongly disagree, $7=$ strongly agree). Items were "Borrowing money to purchase digital products such as TV sets is acceptable in the general society," "Borrowing money to purchase digital products such as TV sets is acceptable among Americans," and, "Americans think it is OK to borrow money to purchase digital products such as TV sets." Maximum likelihood factor analysis with Promax rotation revealed that all items loaded on one factor and the scale was reliable $(\alpha=.88)$. The three items were averaged to create an injunctive norm index. 


\section{Interest rate perceptions}

I measured perceptions of the interest rate in two seven-point semantic differential scales (inexpensive: expensive, very low: very high), participants rated how expensive the interest rate was. The two items were averaged to form a scale $(\mathrm{r}=.87)$.

TV perceptions

I asked participants to rate how expensive they thought the TV set was on a seven-point scale from "not at all" to "very expensive." On average, consumers thought that the TV was very expensive $(\mathrm{M}=6.67)$.

\section{Results}

\section{Manipulation Checks}

Injunctive norms manipulation check. As predicted, participants in the socially-approved condition (90\% of Americans) perceived the debt to be more socially approved than participants in the socially-unapproved condition $\left(\mathrm{F}(1,67)=6.08, \mathrm{p}<.001 ;\right.$ Adjusted $\mathrm{R}^{2}=.07, \mathrm{M}_{\text {approved }}=5.3$, $\left.\mathrm{M}_{\text {unapproved }}=4.4\right)$.

Interest rate manipulation check. An analysis of variance (ANOVA) where interest perceptions (average of two items measuring how expensive the interest rate was) was entered as the dependent and interest manipulation (6\% vs. 12\%) was entered as the independent variable, indicated that there was a significant difference in how expensive participants perceived the two interest rate manipulation conditions $\left(\mathrm{F}(1,67)=16.36, \mathrm{p}<.001\right.$; Adjusted $\mathrm{R}^{2}=.18, \mathrm{M}_{\text {high- }}$ interest $\left.=5.66, \mathrm{M}_{\text {Low-interest }}=4.30\right)$. 


\section{Discussion}

The purpose of this pretest was to test the social approval and the interest rate manipulations. Findings indicated that both manipulations were successful. I used these manipulations in Study 2 to test the hypotheses proposed in this research.

\section{Study 2- Manipulating Social Norms of Debt by Information Provision}

The goal of study 2 was to test the proposed hypotheses by manipulating social norms of debt repayment. In study 1 , I manipulated the social norms of debt by manipulating the necessity of the purchase for which the loan was borrowed. In study 2, I manipulate social norms by providing statistical information on the typicality of a specific type of loan in the society.

\section{Participants}

One hundred and twenty-nine U.S. respondents were recruited from Amazon Mechanical Turk. In exchange for their time, participants were paid \$1.50. Five attention check questions were added throughout the survey to check if participants were paying attention to the survey. Ten participants who failed at least one of the attention checks were excluded from the study, leaving 119 participants $\left(57 \%\right.$ female, $\left.M_{\text {age }}=38, M_{\text {income }}=\$ 60,066\right)$. The study manipulated debt type at two levels (socially acceptable vs. unacceptable) ${ }^{3}$.

\section{Procedure}

The scenario was similar to pretest B. Participants read a scenario in which they imagined they took out a loan to purchase a TV. They were then told that they were about to pay the third payment on this loan, and they read an online article published by the Association of Consumers

\footnotetext{
${ }^{3}$ Interest rate was not manipulated due to the unavailability of funds for data collection.
} 
and Bankers explaining that either $10 \%$ or $90 \%$ of Americans borrow money to purchase digital products. After reading the consent form and the scenario, participants were asked to answer questions about the level of immediate and anticipatory PoP evoked by the thoughts of current and future payments. Participants were then asked to answer questions measuring ease of justification, debt repayment intention, injunctive and descriptive norms, and manipulation checks. Next, participants answered questions regarding their sensitivity to the pain-of-payment, financial self-efficacy, financial literacy, debt aversion, and their current financial status. Participants then answered demographic questions, were asked about the purpose of the study, were thanked and paid.

\section{Measures}

\section{Mediators and Moderator}

Anticipatory pain-of-payment $(\alpha=.950)$, ease of justification $(\alpha=.945)$, and financial self-efficacy ( $\alpha=.883)$ were measured using the same measures used in study 1 . Averages were calculated for all items to create scales for these variables. Debt aversion was measured with the same scale used in study 1 . Similar to study 1 , the three items measuring debt aversion did not load on one factor. The item with the lowest item-total correlation, which was the same item dropped in study 1, was dropped and the average of the other two items was calculated to create a debt-aversion scale $(\mathrm{r}=.532)$.

\section{Manipulation Checks}

Injunctive norms were measured with the same scale used in the pretest. Since the social approval manipulation manipulates the commonality of borrowing money for this purpose, I also measured descriptive norms to make sure that the manipulation is tapping into injunctive norms and not descriptive norms. In addition, because the manipulation was specifically about 
American consumers, I made sure to only recruit participants from the U.S. on MTurk. I also added one item that measured how similar the focal participant perceived him/herself to other Americans on a 7-point semantic differential scale (not at all similar: very similar).

\section{Dependent Variable}

One question was used to measure consumers' intentions to repay their debts.

Participants read:

Now imagine:

At the end of the month, you receive your salary. After paying off all other expenses, you have an extra $\$ 800$. You can spend this money in any way you want including paying down the loan you borrowed to purchase the TV. Paying more towards this loan will help you pay it off faster. How much of the $\$ 800$ will you put towards this loan? No need to put a dollar sign.

Participants were asked to enter how much of this $\$ 800$, they are willing to pay towards this debt in an open-ended box $(\mathrm{M}=\$ 485)$.

\section{Control Variables}

Financial literacy was measured using eight questions that tapped into consumers' understanding of compound interest, debts, time value of money and interests. All items were adopted from Cook and Sadeghein (2018). A financial literacy score was calculated for participants such that they received 1 point for each correct answer. Thus, financial literacy scores could range from 0 to 8 .

To measure participants' real financial status, I asked several multiple-choice questions about participants' level of outstanding mortgage debt, level of outstanding credit card debt, level of an outstanding auto loan, level of other debts, and income. In each question, I asked 
participants to choose the level of outstanding debt they owe from multiple range options (e.g., 10,000 to 30,000 ; the intervals were different based on the debt type).

Individuals' sensitivity to the pain-of-payment was measured with the tightwadspendthrift scale (Rick, Cryder, and Loewenstein 2008). Exploratory factor analysis indicated that these four items loaded on the same latent factor. However, one of the items had low factor loading (.21) and the scale was not reliable (the same item that had low factor loading and low item-total correlation in the first study). This item also had low item-total correlation, and thus; was dropped. The average of the other three items was calculated to form a pain sensitivity scale $(\alpha=.77)$.

\section{Result}

Manipulation Checks

An ANOVA (independent variable $=$ the social approval manipulation, dependent variable $=$ injunctive norms) indicated that the manipulation was successful. Perceptions of injunctive social norms were significantly different between the two conditions. Participants who saw the socially-unapproved manipulation perceived the same debt to be more socially unapproved than those that saw the socially-approved manipulation $(F(1,76)=26.72, p<.001$, $\left.\mathrm{R}^{2}=.25, \mathrm{M}_{\text {unapproved }}=5.36, \mathrm{M}_{\text {approved }}=3.86\right)$.

An ANOVA (independent variable $=$ the social approval manipulation, dependent variable $=$ descriptive norms $)$ indicated that the manipulation also significantly influenced the perception of descriptive norms. Participants who saw the socially-unapproved manipulation perceived the same debt to be more common and typical than those that saw the sociallyapproved manipulation $\left(\mathrm{F}(1,76)=113.09, \mathrm{p}<.001, \mathrm{R}^{2}=.59, \mathrm{M}_{\text {unapproved }}=6.15, \mathrm{M}_{\text {approved }}=3.01\right)$. 
The influence of debt type and the interest rate on pain-of-payment

Hypothesis 1 predicted that debts that are perceived as socially unapproved evoke higher levels of immediate and anticipatory pain-of-payment. Hypothesis 2 predicted that this effect is driven by consumers' perceptions of how easy it is to justify having this debt. I tested both of these hypotheses by running a mediation model using the PROCESS SPSS macro (model 4, Hayes 2012). Financial literacy, sensitivity to the pain-of-payment, perceived similarity to Americans, and debt aversion were entered into the model as covariates. In all analyses, debt type was coded such that the socially approved debt was coded as " 1 " and the socially unapproved debt was coded as " 0 ." Results indicated that debt type does not influence either the ease of justification or anticipatory pain-of-payment. However, ease of justification was significantly related to anticipatory pain-of-payment $(\mathrm{B}=-.61, \mathrm{SE}=.09, \mathrm{p}<.001,95 \% \mathrm{CI}[-.43$, -.79]). All covariates (financial literacy, perceived similarity to Americans, individual sensitivity to pain, debt aversion) were unrelated to ease of justification. Individual sensitivity to pain, perceived similarity to Americans, and debt aversion were also unrelated to anticipatory pain-ofpayment. However, financial literacy had a significant influence on anticipatory pain-of-payment payment $(\mathrm{B}=-.25, \mathrm{SE}=.10, \mathrm{p}<.05,95 \% \mathrm{CI}[.03, .47])$.

In addition to the previous model, I ran the same mediation model and controlled for the participant's financial situation variables (level of mortgage, level of credit card debt, level of an auto loan, amount of other debts, income). Adding these covariates to the mediation model did not change the model and none of these variables were related to PoP or to ease of justification. Based on these results, I did not find any support for $\mathrm{H} 1$ or $\mathrm{H} 2$. 
The effect of the pain-of-payment on debt repayment

Hypothesis 3 predicted that higher levels of anticipatory pain-of-payments lead to a tendency to accelerate debt repayments and this relationship depends on consumers' perceived financial self-efficacy. To test this hypothesis, I ran a PLS-SEM analysis used SmartPLS (Ringle, Wende, and Becker 2015). I created a path model including the independent variable (debt type), mediators (ease of justification and anticipatory pain) and control variables (financial literacy, debt-aversion, income, and tightwad-spendthrift tendency). The model is shown in Figure 6.

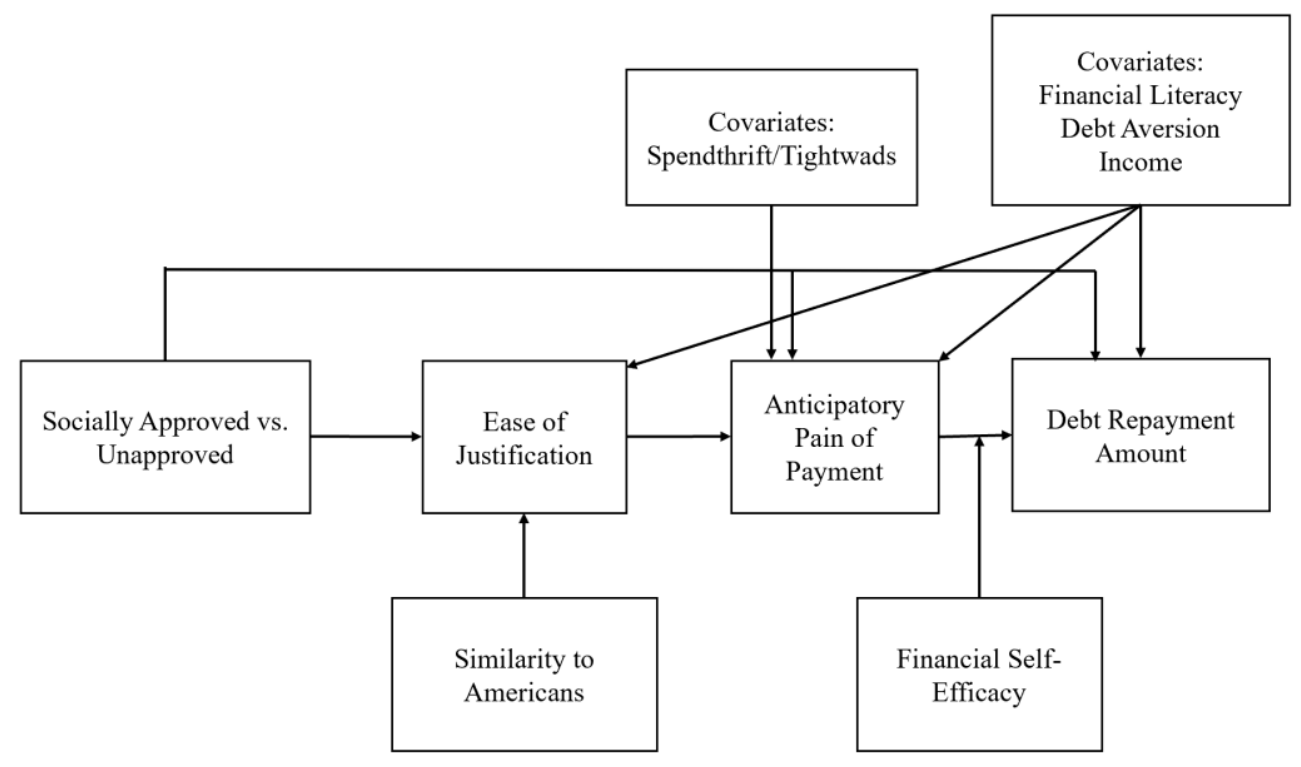

Figure 6-Study 2 Path Model

The results of the analysis are shown in Table 5. Ease of justification was significantly influenced by perceptions of similarity with Americans $(B=.19, S E=.09, p<.05)$. However, the manipulation did not significantly influence this variable. None of the covariates significantly 
influenced ease-of-justification. The similarity to Americans explained $1.8 \%$ of the variance in ease-of-justification (Adjusted $\mathrm{R}^{2}=.018$ ).

Anticipatory pain-of-payment was significantly influenced by ease-of-justification $(\mathrm{B}=.611, \mathrm{SE}=.07, \mathrm{p}<.001)$, but it was not influenced by the manipulation or any of the covariates. Ease of justification explained $40 \%$ of the variance in anticipatory PoP (Adjusted $\left.\mathrm{R}^{2}=.40\right)$

Table 5- Study 2- PLS Model Results, Dependent Variable was Repayment Amount

\begin{tabular}{|c|c|c|c|c|c|}
\hline Path & Hypothesis & B & SD & t-value & p-value \\
\hline Debt Type -> Anticipatory Pain & $\mathrm{H} 1$ & -0.068 & 0.082 & 0.822 & 0.411 \\
\hline Debt Type -> Ease of Justification & $\mathrm{H} 2$ & 0.115 & 0.092 & 1.258 & 0.209 \\
\hline Ease of Justification -> Anticipatory Pain & $\mathrm{H} 2$ & 0.611 & 0.072 & 8.533 & $<.001$ \\
\hline $\begin{array}{l}\text { Anticipatory pain X financial self-efficacy -> Debt } \\
\text { Repayment Amount }\end{array}$ & H3 & 0.022 & 0.107 & 0.209 & 0.834 \\
\hline Anticipatory Pain -> Debt Repayment Amount & & 0.148 & 0.098 & 1.5 & 0.134 \\
\hline Debt Type -> Debt Repayment Amount & & 0.02 & 0.096 & 0.209 & 0.834 \\
\hline Debt Aversion -> Debt Repayment Amount & & 0.064 & 0.115 & 0.553 & 0.581 \\
\hline Debt Aversion -> Ease of Justification & & -0.093 & 0.137 & 0.684 & 0.494 \\
\hline Debt Aversion -> Anticipatory Pain & & 0.242 & 0.153 & 1.577 & 0.116 \\
\hline Financial Literacy -> Anticipatory Pain & & 0.149 & 0.081 & 1.848 & 0.065 \\
\hline Financial Literacy -> Debt Repayment Amount & & 0.212 & 0.092 & 2.297 & $<.05$ \\
\hline Financial Literacy $->$ Ease of Justification & & 0.068 & 0.088 & 0.774 & 0.439 \\
\hline $\begin{array}{l}\text { Financial Self-Efficacy -> Debt Repayment } \\
\text { Amount }\end{array}$ & & 0.112 & 0.118 & 0.95 & 0.342 \\
\hline Income -> Anticipatory Pain & & 0.034 & 0.059 & 0.569 & 0.57 \\
\hline Income -> Debt Repayment Amount & & 0.068 & 0.112 & 0.61 & 0.542 \\
\hline Income $->$ Ease of Justification & & -0.05 & 0.069 & 0.723 & 0.47 \\
\hline Similarity to Americans $->$ Ease of Justification & & 0.192 & 0.09 & 2.132 & $<.05$ \\
\hline Spendthrifts vs. Tightwads -> Anticipatory Pain & & 0.052 & 0.086 & 0.61 & 0.542 \\
\hline
\end{tabular}

The debt repayment amount was not influenced by the manipulation or by anticipatory pain-of-payment or any of the covariates except financial literacy. Financial literacy was the only variable that was significantly and positively related to debt repayment amount $(\mathrm{B}=.21, \mathrm{SE}=.09$, $\mathrm{p}<.05$ ) and explained $5.2 \%$ of the variance in this variable (Adjusted $\mathrm{R}^{2}=.052$ ). I ran a separate 
model in which I controlled for all variables measuring consumers' financial status. None of these variables significantly influenced anticipatory pain-of-payment or repayment amount. In sum, the results of this study did not support any of the hypotheses proposed in this essay.

\section{Discussion}

The purpose of the current research was to manipulate injunctive norms to show that socially unapproved debt types get paid faster than socially approved debts with an equal balance. I proposed that this happens because socially unapproved debts are harder to justify and hence, they evoke higher levels of anticipatory pain when consumers think about future debt repayments. In the second study, I manipulated the social approval of debt by providing statistical information about the commonality of the loan in society (90\% vs. $10 \%$ of Americans borrow for this purpose). I then examined whether this manipulation influenced consumers' ease-of-justification, anticipatory pain-of-payment and the ripping off the Band-Aid effect. Unfortunately, I did not find support for any of the hypotheses in this study.

One possibility for such null results is that the manipulation proposed was not tapping into injunctive norms. In this study, I also measured participants' perceptions of injunctive and descriptive norms. I ran two ANOVAs to test the influence of manipulation on injunctive and descriptive norms (no covariates were added to the model). The ANOVAs showed that the manipulation significantly influenced perceptions of both norm types; however, the effect of the manipulation is much stronger on descriptive norms than injunctive norms $\left(\mathrm{R}^{2}\right.$ Descriptive $=.59$ vs. $\mathrm{R}^{2}$ Injunctive $=.25$ ). It is possible that the designed manipulation is changing participants' perceptions of descriptive norms, instead of injunctive norms, which is resulting in the null findings. 
Since I measured descriptive and injunctive norms in this research, I ran a PLS-SEM model using SmartPLS (Ringle, Wende, and Becker 2015). In the model, debt type was the independent variable and debt repayment was the dependent variable. Two mediation paths were added to the main effect. The first path was debt type->injunctive norms-> ease-of-justification>anticipatory pain. This path reflects the argument that injunctive norms (how socially approved a debt type is) are the reason why consumers perceive a debt type as easy-to-justify and these norms are the mechanism behind experiencing the pain-of-payment. The second mediation was debt type->descriptive norms->debt repayment. I also added all covaries that were entered into the main model (financial literacy, debt aversion, spendthrift vs. tightwad tendency, similarity to Americans, and income). The model is shown in Figure 7.

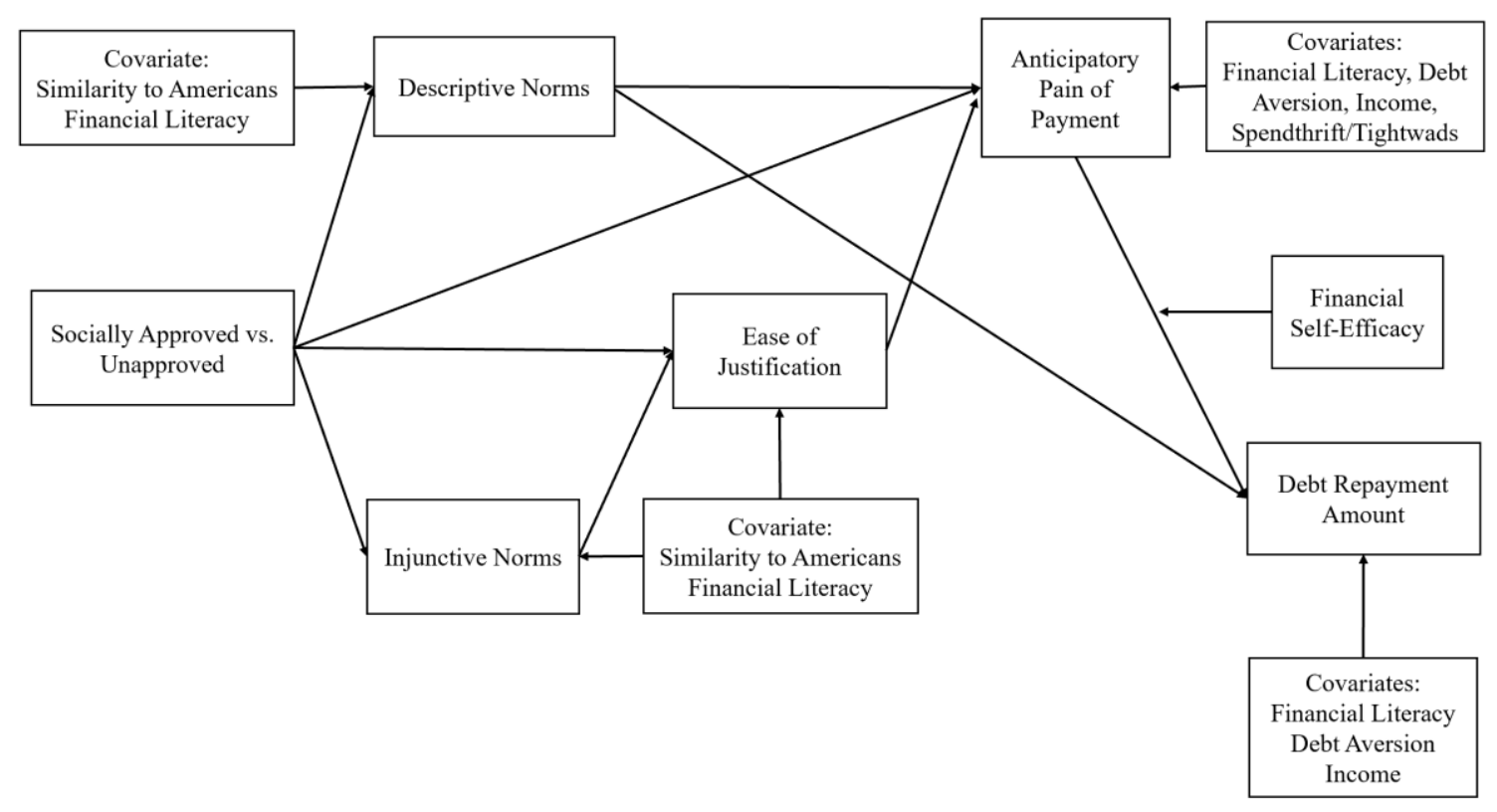

Figure 7- PLS Path with Descriptive Norms 
Table 6 shows the results of this analysis. The analysis indeed showed a significant debt type->descriptive norms->debt repayment path, which indicates that the current manipulation significantly influences debt repayment intentions through perceptions of descriptive norms. Perceptions of descriptive norms were significantly driven by debt type $(B=0.57, S E=.06$, $\mathrm{p}<.001)$. None of the covariates significantly influenced perceptions of descriptive norms. Debt type explained $29.4 \%$ of the variance in descriptive norms and descriptive norms explained $6.7 \%$ of the variance in debt repayment. The manipulation also significantly influenced injunctive norms but only explained $8 \%$ of the variance in this variable. While descriptive norms have a significant and moderate influence on debt repayment, neither anticipatory pain-of-payment nor the interaction of PoP and financial self-efficacy was related to debt repayment. These results indicate that what was manipulated in this study was consumers' perceptions of descriptive norms and not injunctive norms. Recall that injunctive norms are proposed as the reason why consumers experience the pain-of-payment and this may be the reason behind finding the null effect.

In addition to the model shown in Figure 7, I ran another PLS-SEM model with the same design, but I also added a variable measuring the interaction between descriptive norms and financial self-efficacy. I also added a path between the interaction and debt repayment. Interestingly the effect of this interaction with debt repayment was also significant $(B=.22$, $\mathrm{SE}=.01, \mathrm{p}<.05)$. Adding this variable to the model increased the explained variance in debt repayment from $6.7 \%$ to $11.2 \%$ (adjusted $\left.\mathrm{R}^{2}=.112\right)^{4}$. The results of this analysis indicated that

\footnotetext{
${ }^{4}$ The same PLS-SEM model was run with an additional path between descriptive norms and anticipatory pain-of-payment. Results indicated that descriptive norms do not influence anticipatory PoP.
} 
perceived descriptive norms can also influence the rip-off of the Band-Aid effect and it is a great avenue to expand this research in the future and explore both types of norms on consumers' decisions to repay their debts.

Table 6-Study 2-PLS Model Results

\begin{tabular}{|l|c|c|c|c|}
\hline Path & B & SD & t-value & p-value \\
\hline Debt Type -> Descriptive & 0.57 & 0.067 & 8.545 & $<.001$ \\
\hline Descriptive -> Debt Repayment Amount & 0.123 & 0.093 & 1.325 & 0.186 \\
\hline Similarity to Americans -> Descriptive & 0.072 & 0.082 & 0.882 & 0.378 \\
\hline Financial Literacy -> Descriptive & 0.03 & 0.081 & 0.364 & 0.716 \\
\hline Debt Type -> injunctive & 0.338 & 0.101 & 3.35 & $<.01$ \\
\hline Debt Type -> Ease of Justification & 0.281 & 0.079 & 3.54 & $<.001$ \\
\hline Ease of Justification -> Anticipatory Pain & 0.605 & 0.073 & 8.337 & $<.001$ \\
\hline Anticipatory Pain -> Debt Repayment Amount & 0.151 & 0.091 & 1.666 & 0.096 \\
\hline Anticipatory pain X financial self-efficacy -> Debt & 0.031 & 0.114 & 0.269 & 0.788 \\
\hline Repayment Amount & & & & \\
\hline Debt Aversion -> Anticipatory Pain & 0.226 & 0.176 & 1.285 & 0.199 \\
\hline Debt Aversion -> Debt Repayment Amount & 0.06 & 0.115 & 0.521 & 0.602 \\
\hline Debt Type -> Anticipatory Pain & -0.07 & 0.075 & 0.934 & 0.351 \\
\hline Financial Literacy -> Anticipatory Pain & 0.158 & 0.077 & 2.055 & $<.05$ \\
\hline Financial Literacy -> Debt Repayment Amount & 0.223 & 0.085 & 2.614 & $<.01$ \\
\hline Financial Literacy -> Ease of Justification & 0.082 & 0.082 & 1.008 & 0.314 \\
\hline Financial Literacy -> injunctive & 0.022 & 0.101 & 0.22 & 0.826 \\
\hline Financial Self-Efficacy -> Debt Repayment Amount & 0.097 & 0.124 & 0.784 & 0.433 \\
\hline Income -> Anticipatory Pain & 0.031 & 0.058 & 0.54 & 0.59 \\
\hline Income -> Debt Repayment Amount & 0.071 & 0.109 & 0.655 & 0.513 \\
\hline Similarity to Americans -> Ease of Justification & 0.206 & 0.083 & 2.468 & $<.05$ \\
\hline Similarity to Americans -> injunctive & 0.044 & 0.108 & 0.406 & 0.685 \\
\hline Spendthrifts vs. Tightwads -> Anticipatory Pain & 0.052 & 0.092 & 0.567 & 0.571 \\
\hline
\end{tabular}

\section{General Discussion}

Consumer debt is rising in the world. Many government agencies and researchers are trying hard to discover ways to motivate consumers to repay their debts. One factor that the previous research has not examined is the social norms surrounding debt types. In particular, in this study, I focused on the injunctive norms that prescribe what types of debts are socially 
approved and what types of debts are unapproved. I proposed that consumers' perceptions of such norms influence their debt repayment behavior through increasing anticipatory pain-ofpayment - the amount of negative affect that consumers experience when thinking about future payments that they must make towards a loan.

In two studies, I found some support for these hypotheses. In study 1 , I showed that debt type influences consumers' anticipatory PoP. Consumers who were told that they had an unnecessary debt reported higher levels of anticipatory PoP because they deemed it harder to justify having such loans to others. High anticipatory pain-of-payment influenced repayment intentions when consumers had moderate levels of financial self-efficacy. In study 2 , the manipulation of injunctive norms was not strong enough. This manipulation tapped more into perceived descriptive norms than injunctive norms. In future research, I will run another study and will design a better manipulation of injunctive norms. While this manipulation was not strongly related to injunctive norms, it significantly and strongly influenced descriptive normsperceptions of how common and typical a debt type is in American society. While not hypothesized, I did find that descriptive norms are significantly related to consumers' debt repayment intentions.

This study contributes to public policy research by providing a new tool-social normsto public policymakers interested in nudging consumers into pre-paying their debts. Both injunctive and descriptive norms can influence consumers' debt repayment behavior. Using interventions that frame debt as socially unacceptable can be effective in encouraging consumers to repay their debts. Normative messages could be attached to consumers' loan statements to motivate debt pre-repayment or repayment. Coupling these normative messages with messages 
intended to increase consumers' perceptions of their financial self-efficacy could increase consumers' debt repayment.

This research also contributes to the literature on social norms and pain-of-payment. Extant research on social norms states that the effect of injunctive and descriptive social norms on consumers' behavior occurs because consumers tend to align their behavior with the norms (Cialdini and Goldstein 2004; Schultz et al. 2007; Otto et al. 2019). I agree that this tendency is the main reason why consumers follow norms. Yet herein I argued and showed that, in addition to a social motivation to align with what other society's members are doing, social norms can also influence consumers' behavior through a personal motivation to reduce the negative affect experienced by not following the norms. Results of two studies showed that when consumers perceive that they have borrowed a debt that is a socially unapproved and is against society's norms, they experience higher levels of pain-of-payment when thinking about the future payments that they must make towards this debt. High levels of anticipatory pain-of-payment increase consumers' intentions to accelerate debt repayment to rip-off the Band-Aid and reduce this negative affect.

\section{Conclusion and Future Research}

In this essay, I tried to understand how social norms surrounding debts influence consumers' debt repayment behavior. I proposed that consumers are more likely to accelerate debt repayment for debts that are considered socially unacceptable. Anticipating repayment of debts that were incurred by socially unacceptable purposes is more aversive than socially acceptable debts, and hence consumers are more likely to repay those types of debts when they 
think they have the ability to do so. The findings of this research can help marketing and public policymakers who are interested in encouraging consumers to repay their debts.

Future research can explore other variables that could influence the Rip-Off the Band-Aid effect. One such factor is consumers' aspiration of achieving financial freedom. Consumers who are more dedicated to achieving financial freedom might strive harder to repay their debts. 


\section{ESSAY III}

\section{Ripping off the Band-Aid: When and How Perceived Benefits of a Product \\ Purchased with a Loan Influences Loan Repayment}

Farnoush Reshadi, Doctoral Candidate, West Virginia University 


\begin{abstract}
Previous research on debt repayment has provided ample evidence that consumers' debt repayment decisions are often influenced by non-economic factors. While the interest rate charged on a loan should be the most important factor influencing debt repayment, research has shown that consumers' debt repayment decisions are more strongly driven by other factors. Following this research, the current essay explores how a consumer's motivation to pre-pay a loan depends on 1) her perception of the future benefits provided by the product purchased with that loan, and 2) her decision to replace that product. Grounded in the literature on the doubleentry mental accounting theory, I argue that consumers are more likely to pre-pay loans borrowed to purchase products that provide low or negative (harm) future benefits. This effect occurs because paying a loan borrowed to purchase a product that provides low or negative future benefits evokes high levels of anticipatory pain-of-payment. To avoid experiencing this negative affect, consumers will be more likely to pay more money towards their debts. I refer to this effect as the "rip off the Band-Aid" effect and I propose that this effect depends on whether the consumer has made a decision to replace the product and whether the consumer perceives herself to have high financial self-efficacy.
\end{abstract}

Keywords: debt repayment, pain-of-payment, perceived benefits, mental accounting 
The changes in the financial industry and the recent economic growth has increased consumers' access to various types of loans. As a result, consumer debt is rising fast in the United States and other parts of the world. In 2018, American's debt reached a new peak of \$13.21 trillion (Household debt and credit report 2018). In the first quarter of 2018, "balances climbed 0.6 percent on mortgages, 0.7 percent on auto loans, and 2.1 percent on student loans" (Household debt and credit report 2018). In addition, American cardholders owe an average of $\$ 5,839$ on their credit cards (Williams 2018). While the availability of loans in society can increase consumers' quality of life and purchase power, having high levels of debt can be detrimental to consumers' well-being. High levels of debt can reduce consumers' available financial slack. Indebted consumers lose their financial resources by paying interest and various fees to financial service companies (Stango and Zinman 2009). Indeed, on aggregate American consumers paid $\$ 34$ billion in overdraft fees in 2017 (LaMagna 2018), and \$113 billion in credit card interest in 2018 (Rounds 2018). Thus, having debt reduces consumers' financial well-being and purchase power. In addition to reducing financial well-being, having debt increases consumers' stress (Worthington 2006) and reduces their subjective well-being (Tay et al. 2017).

Indebted consumers can reduce their interest burden by using their available financial resources to pre-pay their loans and avoid paying interest. However, despite high levels of interest and fees charged on various debts, many consumers still prefer continuing debt repayment according to the pre-determined schedule and avoid pre-payment of those debts. This occurs even when consumers can switch to loans with lower interest rates (Stango and Zinman 2009), or when they have saved the required financial resources to pay off those high-interest debts earlier than the loan contract (Sussman and O'Brien 2015). Engaging in such financially suboptimal behavior wastes consumers' valuable financial resources and thus, their financial 
well-being. Hence, it is of utmost importance for researchers to study this suboptimal behavior, understand what factors influence consumers' debt repayment intentions and discover ways to nudge consumers to behave more rationally. In this study, I seek to understand a few variables that may play a role in consumers' debt repayment decisions.

From an economically rational perspective, consumers' debt repayment decisions must be driven by the economic consequences of not repaying the debt. Consequences include losing money by paying more debt due to the annual interest rate (APR) charged on the loan. However, research has shown that the interest rate charged on a loan is not a strong predictor of debt repayment decisions. Consumers debt repayment decisions are driven by various factors such as the debt accounts' remaining balance (Amar et al. 2011; Besharat, Carrillat, and Ladik 2014; Besharat, Varki, and Craig 2015; Brown and Lahey 2015; Gal and Mcshane 2012; Gathergood et al. 2018; Ponce, Seira, and Zamarripa 2014), whether the financial resource allocated to repayment was received as a reward vs. hard-earned money (Besharat, Carrillat, and Ladik 2014), the hedonic vs. utilitarian nature of the product purchased with the loan (Besharat, Carrillat, and Ladik 2014; Besharat, Varki, and Craig 2015), the minimum required payment amount charged on credit cards (Hershfield and Roese 2015; Jones, Loibl, and Tennyson 2012; McHugh and Ranyard 2016; Navarro-Martinez et al. 2011; Salisbury 2014; Stewart 2009), whether the debt was incurred in distant or proximal past (Besharat, Varki, and Craig 2015), and the number of debt accounts one owes (Amar et al. 2011). This work provides ample support that consumers' debt repayment decisions are not financially optimal; this work has shown that the interest rate charged on a loan is not a good predictor of debt repayment behavior and debt repayment decisions are influenced by various emotional and situational factors. While existing work provides valuable insights, our discipline has not studied how consumers' debt repayment 
decisions are driven by their perceptions of the benefits provided by the product/service purchased with the loan. I argue that consumers' debt repayment decisions may also be influenced by their perceptions of the benefits that a product provides. In this study, I seek to understand how consumers' perceptions of the benefits received from a product/service financed with a loan influence their loan repayment decisions.

I propose that expected future benefits received from consuming a product/service influence consumers' debt repayment through increasing or decreasing the level of experienced pain-of-payment. Pain-of-payment is a negative psychological emotion that consumers experience when they become aware of losing a certain amount of their financial resources (Zellermayer, 1997; Prelec and Loewenstein, 1998; Mazar et al. 2107). The comprehensive literature review conducted in essay 1 revealed that there are two types of pain-of-payment (PoP): immediate and anticipatory PoP. Immediate PoP is the negative emotion evoked immediately after a reduction in consumers' financial slack, such as right after making a payment. Anticipatory PoP is the negative emotion experienced when a consumer becomes aware of a future reduction in her financial resources, such as knowing that one should make multiple payments on a loan in the future. Immediate and anticipatory PoP can be influenced by various variables including the amount of money spent, consumers' financial situation, and consumers' tendencies to experience PoP (Prelec and Loewenstein, 1998; Rick et al., 2011; Zellermayer, 1997). When consumers purchase a product or consider purchasing a product, they may experience PoP. Prelec and Loewenstein (1998) proposed that PoP can be buffered by thinking about the benefits received from the product. Specifically, consumers will experience lower levels of PoP when they purchase a product that they expect will provide high levels of benefits in the future. 
Similar to any other situation where consumers spend or lose money, consumers experience PoP when making debt repayments. In their double-mental accounting theory, Prelec and Loewenstein (1998) argued that the level of experienced PoP will be higher when consumers have to make debt repayments for products that do not provide any further benefits. While this theory proposes useful insights, it is under-developed and has received little attention from scholars beyond the theoretical proposals to date. In this essay, I explore some of the boundary conditions and mechanisms behind this effect.

Based on the mental accounting theory and the coping literature (Folkman and Lazarus 1988; Lazarus and Folkman 1991), I argue that when making loan repayments, consumers will accelerate repaying debts borrowed to purchase a product that provides low or negative future benefits. This effect is more intense when consumers are planning to replace the product in the near future. I argue that this occurs because paying for products/services that provide low benefits evoker higher levels of PoP. To cope with this negative affect, consumers will be more likely to accelerate debt repayment or paying-off the debt. When making repayments for a product that provides low or negative future benefits, consumers may prefer to experience "more pain-of-payment now" than experiencing an enduring PoP over the long term. The idiom of "ripping off the Band-Aid" is reflective of this principle. Consumers are likely to prefer to endure more or sharper immediate PoP evoked by making higher debt repayments now, in exchange for experiencing lower levels of pain over the long term evoked by continuing the default loan payment for a product that provides low or negative future benefits.

The current research contributes to the literature in several ways. First, this essay contributes to the debt repayment literature by showing that consumers' debt repayment decisions are not financially optimal and are influenced by emotions and perceptions of the future benefits 
provided by a product purchased with the loan. In addition, this essay also contributes to the mental accounting theory by demonstrating when and how the pain-of-payment influences debt repayment decisions. Third, this research contributes to the literature by studying the psychology of debt repayment in a context that has been understudied. Previous research on the psychology of loan repayment has been mostly focused on studying how consumers prioritize repayment of their multiple credit card debts when they have limited financial resources. Research that studies debt repayment in the context of long-term loans that require making monthly payments (e.g., student loans, mortgages, and personal loans) is lacking. This research addresses this gap by studying debt repayment behavior in the context of long-term loans. In particular, I examine how consumers' expectations of perceived future benefits of a product influence their decisions to pre-pay a loan earlier than the predetermined loan term. In the next section, I will explain my hypotheses and the logic behind them.

\section{Theoretical Development}

\section{Mental Accounting, Budgeting, and the Double-Entry Mental Accounting Theory}

The theory of mental accounting (Thaler 1980, 1985, 2008) suggests that similar to companies, consumers follow an accounting system in which they mentally record, organize and keep track of their expenses in the form of "mental accounts." Consumers do so to allocate budget limits for their purchases (Heath and Soll 1996) and control their spending (Gourville and Soman 1998; Prelec and Loewenstein 1998). According to Thaler (1999), "Mental accounting procedures have evolved to economize on time and thinking costs, and also to deal with selfcontrol problems" (p. 202). 
Consumers may use the mental accounting system in different ways. In the simplest form, consumers open an earmarked mental account for various purchase categories and keep track of their purchases in each category to control overspending (Thaler 1985). For example, consumers may create a mental account for groceries or entertainment, keep track of the products they purchase in those categories and make sure that they do not go over the limit of their budget in each mental account. The double-entry mental accounting theory (Prelec and Loewenstein 1998) proposes another way that consumers may use mental accounting to track their expenditures. In this type of mental accounting, instead of product categories, consumers set up a mental account for a specific transaction and keep track of all expenses paid and all benefits accrued by that transaction over time. Keeping this type of "transaction-specific" mental accounts compels customers to consume products they have purchased, and refrain from abandoning them when faced with tempting alternatives (Thaler 1985); hence, keeping them from overspending. The theory of double-entry mental accounting seeks to explain how consumers record these transaction-specific mental accounts, and how these mental accounts influence consumers' savings and debt repayment decisions.

The double-entry mental accounting posits that when making a purchase, consumers open a transaction-specific mental account where they store the pleasure from consuming the product and the "imputed cost" of the consumption. The theory assumes "transaction coupling" between consumption and payments, which argues that each episode of product consumptions reminds consumers of the cost paid for that purchase and vice versa. "Each time a consumer engages in an episode of consumption, we assume she asks herself how much is this pleasure costing me? The answer to this question is the imputed cost of consumption" (Quispe-Torreblanca et al. 2019, p. 8). At each episode of consumption or payment, consumers compare the benefits and costs 
accrued in that episode. If costs are higher than benefits, consumers will experience a negative emotion, called the pain-of-payment. The pain-of-payment is a psychological reaction to losing financial resources (Zellermayer 1997b); it can be buffered by thinking about the benefits received from the consumption in each episode.

The double-entry mental accounting theory (Prelec and Loewenstein 1998) describes how consumers mentally keep track of the pleasure received from consumption and the pain-ofpayment for a purchased product. A central assumption of this theory, called prospective accounting, is that when consumers finish paying for a purchase before consumption, they will enjoy that purchase as if it were freely offered to them and they did not pay for it. This occurs because when payments are over, consumers will receive benefits without experiencing pain-ofpayment. On the other hand, Prelec and Loewenstein (1998) argued that when a product's benefits are over, but the consumer still has to make payments, each payment will be experienced as pure loss and will be highly painful. In other words, prospective accounting assumes that "people only care about future costs and benefits: for each transaction, they offset the pain of repayments against future consumption and offset the pleasure of consumption against the pain of future repayments" (Quispe-Torreblanca et al. 2019, p. 3). Since consumers are utility-maximizing, the prospective accounting hypothesis predicts that consumers are "generally debt-averse" (p. 4), and prefer to pre-pay for products to be able to enjoy the consumption of that product without experiencing pain-of-payment. However, according to Prelec and Loewenstein $(1998 ; 2019)$, this tendency is stronger for non-durable products that provide short-term benefits vs. durable products that last a long time. Making payments for a durable product may be painful, but payments will probably be more painful after the product's benefits are consumed; because of this, consumers prefer to pay-off the debt faster for non- 
durables than durables. This prediction is consistent with the seminal work on mental budgeting, which suggests that consumers' debt repayment behavior is influenced by the longevity of the product purchased with the loan (Hirst, Joyce, and Schadewald 1994).

In sum, the double-entry mental accounting theory suggests that consumers are more likely to pay-off a loan when they expect the product purchased with the loan to provide low benefits in the future. While the prediction of double-mental accounting is plausible, this theory is under-developed and has received little attention by scholars beyond Prelec and Loewenstein's (1998) theoretical proposals. A few studies have used the double-mental accounting theory to show how consumers' purchase intentions or preferences are influenced by their perceptions of the benefits of the product/service (Auh, Shih, and Yoon 2008; Patrick and Park 2006). However, no research has examined this theory in the context of debt repayment. In a recent field study, Quispe-Torreblanca et al. (2019) tested the effect of product durability on debt repayment. They showed that repayment of debts incurred by purchasing non-durables is $10 \%$ more likely than repaying debts incurred by durable goods. While this research provides useful insight, the authors focused on the relationship between product durability and debt repayment and did not consider any other type of benefits (e.g., functional, emotional, and usage instances). In addition, this study was limited to revealing the main effect of the durability of the product on debt repayment and did not explain when and why this effect happens. Hence, in this essay I aim to examine this hypothesis. I call this effect the "rip off the Band-Aid" effect, and I examine this effect in the context of personal loan repayments.

I argue that consumers' loan repayment decisions are influenced by the perceived future benefits of the product. Similar to the assumption of prospective accounting, I assume that consumers only consider future costs and benefits in their mental accounting activities and their 
decisions are based on future perceived costs and benefits. I define the perceived future benefits of the product as the amount of value or utility that the consumer expects to receive from the product in the future. This definition of product benefit goes beyond durability and encompasses any type of benefits provided by the product (e.g., functional and emotional benefits), as well as the expected product use. Thus, the perceived benefits of a product may be low for a durable product that has no further use, even if it is still in good shape. In addition, this definition takes into account situations where the consumer expects product consumption to result in harm in the future. Previous research on product benefits only examined conditions where the product offers high, low or no amount of benefits to the consumer. However, the marketing literature is rife with situations where a product does not only fail to provide benefits but also harms the consumer. For example, consider a consumer who buys a new laptop charger, which stops working after a month and damages the laptop as well. I refer to such situations as providing negative benefits and I argue that paying for a product that has future negative benefits is more painful than paying for a product that has low or high future benefits. Thus, I propose:

H1- The level of perceived future benefits received from a product/service is negatively related to the anticipatory pain of making future debt repayments.

\section{The Moderating Effect of Replacement Decisions}

In the previous section, I proposed that expecting low levels of benefit from a product increases consumers' repayment of the loan they borrowed to purchase that product. In this section, I propose that this effect depends on the consumer's decision to replace the product. I argue that consumers will be more likely to rip-off the Band-Aid for a product that provides low or negative benefits when they decide to purchase a new product that offers a similar benefit. The mental accounting literature (Thaler 1980; 1985; 2008) argues that consumers make 
earmarked mental accounts for various product categories to keep track of products purchased in that category. I propose that consumers will prefer to close a mental account for a certain product before purchasing an alternative product that serves the same purpose. For example, consumers do not want to buy a new TV for their living room when they are still paying off their previous TV set.

Previous research has provided some support for this proposition. Hirst, Joyce, and Schadewald (1994) conducted an experiment in which they asked participants to imagine that they took out a $\$ 7000$ loan. Half of the participants were told that they took out the loan to renovate their house that has a life expectancy equal to the house's life expectancy. The other half were told that the purpose of the loan was to redecorate the house and it will last about four years before they had to redecorate again. Participants saw two types of loans and were asked to choose the loan that they preferred. Loan A was a 3-year repayment plan with 12\% APR and a monthly payment of $\$ 232.50$, and loan B was a 15 -year repayment plan with $11 \%$ APR and a monthly payment of \$79.56. Hirst, Joyce, and Schadewald (1994) showed that consumers' preferences differed between the two conditions. Seventy-four percent of participants (20/27) preferred the short-term loan to pay for the redecoration, compared with only $31 \%(9 / 27)$ in the home improvement condition. The authors argued that this effect occurs because consumers tend to match loan payment duration with the longevity of the product. However, this study may have a confound. The high preference for short-term goal for redecoration might occur because consumers were told in the study that they will have to pay to redecorate again after four years (product replacement), while the participants in the home improvement were not told about having to pay for a new house and/or home improvement. I argue that consumers' preference for the short-term or the longer-term loan is driven by the fact that consumers do not want to have 
two open mental accounts for two loans that serve the same purpose. They prefer to close the mental account, by ripping off the Band-Aid before borrowing money for the same purpose.

Paying money to purchase a product/service that serves a specific purpose is more painful when consumers have a current debt that was incurred by purchasing a product/service with the same purpose. For example, borrowing money to purchase a laptop is more painful when the customer is still making payments for the loan she took to buy her previous laptop vs. when the previous account is paid off. This happens because consumers assign both purchases to the same mental account, and payments are more painful when consumers must pay for two products that serve the same purpose. Hence, I propose that:

H2- The negative effect of perceived future benefits of a product on anticipatory pain-ofpayment will be stronger when consumers are planning to replace that product with an alternative option that serves the same purpose.

\section{Anticipatory Pain-of-Payment and Ripping off the Band-Aid}

The double-entry mental accounting theory (Prelec and Loewenstein 1998) posits that consumers will accelerate debt repayment when they anticipate high levels of PoP in the future. PoP is a negative psychological reaction to losing money. People generally approach pleasure but avoid pain (Higgins 1997). Prelec and Loewenstein (1998) argued that consumer's debt repayment decisions depend on a comparison between how much pain-of-payment they feel at the moment if they pay off the debt (immediate pain), and how much pain-of-payment they anticipate experiencing in the future if they continue with the default loan payment plan. If the level of anticipatory pain-of-payment is higher than the pain evoked by paying off the debt, consumers will decide to pay off the debt to avoid experiencing pain in the future and enjoy consuming the product without having to make future payments. 
While I agree with this hypothesis, based on the coping literature (Folkman and Lazarus 1988; Lazarus and Folkman 1991), I argue that higher levels of anticipatory PoP only lead to higher levels of debt repayment when consumers perceive themselves to have high levels of financial self-efficacy. PoP is a negative emotion evoked by becoming cognizant of losing money. Research has shown that experiencing negative emotions can have a motivational influence on consumers' decisions (Folkman and Lazarus 1988; Lazarus and Folkman 1991). Consequently, if consumers feel that an activity can help reduce the intensity of the negative emotion, they may be more likely to take that action than they otherwise would (Shen and Wyer Jr. 2008).

The coping literature posits that when faced with negative emotions such as fear or pain, consumers engage in two types of coping strategies: emotion-focused and problem-focused (Folkman and Lazarus 1988). Problem-focused coping encompasses behavior that would change the environment or address the source of the negative emotion to reduce stress. Emotion-focused coping reduces the negative emotion that solving the underlying problem that caused it (for example, by changing the focus of consumers' attention) (Folkman and Lazarus 1988, p. 467). While some coping strategies may be unconsciously activated, most coping strategies are deliberate and require an analysis of the situation at hand to reduce the negative emotion (Ramanathan and Williams 2007; Schwartz et al. 1999). When consumers know the source of the negative emotion, they are more likely to decide to engage in problem-focused coping behavior (Raghunathan, Pham, and Corfman 2006). However, Folkman and Lazarus (1980) argue that engaging in problem-focused vs. emotion-focused coping depends upon consumers' perception of the efficacy of coping in reducing the negative emotion. Consumers will engage in problemfocused coping when they feel that they can take action to reduce the pain. If they cannot take 
any actions to reduce the stressor, they will engage in emotion-focused coping by distracting themselves from the stimuli and the environment.

Based on the coping literature, I suggest that when consumers experience high levels of immediate pain and expect this pain to continue in the future (high anticipatory PoP), they engage in coping mechanisms to avoid experiencing such psychological negative emotion. A problem-focused coping mechanism to deal with PoP is to pay-off the debt and rip-off the BandAid. Consumers will engage in this type of coping when they believe that they can take the necessary actions to come up with the financial and non-financial resources to pay-off the debt. The aversive impact of anticipatory pain-of-payment motivates consumers to consider paying off their debt. However, consumers will only do so if they have the available resources to perform this task. To pre-pay a debt or rip off the Band-Aid, a consumer needs to have the required financial resources to pay off the debt or to have the ability to obtain the required monetary resources by reducing her current spending or increasing her earnings. Even if the consumer does not have the available financial resources to pay towards the loan, the consumer can take action to save money or earn more money to pay towards the loan.

This strategy is evident in the behavior of consumers who follow the American financial advisor, Dave Ramsey. Dave Ramsey advises consumers on various financial matters such as debt repayment. He has created a multiple-step technique in which indebted consumers decide to live on the minimum amount of financial resources to save money and repay their debts. He encourages consumers to cut any unnecessary expenses (e.g., dining out) to save money and put that money towards their debts. According to Dave Ramsey, four million Americans have taken this approach, and have repaid their debts. Thus, I propose that paying off debt motivated by anticipating high levels of PoP, depends on the consumer's assessment of her self-efficacy to 
discover necessary financial and non-financial resources to find the required money to pay off the debt.

Previous literature (Lown 2011) refers to this construct as "financial self-efficacy." Selfefficacy is an individual's perceptions of her ability to activate the resources, motivations, and actions required to accomplish a specific task (Gist and Mitchell 1992). Whether a consumer engages in a particular behavior depends on how much she believes she can be successful in performing that task (Bandura 1986). Financial self-efficacy is a form of self-efficacy that is relevant to a consumer's belief in her ability to perform positive financial behavior such as debt repayment (Lown 2011). Financial self-efficacy covers various aspects of self-efficacy related to making positive financial decisions such as ability and motivation to perform positive financial behavior as well as the individual's estimation of her available resources (Lown 2011). Previous research indicates that consumers are more likely to engage in positive financial behavior when they perceive higher levels of financial self-efficacy (Perry and Morris 2005; Danes and Haberman 2007; Lown 2011). Thus, I propose that the level of financial self-efficacy moderates the relationship between anticipatory pain and repayment intentions.

H3- Higher levels of anticipatory pain-of-payment increases debt repayment intentions when consumers perceive high (vs. low) levels of financial self-efficacy.

Figure 8 shows the proposed framework. To test my predictions, I conducted two studies, which are explained in the next section. 


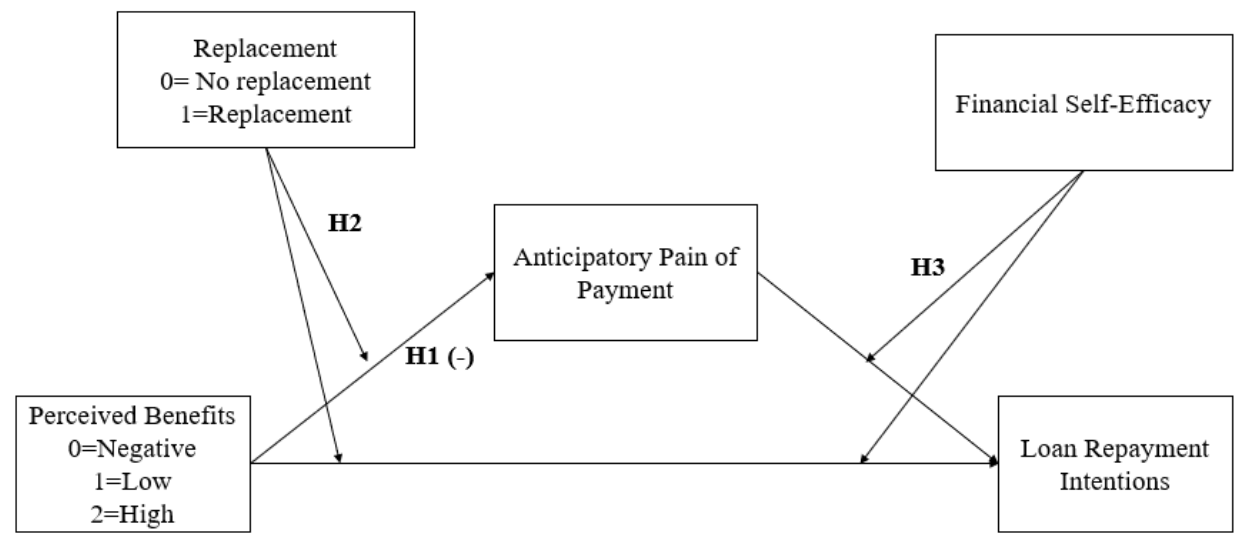

Figure 8- Study Framework

\section{Methodology}

\section{Overview of Studies}

Across two studies, I tested the proposed hypotheses. The purpose of study 1 was to explore the relationship between perceived benefits and debt repayment. Study 1 had a 3 (benefit level: negative, low, high) between-subjects factorial design. In this study, participants engaged in a debt repayment game that simulated loan repayment in real life. Participants first read the description of a loan they borrowed to purchase a car. Perceived future benefits of a product were manipulated by varying how long the car can be used in the future without spending money on maintenance. This manipulation was tested in a pretest, which is explained in the next section, and was used in both studies. After reading the loan description, participants were asked to complete seven rounds of a debt repayment game in which they decided on how much money they would devote to paying on the loan they read in the scenario.

The purpose of study 2 was to examine the moderation effect of replacement decisions. This study was a 3 (benefit level: negative vs. low vs. high) $* 2$ (replacement: yes vs. no) 
factorial design. In study 2, participants read the same loan scenario used in study 1 and they were either told that they decided whether or not to replace the car. This manipulation was also tested in pretest A. The following section explains the design, procedure, and results of these studies.

\section{Pretest A- Testing Benefits and Replacement Manipulations}

\section{Participants and Design}

The purpose of this study was to test the benefits and the replacement manipulations ${ }^{5}$. The study had a 3 (benefit level: negative vs. low vs. high) by 2 (replacement: yes vs. no) between-subjects factorial design. Participants were randomly assigned to one of the six conditions. One-hundred and seventy-four U.S. respondents were recruited from Amazon Mechanical Turk (MTurk). In exchange for their time, participants were paid $\$ 0.70$. Three questions were added to the survey to check if participants were paying attention to the scenario. Twenty-six participants who failed at least one of the attention checks were excluded from the study, leaving 148 participants (48.6\% female, $\left.\mathrm{M}_{\mathrm{age}}=37, \mathrm{M}_{\mathrm{income}}=\$ 60,480\right)$.

\section{Procedure}

Participants were provided with a scenario in which they imagined that one year ago they took out a loan to purchase a car and they must pay the $12^{\text {th }}$ payment on this loan today. The car was priced at $\$ 8,000$ and participants were told that they borrowed a 48 -month loan with an annual interest rate of $10 \%$ to purchase this car. Participants then read that right before making the $12^{\text {th }}$ payment, they remembered a recent incident with their car. They were told that the car

\footnotetext{
${ }^{5}$ Materials and details of the pretest are available in Appendix B.
} 
broke down the day before the payment, and they had to tow it to a mechanic. Participants were then randomly assigned to one of the three benefits manipulations. Participants in the highbenefits condition read that the mechanic told them that their car's crucial parts were new and unworn, and they could drive their car for many more years without replacing those costly parts. Participants in the low-benefits condition read that the mechanic told them that their car's crucial parts were old and worn but they could still drive the car for a few more years without replacing those costly parts. Participants in the negative-benefits condition read that the mechanic told them that their car's crucial parts were old and worn and it was not safe to drive their car without replacing costly parts.

Participants then read the replacement manipulation. Participants in the replacement manipulation were told that they decided to replace their car soon. Participants in the no replacement condition were told that, regardless of their experience with the mechanic, they decided not to replace the car in the near future.

After reading the scenario, participants answered questions about the perceived future benefits of the car, manipulation checks, and attention checks. Participants indicated how realistic the scenario was on a 7-point semantic differential scale (not at all: very much). Overall, participants reported that the scenario was realistic $(M=6.06)$ and the realism did not vary across the different conditions. Participants were then asked how expensive they thought both the car and the annual interest rate charged on the loan were on a 7-point semantic differential scales (cheap: expensive). On average, participants thought that the car was not expensive ( $M=3.36)$. In addition, participants rated the interest rate as moderately expensive $(M=5.45)$. Finally, participants answered demographic questions, were thanked and paid. 


\section{Measures}

\section{Independent Variables}

The perceived future benefits of the product were measured using eight items. Five of eight items asked participants to agree/disagree with the following statements on a 7-point scale:

- I would miss out on many benefits if I sell this car.

- I would get a lot of pleasure from this car in the future.

- This car would not be beneficial for me in the future.

- I would get a lot of harm from using this car in the future.

- I would receive many benefits from this car in the future.

In addition, participants answered three 7-point semantic differential scales regarding how useful (not at all useful: very useful), beneficial (not at all beneficial: very beneficial) and safe (very unsafe: very safe) the car described in the scenario would be in the future. In an exploratory factor analysis, all eight items loaded on the same factor. The Cronbach's alpha for the eight items was .94 . The average of all eight items was calculated to create a future benefits scale. Intention to replace the car was measured by asking participants to identify the replacement manipulating that they read in the scenario (Which one did you read in the scenario? 1- Your car was an old model, so you made a decision to replace this car soon; 2- Although your car was an old model, you made a decision NOT to replace this car any time soon; 3- None of the above; 4- I do not remember). In addition, participants were asked how likely they were to replace this car in the near future on a 7-point semantic differential scale (not at all likely: likely). 


\section{Results}

\section{Manipulation Checks}

In two different multiple-choice questions, participants were asked to choose the price of the car, and the interest rate charged on the loan in the scenario. Ninety-six percent of participants correctly chose the price of the car. Eighty-six percent correctly chose the annual interest rate charged on the loan.

Future benefits manipulation check. In a multiple-choice question, participants were asked to choose the benefit manipulation they read in the scenario. Seventy-eight percent of participants in the high-benefits condition, $88 \%$ in low-benefits condition and $78 \%$ of participants in the negative benefits condition correctly identified the benefits manipulation they read in the scenario.

An ANOVA, in which the benefit manipulation was the independent variable and the perceived future benefits measure was the dependent variable, was used to test the benefits manipulation (see Figure 9). As predicted, the three benefit conditions were significantly different in the level of perceived future benefits $\left(F(2,145)=126.03, p<.001\right.$; Adjusted $\mathrm{R}^{2}=.63$, $\mathrm{M}_{\text {Negative-benefits }}=2.55, \mathrm{M}_{\text {Low-benefits }}=4.07, \mathrm{M}_{\text {High-benefits }}=5.72$.). All three benefit levels were significantly different from each other. 


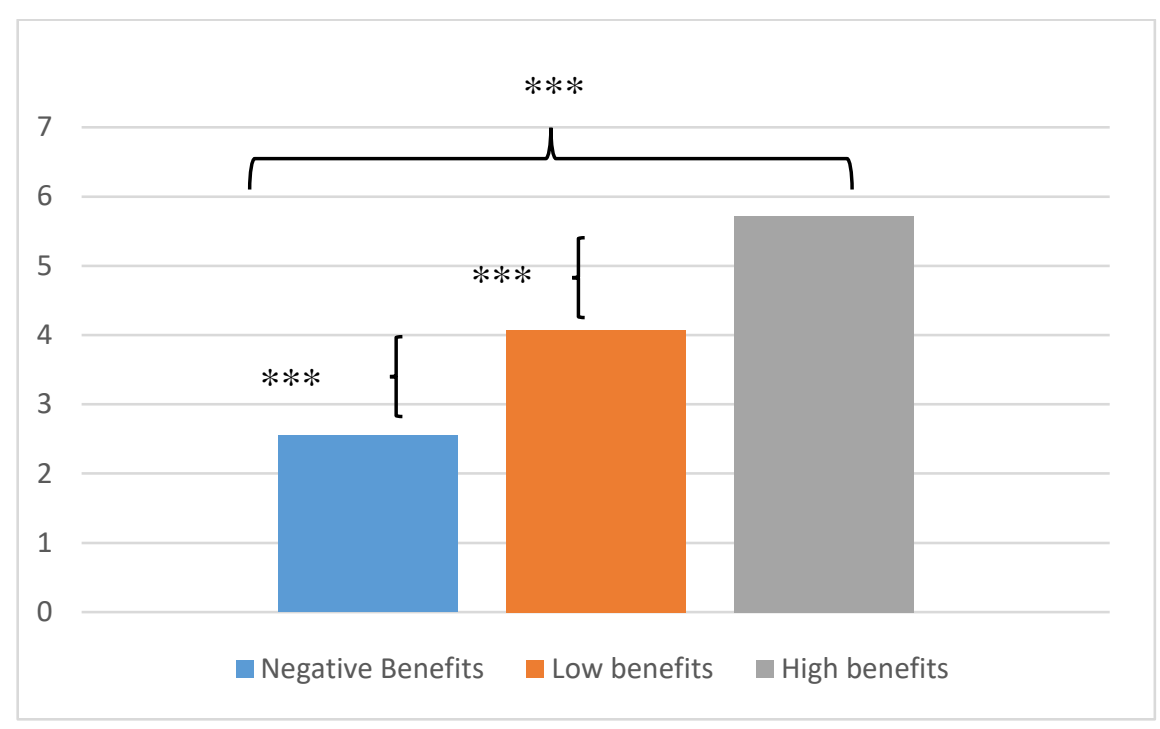

Figure 9- Results of the Benefits Manipulation Check

$* * *$ denotes $\mathrm{p}<.001$

Replacement manipulation check. Seventy-nine percent of participants in the no replacement condition, and $57 \%$ in replacement condition correctly identified the replacement manipulation they read in the scenario. One item measured participants' likelihood of replacing the car. The replacement manipulation was not significantly related to this item. However, this item was significantly influenced by the perceived benefits of the car $(\mathrm{F}(2,93)=30.5, \mathrm{p}<.001$; Adjusted $\mathrm{R}^{2}=.40$ ). It appears that in addition to changing benefit perceptions, the benefits manipulation also evoked thoughts of replacing the car. When the car was expected to provide high levels of benefits in the future, participants were not likely to replace the car $(\mathrm{M}=3.35)$. However, when the future benefits were low $(M=5.3)$ or negative $(M=6.1)$, participants were more likely to make a decision to replace the car in the future. 


\section{Conclusion}

The purpose of this pretest was to test the benefits and replacement manipulation. The benefits manipulation strongly and significantly changed consumers' perceptions of the perceived future benefits of the product. The replacement manipulation did influence perceptions of replacement however, many participants did not correctly identify the manipulation. Thus, the wording of this manipulation was changed in study 1 to increase the strength of this manipulation. In addition, the eight items measuring the perceived future benefits of the car was reduced to the three items with the highest factor loadings for parsimony.

\section{Study 1- Exploring the Effect of Remaining Benefits on Loan Repayment}

Study 1 was conducted to test hypotheses 1 and 3 . The goal of this study was to examine whether future benefits perceptions change consumers' loan repayment behavior in a loan repayment game. Participants read the benefits manipulation described in the pretest, answered a few questions about that scenario and then they played seven rounds of the loan repayment game. In each round, participants were asked to allocate $\$ 600$ to three different purposes: 1) paying off the loan, 2) saving, and 3) spending on something they desired. In each round of the game, each representing one month of loan repayment, participants had to decide how much of this $\$ 600$ they wanted to allocate to each of the aforementioned purposes.

I predicted that participants' allocation decisions in the game were related to their perceptions of the future benefits of the car purchased with the loan. In particular, lower benefit perceptions should cause participants to pay off more of the debt by allocating more of their available cash (\$600) towards the debt (vs. saving and spending) in the seven rounds of the 
game. Using this loan repayment design allowed me to more closely measure consumers' loan repayment behavior.

\section{Participants and Design}

Study 1 was a 3 (benefit levels: negative, low, high) between-subjects factorial experiment. Two-hundred and eight workers were recruited from Amazon Mechanical Turk. Six different questions were embedded throughout the survey to check if participants were paying attention to the study. Fifty-two participants who failed more than one of the attention checks were excluded from the study. The final sample consisted of 156 participants $\left(\mathrm{M}_{\mathrm{Age}}=36, \mathrm{M}_{\text {Income }}=\right.$ $\$ 48,781,48.7 \%$ female $)^{6}$.

In this study, after reading the consent form, participants read the scenario similar to the pretest. Participants were provided with a scenario in which they were asked to imagine that one month ago, they borrowed a $\$ 7,900^{7}$ loan with an annual interest rate of $10 \%$ to purchase a used car. Participants were told that they had to make 48 monthly payments of $\$ 200$ to pay off this debt. Participants were then randomly assigned to one of the three benefit manipulations. Replacement decisions were not manipulated in this study. After reading the scenario, participants answered a few questions about their level of anticipatory pain-of-payment when contemplating the future 48 monthly payments they had to make to pay off the loan, and the perceived benefits manipulation checks. Participants then read the instructions for playing the loan repayment game. To make sure that participants were paying attention and understood the

\footnotetext{
${ }^{6}$ Material and scenario are shown in Appendix C

${ }^{7}$ The amount of the loan in the pretest was $\$ 8,000$. I reduced this amount to $\$ 7,900$ in this study to decrease monthly payments from $\$ 203$ to $\$ 200$ and make the payments a round number to simplify the allocation task. The reason for this change was to eliminate concerns that MTurk participants will enter a random number in the allocation task because calculating the remaining budget would be harder when the participant allocates \$203 vs. $\$ 200$ to one of the three purposes.
} 
game instructions, after reading the game instructions, they were asked three questions based on the information they read. Participants were only able to play the game if they correctly answered all of these questions. Participants then played the loan repayment game for seven rounds, representing seven months of loan repayment. In each round, participants first saw a loan statement summarizing their monthly payments, fees accrued that month, interest accrued in that period and the total loan balance. Participants were then asked to allocate their $\$ 600$ across the three purposes (see Figure 10). To motivate participants to pay at least the monthly payments of the loan, a $\$ 25$ fee was charged if participants did not pay the monthly payments $(\$ 200)$. After completing the allocation task, participants answered three questions measuring immediate painof-payment. The new loan statement was then calculated, and participants played the next round. To make sure that participants did not forget the manipulation, I repeated the benefit manipulation after round 1 of the game and asked participants to describe how they feel about this loan. After completing the game, participants answered several questions measuring anticipatory PoP when considering the future 41 payment, financial self-efficacy, control variables, and demographics. Participants were then thanked and paid.

\section{In the three boxes below, type in the amount you want to allocate for each purpose. The total must be $\$ 600$.}

Pay on the loan

Put in savings account 


\section{Measures}

\section{Independent Variable}

Perceived benefits were measured using the shortened version of the benefits measure in the pretest. Three items that had the highest loading in the pretest were kept measuring the future benefits of the car. Participants were asked to report how much they thought the car would be useful, beneficial and safe in the future in three seven-point semantic differential scales (not at all useful: very useful, not at all beneficial, very beneficial, not at all safe: very safe). All three items loaded on the same factor and were reliable $(\alpha=.93)$. The average of the three items was calculated to form a perceived benefits measure. In addition, participants were asked to enter a number indicating their opinion on how many more years they thought they could drive this car before it was considered a junk car.

\section{Mediator}

Anticipatory PoP was measured with five items adopted from Thomas et al. (2011). All items asked about the level of pain evoked when thinking about the remaining 48 payments that had to be made on the loan. All five items loaded on the same factor and were reliable $(\alpha=.94)$. The average of the five items was calculated to form an anticipatory PoP measure.

\section{Moderator}

Financial self-efficacy was measured with four items adopted from Lown's (2011) scale. The four items that had the highest factor loadings in Lown's (2011) study were used to measure this variable. Participants were asked to rate how much they agree/disagree with four statements measuring financial self-efficacy perceptions on a 7-point scale (sample items include "It is easy for me to stick to my spending plan when unexpected expenses arise" and "I am confident in my 
ability to manage my finances"). All four items loaded on one factor and the scale was reliable $(\alpha=.856)$. The four items were averaged to form a financial self-efficacy scale.

\section{Control Variables}

Debt aversion is an individuals' tendency to consider all types of debt negatively (Callender and Jackson 2005). This variable may influence consumers' debt repayment behavior. To make sure that this variable does not influence our results, debt aversion was measured using three items adapted from Callender and Jackson (2005). Respondents were asked to rate how much they agreed or disagreed with three statements ("You should always save up first before buying something," "Owing money is basically wrong," and "There is no excuse for borrowing money") on a 7-point scale. A factor loading indicated that all three items loaded on the same factor. However, similar to results in Essay 2, the first item had low factor loading and low itemtotal correlation. Thus, that item was dropped from the scale and the average of the second and third statements $(\mathrm{r}=.59)$ was calculated to create a debt-aversion scale. Higher numbers on this scale indicate greater debt aversion tendencies.

Spendthrift vs. Tightwad Tendencies. Previous research has shown that consumers are different in the level of sensitivity to the pain-of-payment (Rick, Cryder, and Loewenstein 2008). This sensitivity influences the level of pain evoked by contemplating future payments of a loan. To control for this trait variable, individuals' sensitivity to the pain-of-payment was measured using the tightwad vs. spendthrift scale. Three items were adopted from Rick, Cryder, and Loewenstein (2008). A factor analysis was conducted. All items loaded on one factor; however, one item had low factor loading and item-total correlation and the scale was not reliable. To improve the reliability of the scale, the item with low item-total correlation was dropped from the 
scale and the average of the other two items was calculated to create an index of sensitivity to PoP $(r=.83)$. Higher numbers of this scale indicate a higher likelihood of being a spendthrift.

Financial Literacy. Consumers' tendencies to make any correct financial decisions may depend on their financial literacy levels. In the context of loan repayment, making an optimal loan repayment decision depends on how well consumers understand loans, interest rates, interest compounding and the time value of money. To measure consumers' financial literacy, participants were asked five questions. Three questions were adopted from Lusardi and Tufano (2011). These three items measured financial literacy related to debt. Two questions, which measured participants' understanding of the time value of money and compound interests were adopted from Cook and Sadeghein (2018). All items are shown in Table 7. A financial literacy score was calculated for participants such that they received one point for each correct answer. Thus, participants, financial literacy scores ranged from 0 to $6(\bar{X}=2.76)$.

Financial Status. To assess consumers' financial status, I asked questions regarding participants' income and debt levels. Participants were asked to enter their income in a text box. In four multiple-choice questions, participants were asked how much in total they owed for their mortgage, student loans, credit card loans and any other type of debt (e.g., to the best of your knowledge, how much do you owe on your mortgage? A) I don't have a mortgage, B) Less than $\$ 50,000$, C) $\$ 50,001-\$ 100,000$, D) $\$ 100,001-\$ 150,000$, E) $\$ 150,001-\$ 200,000$, F) More than $\$ 200,001$, G) I do not know). 
Table 7- Financial Literacy Measure

\begin{tabular}{|c|c|c|}
\hline Question & Options & Source \\
\hline $\begin{array}{l}\text { Cheryl owes } \$ 1,000 \text { on her bank } \\
\text { overdraft and the interest rate she } \\
\text { is charged is } 15 \% \text { per year. If she } \\
\text { didn't pay anything off, at this } \\
\text { interest rate, how much money } \\
\text { would she owe on her overdraft } \\
\text { after one year?' }\end{array}$ & $\begin{array}{ll}\text { - } & \$ 850 \\
\text { - } & \$ 1,000 \\
\text { - } & \$ 1,150 \\
\text { - } & \$ 1,500 \\
\text { - } & \text { I do not know }\end{array}$ & $\begin{array}{l}\text { Lusardi and } \\
\text { Tufano (2011) }\end{array}$ \\
\hline $\begin{array}{l}\text { Sarah owes } \$ 1,000 \text { on her credit } \\
\text { card and the interest rate she is } \\
\text { charged is } 20 \% \text { per year } \\
\text { compounded annually. If she } \\
\text { didn't pay anything off, at this } \\
\text { interest rate, how many years } \\
\text { would it take for the amount she } \\
\text { owes to double?' }\end{array}$ & $\begin{array}{l}\text { - } \quad \text { Less than } 5 \text { years } \\
\text { - } \text { Between } 5 \text { and } 10 \text { years } \\
\text { - } \quad \text { More than } 10 \text { years } \\
\text { - } \quad \text { Do not know }\end{array}$ & $\begin{array}{l}\text { Lusardi and } \\
\text { Tufano (2011) }\end{array}$ \\
\hline $\begin{array}{l}\text { David has a credit card debt of } \\
\$ 3,000 \text { at an Annual Percentage } \\
\text { Rate of } 12 \% \text { (or } 1 \% \text { per month). } \\
\text { He makes payments of } \$ 30 \text { per } \\
\text { month and does not gain any } \\
\text { charges or additional spending on } \\
\text { the card. How long will it take } \\
\text { him to pay off this debt?' }\end{array}$ & $\begin{array}{l}\text { - } \text { Less than } 5 \text { years } \\
\text { - } \text { Between } 5 \text { and } 10 \text { years } \\
\text { - More than } 10 \text { years } \\
\text { - None of the above, he will continue to be } \\
\text { in debt } \\
\text { - Do not know }\end{array}$ & $\begin{array}{l}\text { Lusardi and } \\
\text { Tufano (2011) }\end{array}$ \\
\hline $\begin{array}{l}\text { Which of the following do you } \\
\text { think would worth more in two } \\
\text { years? }\end{array}$ & $\begin{array}{l}\text { - } \$ 100 \text { received today, and then put in a } \\
\text { savings account at an interest rate of } 10 \% \text {, } \\
\text { compounded annually } \\
\text { - } \$ 120 \text { received two years from today } \\
\text { - } \quad \text { They would be worth the same amount } \\
\text { - } \quad \text { I am not sure }\end{array}$ & $\begin{array}{l}\text { Cook and } \\
\text { Sadeghein } \\
(2018)\end{array}$ \\
\hline $\begin{array}{l}\text { Assume a friend inherits } \$ 10,000 \\
\text { today and his sibling inherits } \\
\$ 10,000 \text { three years from } \\
\text { now. Who is richer because of the } \\
\text { inheritance? }\end{array}$ & $\begin{array}{ll}\text { - } & \text { My friend } \\
\text { - } & \text { His sibling } \\
\text { - } & \text { They are equally rich } \\
\text { - } & \text { I'm not sure }\end{array}$ & $\begin{array}{l}\text { Cook and } \\
\text { Sadeghein } \\
(2018)\end{array}$ \\
\hline
\end{tabular}

Cost of Maintenance. One factor that was likely to influence the results was the cost of maintaining the car. I manipulated the perceived benefits of the car by changing perceptions of the longevity of the car and the amount of money that the consumer must spend on the car in the 
future. Research on pain-of-payment proposes that consumers experience higher levels of painof-payment when they are required to spend additional money on a product that they have already bought (Zellermayer, 1997). Although this proposition has not been experimentally tested, it is possible that the difference in the level of evoked anticipatory PoP between the three benefits manipulation conditions is caused by this perception. If the benefits manipulation changes the perceptions of maintenance costs that the consumer needs to spend to fix this car, the repayment acceleration may be driven by an aversion to spending more money on an old car. Hence, I added one question to measure and control for this perception. I asked participants, "How much do you think it would cost to maintain the car described in the scenario in the future?" on a 7-point semantic differential scale (very low: very high).

\section{Results}

\section{Manipulation Checks.}

An analysis of variance (ANOVA) indicated that the benefit manipulation was significantly related to participants' perception of the future benefits of the car $(\mathrm{F}(2,153)=$ 32.74, $\mathrm{p}<.001$; Adjusted $\mathrm{R}^{2}=.29$ ). Participants' perceptions of the future benefits of the car were significantly higher in the high-benefits $(M=5.12)$ condition compared to the negative-benefits condition ( $M=2.70, p>.001)$. Participants' perceptions of the future benefits of the car were significantly higher in the low-benefits $(M=4.76)$ condition compared to the negative-benefits condition $(\mathrm{M}=2.60, \mathrm{p}<.001)$. However, the low-benefits and the high-benefits conditions did not differ significantly.

Anticipatory Pain-of-Payment Measured Before Making Any Payments on the Loan.

Hypothesis 1 predicted that consumers' perceptions of the future benefits of a product are negatively related to the level of evoked anticipatory PoP. To test this hypothesis, I ran an 
analysis of covariance (ANCOVA) with the benefits manipulation as the independent variable, the anticipatory pain-of-payment measured before playing the repayment game as the dependent variable and with all control variables (e.g., financial knowledge, individual sensitivity to pain and financial status) as covariates.

The perceived future benefits of the car were not significantly related to anticipatory PoP $\left(\mathrm{F}(2,147)=2.22, \mathrm{p}=.112 ; \eta^{2}=.03\right)$. However, the level of evoked anticipatory PoP was significantly lower in the high-benefits condition compared to the negative-benefits condition $\left(\mathrm{M}_{\text {High-benefits }}=5.10, \mathrm{M}_{\text {Negative-benefits }}=5.72, \mathrm{p}<.05\right)$. In addition, PoP was marginally higher for the negative-benefits condition compared to low-benefits condition $\left(\mathrm{M}_{\text {Low-benefits }}=5.11, \mathrm{M}_{\text {Negative - }}\right.$ benefits $=5.72, \mathrm{p}<.05)$. From the control variables, only maintenance cost perceptions were significantly related to anticipatory $\mathrm{PoP}\left(\mathrm{F}(1,149)=22.34, \mathrm{p}<.001 ; \eta^{2}=.14\right)$. This result provides some support for $\mathrm{H} 1$. Anticipatory Pain-of-Payment Measured After Making Seven Payments on the Loan.

The level of anticipatory PoP was also measured after participants completed the loan repayment game. I conducted an analysis of covariance (ANCOVA) with the benefits manipulation as the independent variable, this measure of anticipatory pain-of-payment as the dependent and all control variables were entered into the model as covariates.

The perceived future benefits of the car were significantly related to anticipatory PoP measured after the game $\left(\mathrm{F}(2,147)=6.89, \mathrm{p}<.01 ; \eta^{2}=.09\right)$. Results indicated that the level of evoked anticipatory PoP was significantly lower in the high-benefits condition compared to the negative-benefits condition ( $\left.\mathrm{M}_{\text {High-benefits }}=4.05, \mathrm{M}_{\text {Negative-benefits }}=5.29, \mathrm{p}<.01\right)$. In addition, PoP was higher for the low-benefits condition compared to the high-benefits condition $\left(\mathrm{M}_{\text {Low-benefits }}=\right.$ 4.81, $\left.\mathrm{M}_{\text {High -benefits }}=4.05, \mathrm{p}<.05\right)$. From the control variables, car maintenance cost perception ( $\mathrm{F}$ 
$(1,147)=35.9, \mathrm{p}<.01 ;$ partial $\left.\eta^{2}=.19\right)$ was significantly related to anticipatory PoP. Figure 11 shows the difference in pain-of-payment across the three benefit levels.

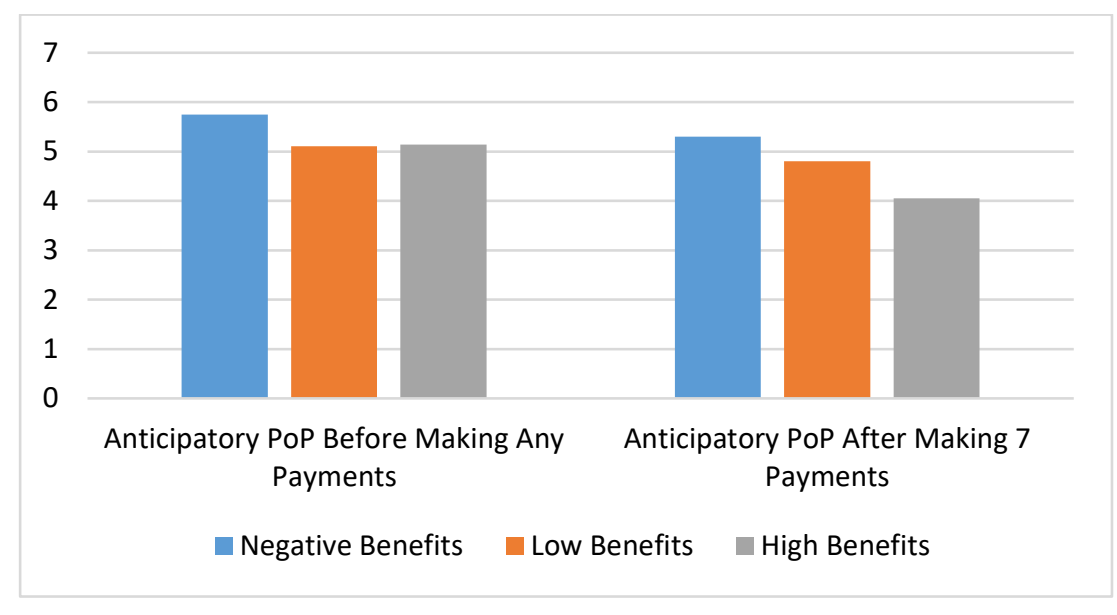

Figure 11- Anticipatory PoP Before and After Playing the Game

\section{Debt Repayment}

Figures 12,13 , and 14 show participants' behavior in the debt repayment game. Table 8 shows participants' allocation behavior in the seven rounds of the game. Average payments allocated to each purpose are shown for all three purposes and all seven rounds of the game.

Hypotheses 1 predicted that the perceived future benefits of a product are negatively related to debt repayment. Hypothesis 3 predicted that high levels of anticipatory PoP lead to higher repayment when consumers perceive high financial self-efficacy. To test these two hypotheses, I ran a moderated mediation model using the SPSS PROCESS macro (Hayes 2012). The benefits manipulation was used as the independent variable, anticipatory PoP before playing the game was entered as the mediator, the amount paid $(\$ 7,900$ minus the loan balance after round seven) was used as the dependent variable, and financial self-efficacy was the moderator. 
All control variables (debt aversion, the spendthrift/tightwad tendency, income, maintenance cost, financial status measures and financial knowledge) were also entered into the model.

A bootstrap with 5,000 draws was administered to examine the moderated mediation model (Hayes 2012, model 29). As discussed in the previous section, results indicated that anticipatory pain-of-payment was not significantly influenced by the benefits manipulation. In addition, neither self-efficacy nor the interaction of self-efficacy and anticipatory PoP had any significant effects on debt repayment. The only variable that was marginally related to the debt repayment variable was the spendthrift/tightwad tendency $(b=-97.26, \mathrm{SE}=54.80, \mathrm{p}<.1)$. These findings did not provide any support for $\mathrm{H} 1$ or $\mathrm{H} 3$.

Table 8-Allocation Behavior in the Seven Rounds of the Game

\begin{tabular}{|l|c|c|c|c|c|c|c|c|c|}
\hline & \multicolumn{3}{|c|}{$\begin{array}{c}\text { Average amount Paid } \\
\text { towards the debt }\end{array}$} & \multicolumn{3}{c|}{ Average amount saved } & \multicolumn{2}{c|}{$\begin{array}{c}\text { Average amount spent on } \\
\text { something desirable }\end{array}$} \\
\hline $\begin{array}{l}\text { Benefit } \\
\text { level }\end{array}$ & High & Low & Negative & High & Low & Negative & High & Low & Negative \\
\hline R1 & 265 & 327 & 340 & 221 & 183 & 213 & 111 & 90 & 46 \\
\hline R2 & 313 & 332 & 355 & 187 & 187 & 195 & 99 & 80 & 50 \\
\hline R3 & 294 & 340 & 366 & 198 & 175 & 199 & 107 & 85 & 35 \\
\hline R4 & 321 & 370 & 353 & 166 & 157 & 200 & 110 & 72 & 47 \\
\hline R5 & 318 & 354 & 363 & 176 & 160 & 201 & 104 & 85 & 39 \\
\hline R6 & 318 & 365 & 358 & 179 & 153 & 196 & 102 & 81 & 45 \\
\hline R7 & 313 & 365 & 366 & 189 & 153 & 196 & 97 & 80 & 36 \\
\hline
\end{tabular}




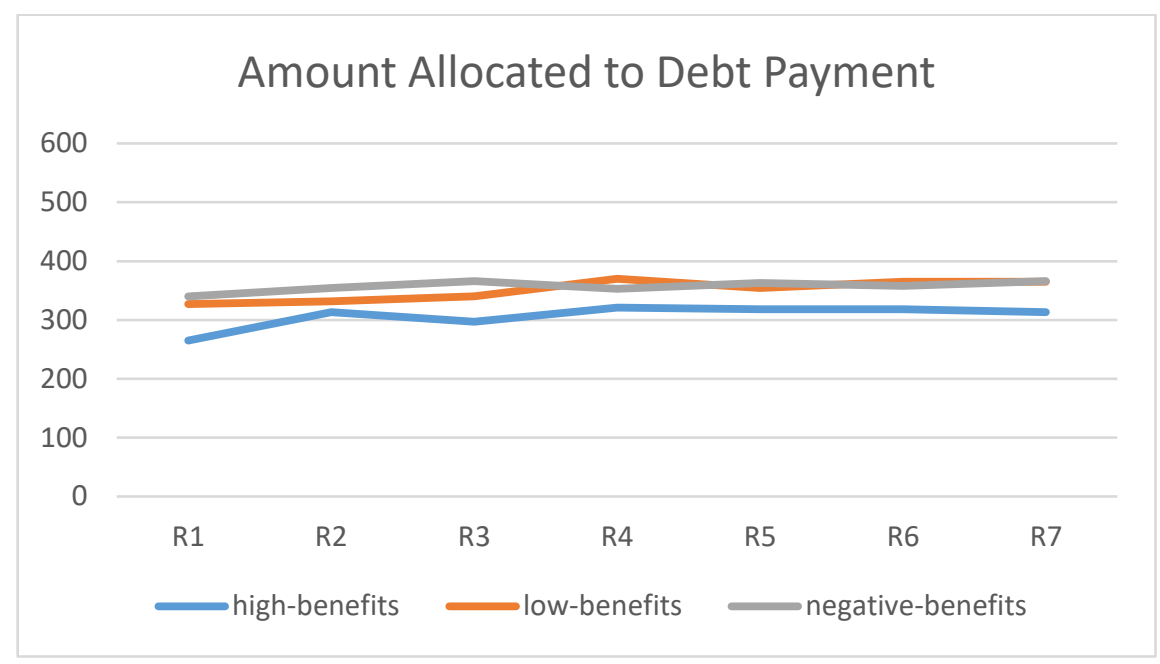

Figure 12-Amount Allocated to the Debt During the Seven Rounds of the Game

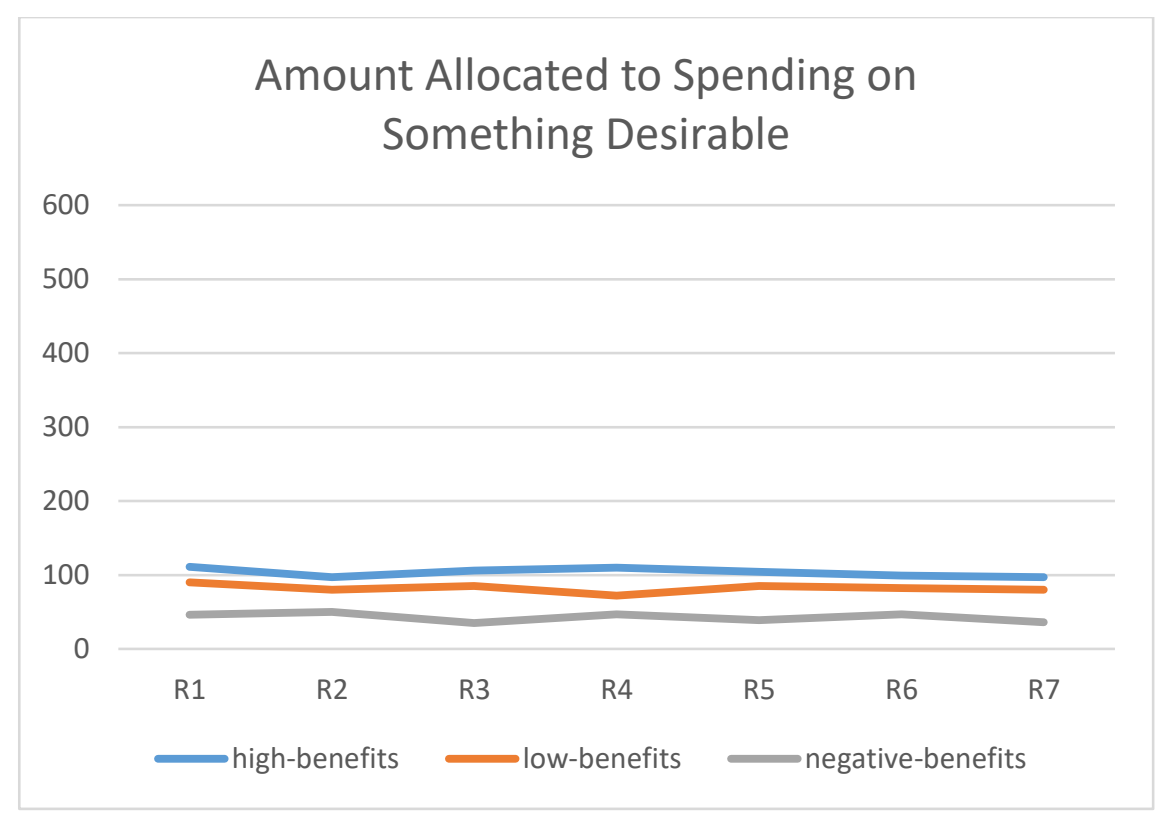

Figure 13-Amount Allocated to Spending During the Seven Rounds of the Game 


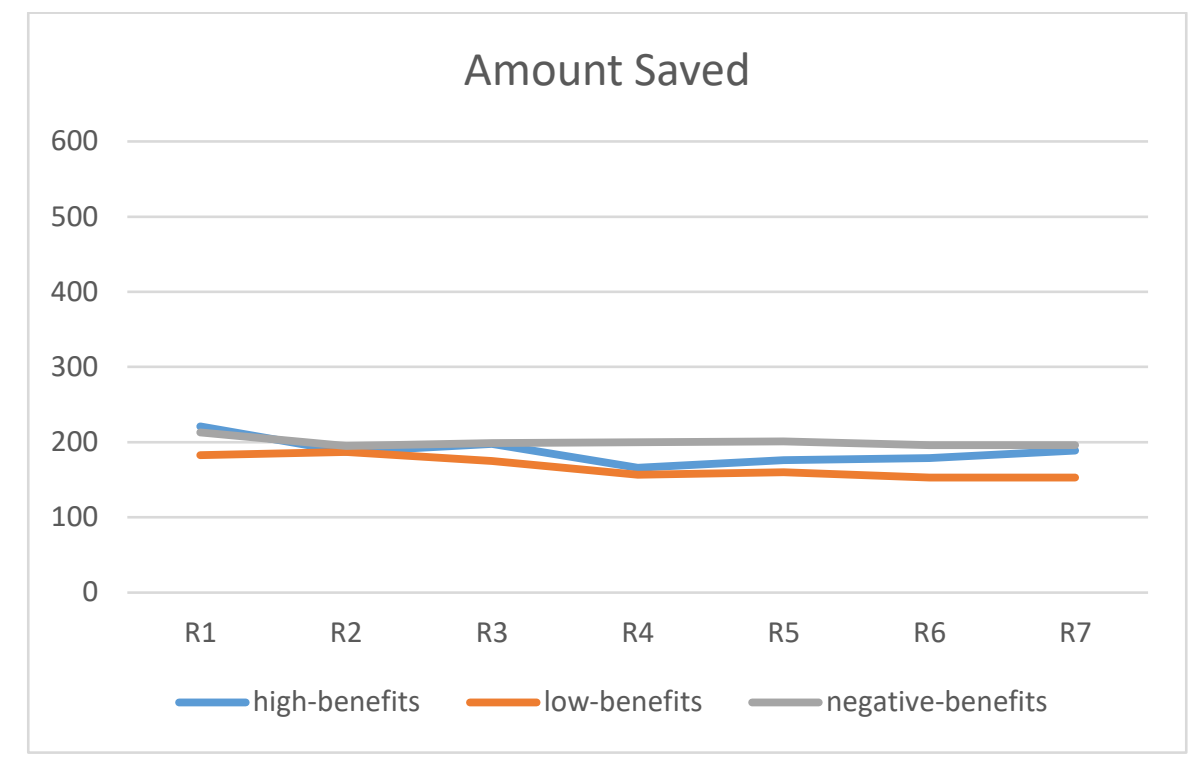

Figure 14-Amount Saved During the Seven Rounds of the Game

In addition to the PROCESS analysis, I ran an ANCOVA with the amount paid as the dependent variable, the manipulation as the independent variable, and all control variables as covariates. Results indicate that there is no significant difference between the three conditions in the amount of the debt they paid. Although the values of the dependent variable were in the predicted directions, the differences were not significant (see Figure 15 for a comparison of means).

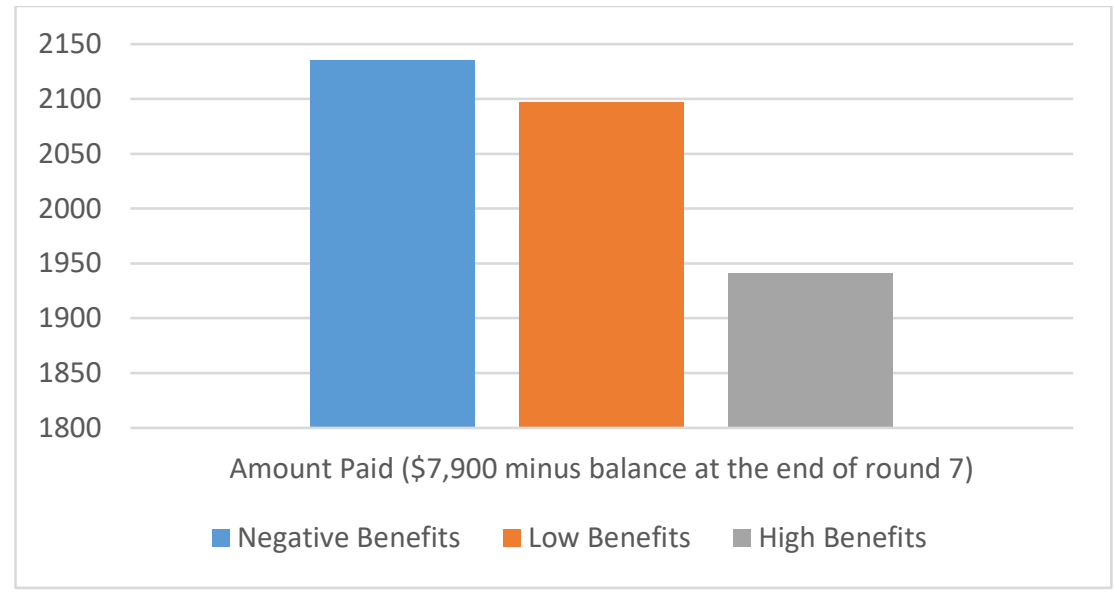

Figure 15- Amount Paid in Each Experimental Condition 


\section{Discussion and Conclusion}

In this study, I explored the relationship between perceived benefits, anticipatory pain and debt repayment in a loan repayment game. I predicted that participants who were told that the product they purchased with a loan had no further benefits were more likely to rip off the Band-Aid by paying more on the loan. However, the results of this study did not support this prediction.

One possibility for the non-significant results in this study is respondents may have experienced fatigue. Since this game was conducted online and the study took about thirty minutes to complete, participants may have lost their attention during the different rounds of the game. To test this theory, I ran another moderated mediation PROCESS model (model 14) with a different dependent variable. Instead of the amount paid after round 7, I entered the amount allocated to the loan in the second round of the game as the dependent variable. I chose the second-round allocation amount since participants read the benefits manipulation right before this allocation task. However, the results of the analysis did not change. The amount allocated to debt repayment was not influenced by anticipatory pain, self-efficacy or their interaction. Similar to the previous analysis, the spendthrift/tightwad tendency was marginally related to the amount paid on the loan $(b=-15.86, S E=8.18, p<.1)$.

Although perceived benefits and anticipatory pain-of-payment were unrelated to debt repayment, these two variables were significantly related to the amount participants allocated to spend on something they liked. I calculated the total amount that participants allocated to spending across the seven rounds. I then ran a PROCESS model (model 14, dependent variable= total spent on something liked, mediator= anticipatory PoP, moderator= financial self-efficacy, independent variable $=$ benefits manipulation) with all control variables. Results indicated that 
perceived benefits $(b=152.10, \mathrm{SE}=46.49, \mathrm{p}<.01)$, anticipatory $\mathrm{PoP}(\mathrm{b}=-240.06, \mathrm{SE}=110.15$, $\mathrm{p}<.05)$, and the interaction of pain and financial self-efficacy $(b=44.22, \mathrm{SE}=21.48, \mathrm{p}<.05)$ were significantly related to the total amount spent. Analysis of the interaction indicated that anticipatory PoP is negatively related to the total money spent when financial self-efficacy is low. In addition, the direct effect of perceived benefits on total spent was significant (effect size= 152.10, $\mathrm{SE}=46.48, \mathrm{p}<.01,95 \% \mathrm{CI}=[60.21,243.98])$. The spendthrift/tightwad tendency was significantly related to the total amount spent $(b=96.69, \mathrm{SE}=36.03, \mathrm{p}<.001)$. No other control variable had a significant effect on the amount spent. Twenty-seven percent of the variance in total amount spend was accounted for by these variables.

This result may be due to participants across the three benefit conditions having different perceptions of how much they need to spend on car maintenance. The pretest study showed that the benefit manipulation indeed taps into participants' perception of how much they will need to spend on car maintenance. If this is true, participants in the negative and low-benefits conditions may have decided to save some of their money to pay for the maintenance cost. Although this possibility sounds plausible, the data does not support it. First, the maintenance cost was controlled in the mediated moderation analysis and it did not have any significant influence on the total amount spent. In addition, the total amount saved during the seven rounds was calculated and was used as the dependent variable in a moderated mediation model (model 14, dependent variable $=$ total saved, mediator $=$ anticipatory PoP, moderator $=$ financial self-efficacy, independent variable $=$ benefits manipulation) with all control variables. Perceived benefits did not have any significant relationship with the total amount saved. In fact, none of the variables in the model were related to this dependent variable. These results indicate that the perceptions of the benefits a product provides in the future may not influence consumers' debt repayment 
intentions, but it does influence how much money consumers plan to spend on discretionary items. Future research might explore this finding in more detail.

\section{Study 2- Exploring the Effect of Remaining Benefits and Replacement Decisions on Loan Repayment}

\section{Procedure and Design}

The goal of study 2 was to test all three hypotheses in one comprehensive study. To this end, Study 2 was a 3 (benefit: negative vs. high vs low) by 2 (replacement decision: no vs. yes) between-subjects factorial experimental design ${ }^{8}$. Participants were provided with the same scenario described in the pretest study (car loan scenario). Participants imagined that they borrowed $\$ 8,000$ to purchase a used car. Before making the $12^{\text {th }}$ payment on the loan, participants had an incident. The car broke and they had to take it to the mechanics, who repaired the car immediately. Participants in the high-benefits condition then read that the mechanic told them that their car's crucial parts were new and unworn, and they did not have to replace any parts in the near future. Participants in the low-benefits condition read that the mechanic told them that the cars' crucial parts were old and worn; however, they did not have to replace any parts soon. Participants in the negative-benefits condition read that the mechanic told them that the cars' crucial parts were old and worn and they had to replace those costly parts soon. Participants then answered several questions regarding their debt repayment intentions, anticipatory pain-of-payment, and perceived self-efficacy. Since many participants failed to correctly identify the replacement manipulation in the pretest, I changed the wording of this

\footnotetext{
${ }^{8}$ Material and scenario are shown in Appendix D
} 
manipulation (insert how it was changed) and used a bold font for the important parts of the manipulation to to increase the effect of this manipulation.

Three-hundred and thirteen U.S. respondents were recruited from Amazon Mechanical Turk (MTurk). In exchange for their time, participants were paid \$1.5. Four questions were added to the survey to check if participants were paying attention to the scenario. Sixteen participants who failed at least one of the attention checks were excluded from the study, leaving 195 participants $\left(48.3 \%\right.$ female, $\left.\mathbf{M}_{\mathrm{age}}=36.2, \mathrm{M}_{\text {income }}=\$ 48,315\right)$. Cell sizes ranged from 25 to 39.

\section{Procedure}

Participants were randomly assigned to one of the six experimental conditions. After reading the consent form, participants read the scenario described above. Then they answered questions measuring anticipatory pain-of-payment, debt repayment intentions, manipulation checks, financial self-efficacy, control variables, and demographics. Participants were then thanked and paid.

\section{Measures}

Perceived future benefits, anticipatory PoP, and financial self-efficacy were measured similarly to study 1 .

\section{Dependent Variable}

Four different questions were used to measure consumers' intentions to repay their debts:

1) Debt repayment amount. I in an open-ended question, participants were asked to imagine that they won $\$ 1,000$ in the lottery the previous night. Participants indicated how much of this $\$ 1,000$ they were willing to pay towards their loan. Participants typed in a number between $\$ 0$ and $\$ 1000$. Hereafter, this measure will be called the debt repayment amount. The purpose of telling participants that this money was won in a lottery was to frame this money as 
windfall money. Extant research argues that consumers tend to spend their windfall money on buying discretionary and hedonic items and they do not use it to pay their debts. If participants are willing to spend the $\$ 1,000$ gained from a lottery on debt repayment, it can support some evidence regarding how strongly consumers want to rip off the Band-Aid.

2) Intentions to make an extra payment. Participant's willingness to make an extra payment on this loan was measured with three semantic differential items. Participants were asked, "You can make an extra payment right now to pay off your loan faster and save on your interest. To what extent do you think you will make an extra payment?" Participants answered this question with three 7-points semantic differential scales (definitely will not make an extra payment: definitely will make an extra payment; very unlikely to make an extra payment: very likely to make an extra payment; probably will not make an extra payment: probably will make an extra payment). All three items loaded on the same factor and the scale was reliable ( $\alpha=.92)$.

3) The rip off the Band-Aid measure. To measure consumers' tendency to rip off the Band-Aid, I asked three questions. Participants reported how much they agreed with these four items on a 7-point Likert scale. The items were:

- I want to pay off this loan as fast as possible.

- I am willing to cut my spending and allocate more money to paying off this loan.

- I will try to make extra payments every month to get rid of this debt as fast as possible.

This measure was a reflective scale designed to measure the tendency to accelerate the repayment of a loan. Correlations between the three items ranged from .72 to .78 . The average of the three items was calculated to form a debt acceleration intentions measure. Hereafter, this measure will be called the "rip off the Band-Aid" measure. 
4) Debt repayment choice. Participants were asked to imagine that they have an extra $\$ 300$ cash on hand and indicated whether they prefer to save this money or use it to make an extra payment on this loan. This variable, "debt repayment choice" hereafter, was coded as $1=$ pay towards the debt, and $0=$ save the money.

\section{Control Variables}

Deb aversion, the spendthrift/tightwad tendency, financial literacy, financial status, and the cost of maintenance were measured with the same scale used in study 1 and were controlled in all analyses.

\section{Results}

\section{Manipulation checks.}

An analysis of variance (ANOVA) with the perceived benefits as the dependent variable and the manipulation (negative, low, and high benefits) as the independent variable indicated that perceptions of the future benefits of the car were significantly different between each of the three conditions $\left(\mathrm{F}(2,192)=174.72, \mathrm{p}<.001 ; \mathrm{M}_{\text {High-benefit }}=6.23, \mathrm{M}_{\text {Low-benefit }}=5.05, \mathrm{M}_{\text {Negative-benefit }}=3.21\right.$, partial $\eta^{2}=.53$ ). All three conditions were significantly different from each other.

To measure consumers' benefits perceptions, participants were asked to enter how many more years they thought they could drive the described car before it becomes a junk car. An analysis of variance (ANOVA) with this measure as the dependent variable and the three experimental conditions (negative, low, high benefits) as the independent variable indicated that perceptions of the future benefits of the car were significantly different between the three experimental conditions $\left(\mathrm{F}(2,190)=34.67, \mathrm{p}<.001 ; \mathrm{M}_{\text {High-benefits }}=7.89, \mathrm{M}_{\text {Low-benefits }}=4.44\right.$, $\mathrm{M}_{\text {Negative-benefits }}=3.52$, partial $\eta^{2}=.26$ ). 
Finally, after playing the game, participants were asked to identify which manipulation they read in the scenario in a multiple-choice question with an "I don't know" option. Eightyfive percent of the participants in the high-benefits condition, $88 \%$ of the participants in the lowbenefits condition, and $83 \%$ of the participants in the negative -benefits condition, correctly identified the manipulation.

To check the replacement manipulation, participants were asked to choose which manipulation they read in the scenario in a multiple-choice question with an "I don't know" option. Sixty-three percent in the no-replacement condition and $89 \%$ of the participants in the replacement condition correctly identified the manipulation they read in the scenario. Effect of Benefits and Replacement on Anticipatory Pain-of-Payment.

I ran an ANCOVA to examine the effect of perceived benefits, replacement and their interaction on anticipatory pain-of-payment. In this model, I controlled for consumers' debt level, spendthrift/tightwad tendency, debt level, financial literacy and the cost of maintenance. The only control variable that significantly influenced pain-of-payment was maintenance cost ( $\mathrm{F}$ $(2,183)=28.03, p<.001$, partial $\left.\eta^{2}=.13\right)$,

Results of the ANCOVA indicated that future benefits $\left(\mathrm{F}(2,183)=5.26, \mathrm{p}<.01 ; \mathrm{M}_{\text {High- }}\right.$ benefits=4.09, $\mathrm{M}_{\text {Low-benefits }}=4.30, \mathrm{M}_{\text {Negative-benefits }}=5.06$, partial $\eta^{2}=.05$ ), and replacement manipulations $\left(\mathrm{F}(2,183)=5.69, \mathrm{p}<.05 ; \mathrm{M}_{\text {replacement }}=4.75, \mathrm{M}_{\text {no-replacement }}=4.21\right.$, partial $\left.\eta^{2}=.03\right)$ were significantly related to anticipatory pain-of-payment. Anticipatory pain evoked in the high and low benefits conditions were not significantly different. However, the difference in anticipatory PoP between the negative-benefits condition and the high-benefits condition $(\mathrm{p}<.01)$, and between the negative and low-benefits conditions were significantly different $(\mathrm{p}<.01)$. In addition, the level of anticipatory pain evoked in the no replacement and replacement 
conditions were significantly different from each other $(\mathrm{p}<.05)$. As H1 predicted, anticipatory pain-of-payment wass reduced when consumers felt they would reap future benefits from the car. Hence, $\mathrm{H} 1$ was supported.

$\mathrm{H} 2$ predicted that the effect of future benefits on anticipatory pain-of-payment should be moderated by a decision to replace the product. I expected PoP to be higher when the consumer decided to replace the product. The effect of the interaction of benefits and replacement on anticipatory pain-of-payment was marginally significant $(\mathrm{F}(2,178)=2.963, \mathrm{p}<.10$, partial $\left.\eta^{2}=.03\right)$. In the low-benefits condition, anticipatory pain-of-payment was significantly different between the replacement and no-replacement conditions $\left(\mathrm{M}_{\text {replacement }}=4.95, \mathrm{M}_{\text {no-replacement }}=3.66\right.$, $\mathrm{p}<.001$, partial $\eta^{2}=.05$ ). However, anticipatory pain-of-payment was not significantly different between the two replacement conditions either in the high-benefits or in the negative-benefits conditions (see Figure 16). Thus, I found support for $\mathrm{H} 2$ only when the future benefits of the product was low.

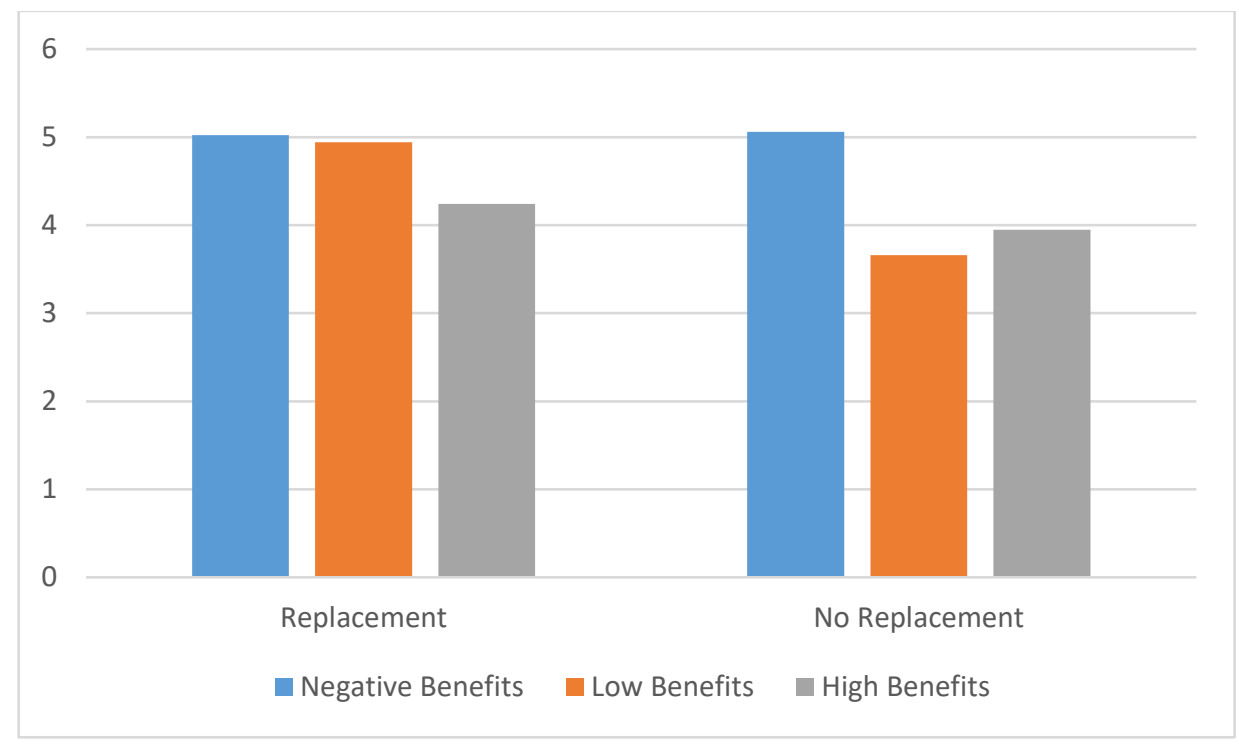

Figure 16- Anticipatory Pain-Of-Payment Evoked in the Six Experimental Conditions 


\section{Debt Repayment Intentions}

Debt repayment intentions were measured in four different ways: debt repayment amount, intentions to make an extra payment, the rip-off the Band-Aid measure, and the debt repayment choice. For the first three dependent variables, I used Hayes' PROCESS SPSS macro (model 29, Hayes 2012) to test all three hypotheses simultaneously. Using model 29 in the PROCESS SPSS macro, I ran the model shown in Figure 17 to test all three hypotheses using the same analysis. The following section explains the results.

Debt repayment amount. This variable measured how much of $\$ 1,000$ gained by winning a lottery each participant would allocate to repaying the described debt. Figure 18 shows the averages of repayment amounts across the six experimental conditions. Respectively, participants in the high, low and negative-benefits conditions paid an average of $\$ 480, \$ 568$ and $\$ 525$ of the $\$ 1,000$ towards the loan. As predicted, participants in the high-benefits condition paid a lower amount towards the loan. However, the differences between the three conditions were not significant. As it is shown in the picture, the repayment amount was not significantly different across the six different experimental conditions.

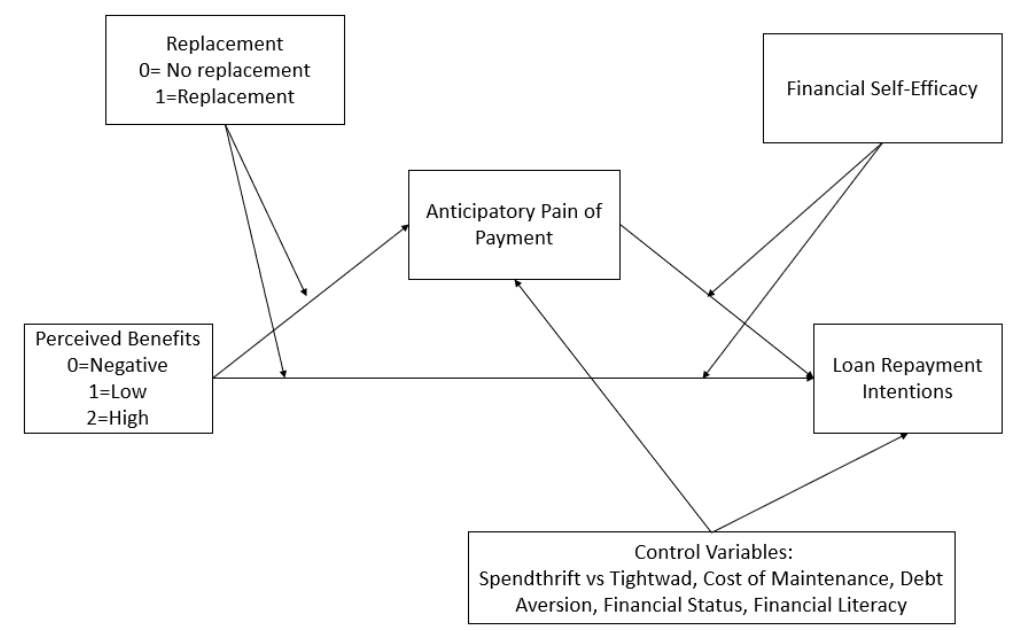

Figure 17- SPSS PROCESS Model 29 with the Study Variables 


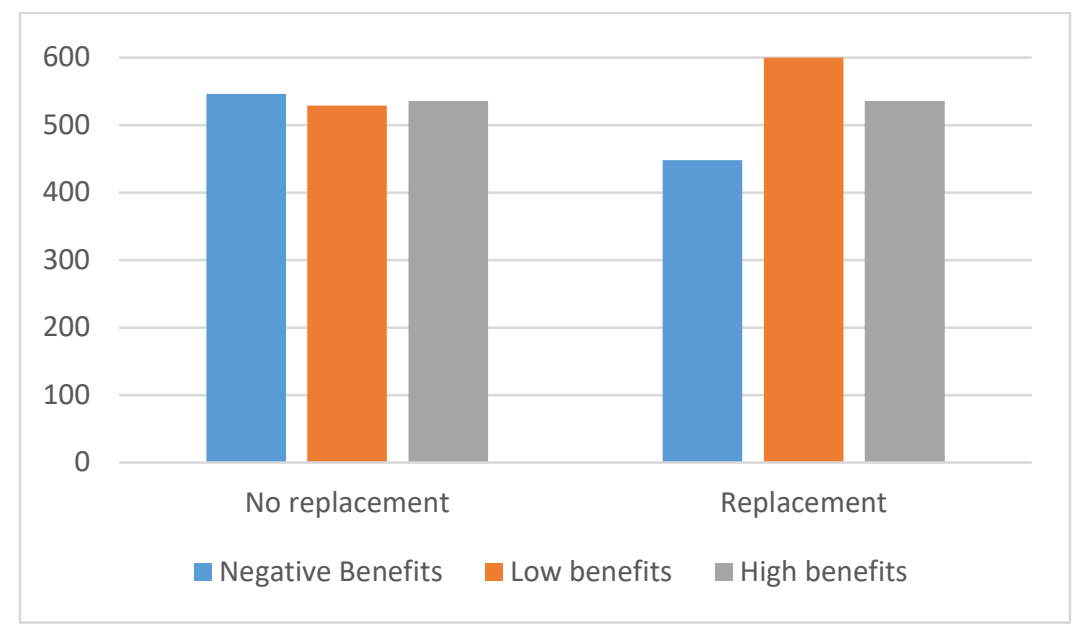

Figure 18- The Average Amount Paid on the Loan in the Six Experimental Conditions.

A bootstrap with 5,000 draws was used to examine the moderated-moderated mediation model (Hayes 2012, model 29). H1 predicted a negative relationship between future benefits and anticipatory PoP. $\mathrm{H} 2$ predicted that the negative relationship between future benefits and anticipatory PoP depends on the consumers' intention to replace the product. As predicted in H1, results indicated that anticipatory pain-of-payment was negatively influenced by the benefits manipulation $(b=-1.04$, $\mathrm{SE}=.20, \mathrm{p}<.001)$. However, neither the replacement manipulation nor the interaction of benefits and replacement manipulation had any effects on anticipatory pain-of-payment. Thus, H2 was not supported. From all control variables, only the cost of maintenance $(b=.35, \mathrm{SE}=.07, \mathrm{p}<.001)$ was significantly related to anticipatory pain-of-payment. About thirty-four percent of the variance in anticipatory pain-of-payment was accounted for by future benefits and the cost of maintenance $\left(\mathrm{R}^{2}=33.86\right)$.

Anticipatory pain-of-payment and financial self-efficacy did not have a significant direct effect on the dependent variable (repayment amount). However, the interaction of these two variables had a significant marginal effect on the repayment amount $(b=22.25, \mathrm{SE}=11.77, \mathrm{p}<.1)$. A JohnsonNeyman analysis of the moderation (Hayes 2012) showed that at low levels of financial self-efficacy, anticipatory PoP was not related to repayment (financial self-efficacy< 5.5). However, at high levels 
of financial self-efficacy (financial self-efficacy $>=5.5$ ), anticipatory pain-of-payment was significantly and positively related to the amount paid towards the debt. This result supports H3.

While the interaction between financial self-efficacy and anticipatory PoP was significantly related to repayment amount, perceived benefits, replacement, and their interaction were not significantly related to the repayment amount. The interaction between perceived benefits and financial self-efficacy on repayment was also non-significant. None of the control variables had a significant influence on the repayment amount. About $7 \%$ of the variance in repayment amount was accounted for by the interaction between financial self-efficacy and anticipatory PoP.

In addition, results indicated that the direct effect of benefits perceptions on repayment amount was non-significant. However, the indirect effect of benefits perceptions on repayment amount was significant at high levels of financial self-efficacy and when the participant was not planning to replace the car (indirect effect $=-28.02, \mathrm{CI}=-68.63 .5$ to -1.26 ). This result shows that when the consumer does not intend to replace the product and when the consumer perceives herself to have high levels of financial self-efficacy, higher perceived future benefits of a product purchased with a loan reduces intentions to repay that loan.

Intentions to make an extra payment. The same PROCESS model was run with this dependent variable to test the three hypotheses. Results showed that the dependent variable (intentions to make an extra payment) was not influenced by anticipatory pain-of-payment, financial self-efficacy or their interaction. The only variable that influenced this dependent variable was the level of debt that participants reported (level of student loans). This analysis did not find any support for $\mathrm{H} 3$.

The rip off the Band-Aid measure. The same model was run using the PROCESS macro with the rip off the Band-Aid measure as the dependent variable to test the three hypotheses. 
Results indicated that anticipatory pain-of-payment was marginally related to the rip off the Band-Aid variable $(b=-.44, S E=.26, p<.1)$. Financial self-efficacy and its interaction with anticipatory PoP did not have a significant effect on the dependent variable.

Debt repayment choice. The last behavioral intention measure was debt repayment choice, in which participants were told that they had an extra $\$ 300$ on hand, and were asked to decide whether they wanted to save this money or pay it towards the debt. The variable was coded such that debt repayment was coded as " 1 " and saving was coded as " 0 ." To test H3, logistic regression analysis was used to test the influence of anticipatory pain-of-payment, financial self-efficacy and their interaction on this variable. A new variable was created by multiplying financial self-efficacy with anticipatory PoP. A logistic regression with the repayment choice as the dependent variable, anticipatory PoP, financial self-efficacy, their interaction, maintenance costs, spendthrift/tightwad tendency, financial knowledge, debt aversion and participant's debt levels as the independent variables were entered into the model. The results of this analysis did not show any significant relationship between anticipatory pain, financial self-efficacy or their interaction on consumers' saving or loan repayment choice. The only control variables influencing this choice were financial knowledge $(b=-.23, \mathrm{SE}=.11, \mathrm{p}<.05)$ and the participant's level of outstanding debt excluding mortgage, credit card debt, and student loans $(b=.13, \mathrm{SE}=.06, \mathrm{p}<.05)$. Nagelkerke R-square was .11 for this model, indicating that the variables in the model accounted for $11 \%$ of the variance in the debt repayment choice. In addition, a chi-square analysis of the relationship between repayment choice and the benefits manipulation indicated that there is no significant relationship between these two variables. Hence, we did not find aby support for $\mathrm{H} 3$ using this measure of repayment. 


\section{Discussion}

In this study, I examined how perceived future benefits of a product and consumers' intentions to replace that product, are related to their intentions to accelerate debt repayment and rip off the Band-Aid. I found that perceived future benefits of a product is indeed related to the level of evoked anticipatory pain-of-payment. Participants reported experiencing lower levels of anticipatory pain-of-payment when thinking about the future payments they had to make on a loan borrowed to purchase a product that provided high levels of benefits in the future. This relationship was moderated by consumers' tendencies to replace the product. Deciding to replace a product purchased with the loan increased the anticipatory pain evoked by contemplating future payments of the loan used to purchase that product. Although the manipulations strongly evoked anticipatory pain-of-payment, I did not find any relationship between the manipulations and debt repayment. Although participants experienced high levels of PoP, they did not make any effort to rip off the Band-Aid.

One question that may arise is whether consumers' debt repayment is indeed driven by the economic consequences of non-payment. In other words, is debt repayment indeed a function of the interest rate charged on the loan? Although I did not manipulate the interest rate in these studies, I measured participants' perceptions of how expensive the interest rate charged on the loan on a seven-point semantic differential scale (not at all expensive: very expensive). I ran four separate regression analyses with this variable as the independent variable and the four repayment measures as the dependent variables. The perception of paying too much interest explained about $.1 \%$ of the variance in the rip-off the Band-Aid measure, $1 \%$ of the variance in repayment amount, $.3 \%$ of the variance in participant's tendency to make an additional payment on the loan, and $2.6 \%$ of the variance in repayment choice. Based on these correlational results, 
consumers' repayment intentions were not driven by their perceptions of the expensiveness of the interest rate.

\section{Conclusion and Future Research}

In this essay, I offered a formal test of the theory of double-entry mental accounting in the context of debt repayment. I proposed that consumers' debt repayment decisions are not solely driven by the interest rate of the loan and can be influenced by the perceived remaining benefit of the product/service purchased with the loan. This effect occurs because paying a loan that extends over time and was borrowed to purchase a product that provides low or negative future benefits evokes high levels of pain-of-payment. To avoid experiencing this negative affect in the future, consumers will be likely to decide to pre-pay the debt (The rip off the Band-Aid effect). I suggested that this effect would be stronger when consumers have made a decision to purchase an alternative product that serves the same purpose and when they perceived themselves to have high levels of financial self-efficacy.

Results of the two studies indicated that perceived future benefits of a product indeed influences perceptions of anticipatory pain-of-payment. Participants reported experiencing significantly higher levels of pain-of-payment when they perceived the car to provide fewer benefits in the future. However, experiencing high levels of anticipatory pain-of-payment and its interaction with self-efficacy did not influence debt repayment decisions in any of the studies. Although participants experienced high levels of pain-of-payment when the product did not provide further value, they did not intend to pay more towards the debt to rip-off the Band-Aid.

The results of this research indicate that consumers' debt repayment decisions and behavior is only influenced by their individual differences and attitude towards debt. In study 1 , 
the only variable that predicted repayment behavior was the spendthrift/tightwad tendency. Although this scale was developed to measure individual differences in sensitivity to pain-ofpayment, this scale was unrelated to pain-of-payment in all studies conducted in this dissertation. Thus, this measure does not capture individual differences in pain-of-payment. The items in this scale measure consumers' tendencies to save vs. spend. In study 1 , this scale was the only predictor of debt repayment.

In study 1, participants were asked to allocate their money to pay off the loan, spending, or saving. Across all experimental conditions and all rounds, the amount participants paid towards the loan was the same. The only variable that significantly influenced repayment was consumers" spendthrift/tightwad tendencies. In study 2 , the only significant predictor of debt repayment was debt aversion tendencies, which explain consumers' attitudes towards debt. This variable was measured with two items that tapped into how much consumers think borrowing money for most any reason is wrong. Debt repayment intentions were influenced by consumers' debt aversion in study 2. In sum, although consumers' debt repayment behavior and intentions were not a function of perceived benefits of a product or anticipatory pain-of-payment, repayment behavior was influenced by individual differences in attitudes towards saving and debt and these two factors did influence the rip-off the Band-Aid effect. Future research could explore other variables that may influence consumers' debt repayment and may trigger the ripoff the Band-Aid effect.

\section{CODA}

The purpose of this dissertation was twofold: first, to advance our knowledge of the theory of pain-of-payment, and second, to study consumers' debt repayment behavior. The 
findings of this dissertation offer several contributions to the literature on pain-of-payment. The comprehensive literature review conducted in Essay 1 revealed that our understanding of the pain-of-payment (PoP) is still limited. Several important aspects of pain-of-payment must be further explored. First, although extant literature demonstrated that pain-of-payment exists, and it is a psychological emotion that consumers experience when they consider spending money, it is still not clear why consumers feel such pain. Previous theories that justify the existence of painof-payment are not comprehensive and cannot explain all findings of previous work that explored this construct.

Second, although research has documented an individual sensitivity to pain-of-payment, one of the most commonly used measures for this construct does not have internal and external validity. Rick et al. (2008) proposed the spendthrift/tightwad scale to measure consumers' individual sensitivity to pain-of-payment. Research that has measured the relationship between this scale and self-reported pain-of-payment shows that the spendthrift/tightwad scale explains only a small part of the variance in pain-of-payment. In addition, in all four studies conducted in this dissertation, respondents completed the spendthrift/tightwad scale. In all four studies, the four items proposed to measure consumers' spendthrift-tightwad tendencies were unreliable. Additionally, exploratory factor analysis on the four items sowed that, in each of the four studies, the four items of the spendthrift-tightwad scale did not load on the same factor, suggesting that this scale is not internally consistent.

Third, although previous literature on pain-of-payment has explored a number of antecedents to experiencing this emotion, most of those antecedents are related to the transaction and the situation. Research on how a consumer's perception of the product/service purchased influences the level of evoked PoP is lacking. To address this gap, this dissertation explored 
three factors related to the purchase itself: 1) social acceptability of a purchase, 2) the remaining benefits expected from a product, and 3) consumers' intentions to replace a product. Findings of Essays 2 and 3 suggest that these three factors indeed influence the level of pain-of-payment that consumer experiences when making a payment.

In addition to contributing to the literature on pain-of-payment, this dissertation sought to examine the role of pain-of-payment in consumers' debt repayment behavior and discover ways to motivate consumers to repay their debts and achieve financial freedom. I hypothesized a positive relationship between anticipatory pain-of-payment and consumers' debt repayment intentions. I proposed that when consumers experience high levels of pain-of-payment due to making future payments on a loan, they would be more likely to pay off their debt to avoid experiencing anticipatory PoP. In the four studies conducted in this dissertation, I did not find any relationship between anticipatory PoP and debt repayment. One possibility for the null findings is experiencing positive emotions when thinking about ripping off the Band-Aid may have reduced the intensity of the evoked PoP. Participants may have experienced positive affect by contemplating the financial freedom they will have after paying off their debt. This positive affect may have dampened the negative emotion evoked by thinking about future payments; this could lead to lower intentions to repay the debt.

Another possibility for finding the null results is that reciprocity may have been a variable mediating the relationship between perceived benefits and repayment intentions. It is possible that the participants who perceived the car to provide high levels of benefits in the future may have felt indebted to the lender who made it possible for them to make that purchase. Thus, these participants may have felt a need to reciprocate this value by making more payments towards the debt. If this assumption is true, then experiencing lower levels of benefits may have 
led to a lower intention to repay the debt. This mediation path works in the opposite direction to the pain-of-payment and may have canceled out the effect of PoP on repayment.

Finally, it is possible that experiencing higher levels of PoP may not have led to repayment because consumers know if they repay the debt, they will have fewer financial resources to spend for other purposes. If consumers have limited financial resources, they must make a decision on how to allocate their limited money to multiple purposes (e.g., buying essentials, paying the bills, etc.). In this situation, they may not want to spend their limited resources on paying off debt when they have the option to pay that debt over a longer period of time, even if they have to pay interest on that debt. Thus, experiencing high anticipatory PoP may not have led to more repayment. This may explain why I found a weak relationship between PoP and the repayment amount measure. In three of the conducted studies, I measured repayment intentions by asking participants to imagine that they have won $\$ 1000$ and they want to allocate some of it to repay the debt. In two of the three studies, I was able to find a weak relationship between PoP and this repayment measure. This finding may be because this measure of repayment intentions removed the financial scarcity and increased participants' liquidity. When participants had available monetary resources, experiencing high levels of anticipatory PoP led to more repayment. Future research must explore these possibilities to provide further knowledge on the relationship between PoP and debt repayment.

\section{References}

Aarts, Henk and Ap Dijksterhuis (2003), "The Silence of the Library: Environment, Situational Norm, and Social Behavior," Journal of Personality and Social Psychology, 84 (1), 18-28. Allcott, Hunt (2011), "Social Norms and Energy Conservation," Journal of Public Economics, 95 (9-10), 1082-95.

Amar, Moty, Dan Ariely, Shahar Ayal, Cynthia E. Cryder, and Scott I. Rick (2011), "Winning 
the Battle but Losing the War: The Psychology of Debt Management," Journal of Marketing Research, 48 (Special Interdisciplinary Issue), 38-50.

Ariely, Dan and Jose Silva (2002), "Payment Method Design : Psychological and Economic Aspects of Payments," MIT Sloan School of Management, Paper 196 (August).

Auh, Seigyoung, Eric Shih, and Yeosun Yoon (2008), "Aligning Benefits with Payments : A

Test of the Pattern Alignment Hypothesis," Journal of Consumer Psychology, 18 (4), 292303.

Bagchi, Rajesh, and Lauren G. Block (2011), "Chocolate Cake Please! Why do Consumers Indulge more when it Feels More Expensive?," Journal of Public Policy \& Marketing, 30 (2), 294-306.

Bandura, Albert (1986), "The Explanatory and Predictive Scope of Self-Efficacy Theory," Journal of Social and Clinical Psychology, 4 (3), 359-73.

Banker, Sachin, Derek Dunfield, Alex Huang, and Drazen Prelec (2017), "Pain-of-Payment and the Moral Tax: the Neural Basis of the Credit Card Effect," in North America - Advances in Consumer Research Volume 45.

Berman, Jonathan Z., An T.K. Tran, John G. Lynch, and Gal Zauberman (2015), "Expense Neglect in Forecasting Personal Finances," Journal of Marketing Research, 53 (4), 535-50. Besharat, Ali, François A. Carrillat, and Daniel M. Ladik (2014), "When Motivation Is Against Debtors 'Best Interest: The Illusion of Goal Progress in Credit Card Debt Repayment," Journal of Public Policy \& Marketing, 33 (2), 143-58. and Gia Nardini (2018), "When Indulgence Gets the Best of You: Unexpected Consequences of Prepayment," Journal of Business Research, 92 (January 2017), 321-28. , Sajeev Varki, and Adam W. Craig (2015), "Keeping Consumers in the Red : Hedonic Debt Prioritization within Multiple Debt Accounts," Journal of Consumer Psychology, 25 (2), 311-16.

Brignall, Miles (2019), “Average UK Household Debt Now Stands at Record \$15,400,” The Guardian, [available at https://www.theguardian.com/business/2019/jan/07/average-ukhousehold-debt-now-stands-at-record-15400].

Brown, Alexander L. and Joanna N. Lahey (2015), "Small Victories: Creating Intrinsic Motivation in Savings and Debt Reduction," Journal of Marketing Research, 52 (6), 768 83.

Brown, Meta, John Grigsby, Wilbert van der Klaauw, Jaya Wen, and Basit Zafar (2015), "Financial Education and the Debt Behavior of the Young," Federal Reserve Bank of New York Staff Reports.

Buchanan, James M. (1969), "Opportunity Cost," in The World of Economics, Springer, 520-25. Burger, Jerry M. and Martin Shelton (2011), "Changing Everyday Health Behaviors Through Descriptive Norm Manipulations," Social Influence, 6 (2), 69-77.

Bursztyn, Leonardo, Stefano Fiorin, Daniel Gottlieb, and Martin Kanz (2015), "Moral Incentives: Experimental Evidence from Repayments of an Islamic Credit Card," NBER Working Paper Series, (September), 21611-n/a.

Callender, Claire, and Jonathon Jackson (2005), "Does the Fear of Debt Deter Students from Higher Education," Journal of Social Policy, 34 (4), 509-40.

Chatterjee, Promothesh, and Randall L. Rose (2012), "Do Payment Mechanisms Change the Way Consumers Perceive Products?," Journal of Consumer Research, 38 (6), 1129-39. Cialdini, R. B., and M. R. Trost (1998), "Social influence: Social norms, conformity and 
compliance," in The Handbook of Social Psychology, New York, NY, U.S.: McGraw-Hill, 151-92.

Cialdini, R.B. (2001), Influence: Science and Practice, Boston, MA: Allyn \& Bacon.

Cialdini, Robert B and Noah J Goldstein (2004), "Social Influence : Compliance and Conformity," Annual Review Psychology., (1974), 591-621.

Cook, Laurel Aynne and Raika Sadeghein (2018), "Effects of Perceived Scarcity on Financial Decision Making," Journal of Public Policy \& Marketing, 37 (1), 68-87.

Credit Card Accountability Responsibility And Disclosure Act of 2009 (2009), 123 STAT. 1734.

Danes, Sharon M., and Heather R. Haberman (2007), "Jamestown 7-24-09 Parking Lot View," Journal of Financial Counseling and Planning, 18 (2), 48-60.

Deaton, Angus (1992), Understanding Consumption, Oxford: Oxford University Press.

Fernandes, D., Jhon. G. Jr Lynch, and R. G. Netemeyer (2014), "Financial Literacy, Financial Education, and Downstream Financial Behaviors," Management Science, 60(8) (February 2017), 1861-83.

Fishbein, M. and I. Ajzen (1975), Belief, Attitude, Intention, and Behavior: An Introduction to Theory and Research, MA: Addison-Wesley.

Fitzgerald, M. Paula (2017), "Reflections on 'Word-of-Mouth Effects on Short-Term and LongTerm Product Judgments'," Journal of Global Scholars of Marketing Science, 27 (3), 18083.

Floyd, Kristopher, Ryan Freling, Saad Alhoqail, Hyun Young Cho, and Traci Freling (2014), "How Online Product Reviews Affect Retail Sales: A Meta-Analysis," Journal of Retailing, 90 (2), 217-32.

Folkman, Susan and Richard S. Lazarus (1988), "Coping as a Mediator of Emotion,” Journal of Personality and Social Psychology, 54 (3), 466-75.

Frederick, Shane, Ravi Dhar, Jing Wang, Nathan Novemsky, and Stephen Nowlis (2009), “Opportunity Cost Neglect," Journal of Consumer Research, 36 (4), 553-61.

Gafeeva, Rufina, Erik Hoelzl, and Holger Roschk (2018), "What Else Can Your Payment Card Do? Multifunctionality of Payment Modes Can Reduce Payment Transparency," Marketing Letters, 29 (1), 61-72.

Gal, David, and Blakeley B. Mcshane (2012), "Can Small Victories Help Win the War?

Evidence from Consumer Debt Management," Journal of Marketing Research, 49 (4), 487 501.

Gathergood, John, Neale Mahoney, Neil Stewart, and Joerg Weber (2018), "How Do Americans

Repay Their Debt? The Balance-Matching Heuristic," SSRN Electronic Journal.

Gerson, Emily Starbuck (2019), "Average U.S. Credit Card Debt in 2019," MagnifyMoney.

Gist, Marilyn E., and Terence R. Mitchell (1992), "Self-Efficacy: A Theoretical Analysis of Its Determinants and Malleability," Academy of Management Review, 17 (2), 183-211.

Goldstein, Noah J., Robert B. Cialdini, and Vladas Griskevicius (2008), "A Room With a Viewpoint: Using Social Norms to Motivate Environmental Conservation in Hotels," Journal of Consumer Research, 35 (3), 472-82.

Gourville, John T. and Dilip Soman (1998), "Payment Depreciation: The Behavioral Effects of Temporally Separating Payments From Consumption," Journal of Consumer Research, 25 (2), 160-74.

Greenberg, Adam Eric and Hal E. Hershfield (2016), "Debt Aversion and the Trajectories of Psychological Pain," in North America - Advances in Consumer Research Volume 44, 123- 
27.

Haruvy, Ernan, Dan Ariely, and Uri Gneezy (2017), "Social Norms and the Price of Zero," Journal of Consumer Psychology, 28 (2).

Haws, Kelly L., William O. Bearden, and Gergana Y. Nenkov (2012), "Consumer Spending Self-Control Effectiveness and Outcome Elaboration Prompts," Journal of the Academy of Marketing Science, 40 (5), 695-710.

Hayes, A. F. (2012), "PROCESS: A Versatile Computational Tool for Observed Variable Mediation, Moderation, and Conditional Process Modeling [White paper]. Retrieved from http://www.afhayes.com/ public/process2012.pdf."

Heath, Chip and Jack B. Soll (1996), "Mental Budgeting and Consumer Decisions," Journal of Consumer Research, 23 (1), 40-52.

Hershfield, Hal E. and Neal J. Roese (2015), "Dual Payoff Scenario Warnings on Credit Card Statements Elicit Suboptimal Payoff Decisions," Journal of Consumer Psychology, 25 (1), $15-27$.

Hirst, D. Eric, Edward J. Joyce, and Michael S. Schadewald (1994), "Mental Accounting and Outcome Contiguity in Consumer-Borrowing Decisions," Organizational Behavior and Human Decision Processes, 58 (1), 136-152.

Hoelzl, Erik, Maria Pollai, and Bernadette Kamleitner (2009), "Experience, Prediction, and Recollection of Loan Burden," Journal of Economic Psychology, 30 (3), 446-54.

"Household Debt and Credit Report" (2018), Federal Reserve Bank of New York. Retrieved from https://www.newyorkfed.org/microeconomics/hhdc.html.

Hsee, Christopher K., Yang Yang, Xingshan Zheng, and Hanwei Wang (2014), "Lay Rationalism: Individual Differences in Using Reason Versus Feelings to Guide Decisions," Journal of Marketing Research, 52 (1), 134-46.

Humphreys, Ashlee, and Rebecca Jen-Hui Wang (2018), “Automated Text Analysis for Consumer Research,” Journal of Consumer Research, 44 (6), 1274-1306.

Inman, J. Jeffrey, Russell S. Winer, and Rosellina Ferraro (2009), "Characteristics, Customer Characteristics, and Customer Activities on In-Store Decision," Journal of Marketing, 73 (September), 19-29.

Jones, Lauren Eden, Cäzilia Loibl, and Sharon L. Tennyson (2012), "The Effects of CARD Act Disclosures on Consumers' Use of Credit Cards," SSRN Electronic Journal, 10.2139/ssrn.2034419, 0-51.

Kamleitner, Bernadette and Berna Erki (2013), "Payment Method and Perceptions of Ownership," Marketing Letters, 24 (1), 57-69.

Kettle, Keri L. and Simon J. Blanchard (2016), "Repayment Concentration and Consumer Motivation to Get Out of Debt," Journal of Consumer Research, 43 (May), 460-77.

Kidd, Carla (2019), "Household Debt in Great Britain: April 2016 to March 2018," Office for National Statistics, [available at https://www.ons.gov.uk/peoplepopulationandcommunity/personalandhouseholdfinances/inc omeandwealth/bulletins/householddebtingreatbritain/april2016tomarch2018].

Kivetz, Ran and Itamar Simonson (2002), "Self-Control for the Righteous: Toward a Theory of Precommitment to Indulgence," Journal of Consumer Research, 29 (2), 199-217.

Knutson, Brian, Scott Rick, G. Elliott Wimmer, Drazen Prelec, and George Loewenstein (2007), "Neural Predictors of Purchases," Neuron, 53 (1), 147-56.

Komos, Matt (2019), "2019 Predictions: Consumer Credit, Balance and Delinquency Rates," 
TransUnion, [available at https://www.transunion.com/blog/consumer-credit-balancedelinquency-rates-2019-predictions].

LaMagna, Maria (2018), "Overdraft Fees Haven't Been This Bad Since the Great Recession," MarketWatch, [available at https://www.marketwatch.com/story/overdraft-fees-haventbeen-this-bad-since-the-great-recession-2018-03-27].

Lamberton, Cait Poynor (2013), "A Spoonful of Choice: How Allocation Increases Satisfaction with Tax Payments," Journal of Public Policy \& Marketing, 32 (2), 223-38.

Lapinski, M. and R. Rimal (2005), "An Explication of Social Norms," Communication Theory, 15 (2), 127-47.

Lazarus, R. S., and S. Folkman (1991), Stress and Coping: An Anthology, New York, NY, US: Columbia University Press.

Lee, Chang-Yuan, Carey K. Morewedge, Guy Hochman, and Dan Ariely (2019), "Small Probabilistic Discounts Stimulate Spending: Pain of Paying in Price Promotions," Journal of the Association for Consumer Research, 2 (April): 160-171.

Lown, Jean M (2011), "Development and Validation of a Financial Self-Efficacy Scale," Journal of Financial Counseling and Planning, 22 (2), 54-63.

Lusardi, A. and P. Tufano (2011), "Debt Literacy, Financial Experience, and Overindebtedness." Mazar, Nina, Hilke Plassmann, Nicole Robitaille, and Axel Lindner (2017), "Pain of Paying? A Metaphor Gone Literal: Evidence from Neural and Behavioral Science," SSRN Electronic Journal, Retrieved from https://papers.ssrn.com/sol3/papers.cfm?abstract_id=2901808.

McHugh, Sandie, and Rob Ranyard (2016), "Consumers' Credit Card Repayment Decisions: The Role of Higher Anchors and Future Repayment Concern," Journal of Economic Psychology, 52, 102-14.

Morris, Joshua, and Szu-Chi Huang (2016), "When Your Hands Are Tied: the Effect of Expense Ownership on Financial Decisions," in North America - Advances in Consumer Research Volume 44, 190-94.

Navarro-Martinez, Daniel, Linda Court Salisbury, Katherine N Lemon, Neil Stewart, William J. Matthews, and Adam J. L. Harris (2011), "Minimum Required Payment and Supplemental Information Disclosure Effects on Consumer Debt Repayment Decisions," Journal of Marketing Research, 48, S60-77.

Nielsen, Christopher S., Roland Staud, and Donald D. Price (2009), "Individual Differences in Pain Sensitivity: Measurement, Causation, and Consequences," Journal of Pain, 10 (3), 231-37.

Okada, E. M. (2005), "Justification Effects on Consumer Choice of Hedonic and Utilitarian Goods.," Journal of Marketing Research, 42, 43-53.

Otto, A. S., Brennan Davis, Kirk Wakefield, Joshua J. Clarkson, and J. Jeffrey Inman (2019), "Consumer Strategies to Improve the Efficacy of Posted Calorie Information: How Provincial Norms Nudge Consumers to Healthier Consumption," Journal of Consumer Affairs, 54, 311-341.

Patrick, Vanessa M. and C. Whan Park (2006), "Paying Before Consuming: Examining the Robustness of Consumers' Preference for Prepayment," Journal of Retailing, 82 (3), 16575.

Peñaloza, Lisa, and Michelle Barnhart (2011), "Living U.S. Capitalism: The Normalization of Credit/Debt," Journal of Consumer Research, 38 (4), 743-62.

Pennebaker, J.W., R.J. Booth, R.L. Boyd, and M.E. Francis (2015), Linguistic Inquiry and Word 
Count: LIWC 2015, Austin, TX: Pennebaker Conglomerates.

Perry, Vanessa G. and Marlene D. Morris (2005), "Who Is in Control? The Role of Self-

Perception, Knowledge, and Income in Explaining Consumer Financial Behavior," Journal of Consumer Affairs, 39 (2), 299-313.

Pomerance, Justin, and Nicholas Reinholtz (2018), "Advancing a Slack-Based Theory of the Pain-of-Payment," in 2018 Society for Consumer Psychology, Dallas, USA, 9-10.

Ponce, Alejandro, Enrique Seira, and Guillermo Zamarripa (2014), "Borrowing on The Wrong Credit Card: Evidence from Mexico," Banco de México, Ciudad de México, 107 (4), 133561.

Prelec, Drazen and George Loewenstein (1998), "The Red and the Black: Mental Accounting of Savings and Debt," Marketing Science, 17 (1), 4-28.

Quispe-Torreblanca, Edika, Neil Stewart, John Gathergood, and George Loewenstein (2019), "The Red, the Black, and the Plastic: Paying Down Credit Card Debt for Hotels Not Sofas," Management Science, (May), 1-19.

Raghubir, Priya and Joydeep Srivastava (2008), "Monopoly Money: The Effect of Payment Coupling and Form on Spending Behavior," Journal of Experimental Psychology: Applied, 14 (3), 213-25.

- and (2009), "The Denomination Effect," Journal of Consumer Research, 36 (4), 701-13.

Raghunathan, Rajagopal, Michel T. Pham, and Kim P. Corfman (2006), "Informational Properties of Anxiety and Sadness, and Displaced Coping," Journal of Consumer Research, 32 (4), 596-601.

Ramanathan, Suresh, and Patti Williams (2007), "Immediate and Delayed Emotional Consequences of Indulgence: The Moderating Influence of Personality Type on Mixed Emotions," Journal of Consumer Research, 34 (2), 212-23.

Real, K. and R. N. Rimal (2003), "Understanding the Influence of Perceived Norms on Behaviors," Communication Theory, 13 (2), 184-203.

Reno, Raymond R., Robert B. Cialdini, and Carl A. Kallgren (1993), "The Transsituational Influence of Social Norms," Journal of Personality and Social Psychology, 64 (1), 104-12.

Reyna, Valerie F. and Evan A. Wilhelms (2017), "The Gist of Delay of Gratification: Understanding and Predicting Problem Behaviors," Journal of Behavioral Decision Making, 30 (2), 610-25.

Rick, Scott (2018), “Tightwads and Spendthrifts: An Interdisciplinary Review," Financial Planning Review, 1 (1-2), 1-9.

Rick, Scott I., Cynthia E. Cryder, and George Loewenstein (2008), "Tightwads and Spendthrifts," Journal of Consumer Research, 34 (6), 767-82.

$\longrightarrow$, Deborah A. Small, and Eli J. Finkel (2011), "Fatal (Fiscal) Attraction: Spendthrifts and Tightwads in Marriage," Journal of Marketing Research, 48 (2), 228-37.

Ringle, Christian M., Wende, Sven, and Becker, Jan-Michael. (2015), "SmartPLS 3," Bönningstedt: SmartPLS. Retrieved from http://www.smartpls.com

Roos, Dave (2018), "How Debt Works," [available at https://money.howstuffworks.com/personal-finance/debt-management/debt1.htm].

Rounds, Hannah (2018), “Average Credit Card Debt in the U.S. in 2018," [available at https://www.magnifymoney.com/blog/news/u-s-credit-card-debt-by-thenumbers628618371/]. 
Salisbury, Linda Court (2014), "Minimum Payment Warnings and Information Disclosure Effects on Consumer Debt Repayment Decisions," Journal of Public Policy \& Marketing, 33 (1), 49-64.

Schultz, P. Wesley, Jessica M. Nolan, Robert B. Cialdini, Noah J. Goldstein, and Vladas Griskevicius (2007a), "The Constructive, Restructive, and Reconstructive Power of Social Norms," Psychological Science, 18 (5), 429-34.

Schwartz, Joseph E., John Neale, Chris Marco, Saul S. Shiffman, and Arthur A. Stone (1999), "Does Trait Coping Exist? A Momentary Assessment Approach to the Evaluation of Traits," Journal of Personality and Social Psychology, 77 (2), 360-69.

Shafir, Eldar, Itamar Simonson, and Amos Tversky (1993), "Reason-Based Choice," Cognition, 49 (1-2), 11-36.

Shah, A., J. Bettman, and J. Payne (2014), "Psychological Tangibility of Money Influences Loss Aversion and Propensity For Gambling," Association for Consumer Research, 42, 184-88.

Shah, Avni, Jim Bettman, and John Payne (2012), "How the Pain-of-Payment Affects Buying Behavior in the Face of Variety," in North America - Advances in Consumer Research Volume 40, and R. (Juliet) Z. Zeynep Gürhan-Canli, Cele Otnes, ed., Duluth, MN: Association for Consumer Research, 121-24.

Shah, Avni M., Noah Eisenkraft, James R. Bettman, and Tanya L. Chartrand (2016), "Paper or Plastic?: How We Pay Influences Post-Transaction Connection," Journal of Consumer Research, 42 (5), 688-708.

Sheehan, Daniel, and Koert Van Ittersum (2018), "In-Store Spending Dynamics: How Budgets Invert Relative-Spending Patterns," Journal of Consumer Research, 45 (May), 49-67.

Shen, Hao and Robert S. Wyer Jr. (2008), "Procedural Priming and Consumer Judgments: Effects on the Impact of Positively and Negatively Valenced Information," Journal of Consumer Research, 34 (February), 727-37.

Sherif, Muzafer and Carolyn Wood Sherif (1953), Groups in Harmony and Tension; An Integration of Studies in Intergroup Relations., New York, NY: Harper and Brothers.

Soman, Dilip (2001), "Effects of Payment Mechanism on Spending Behavior: The Role of Rehearsal and Immediacy of Payments," Journal of Consumer Research, 22 (4450-74). - (2003), "The Effect of Payment Transparency on Consumption: Quasi-Experiments from the Field," Marketing Letters, 143 (2001), 173-83.

- and Amar Cheema (2002), "The Effect of Credit on Spending Decisions: The Role of the Credit Limit and Credibility," Marketing Science, 21 (1), 32-53.

Soster, Robin L., Andrew D. Gershoff, and William O. Bearden (2014), "The Bottom Dollar Effect: The Influence of Spending to Zero on Pain-of-Payment and Satisfaction," Journal of Consumer Research, 41 (3), 656-77.

Spiller, Stephen A. (2011), “Opportunity Cost Consideration,” Journal of Consumer Research, 38 (4), 595-610.

Stango, Victor, and Jonathan Zinman (2009), "What Do Consumers Really Pay on Their Checking and Credit Card Accounts? Explicit, Implicit, and Avoidable Costs," The American Economic Review, 99 (2), 424-29.

Stewart, Neil (2009), "The Cost of Anchoring on Credit-Card Minimum Repayments," Psychological Science, 20 (1), 39-41.

Sussman, Abigail B. and Rourke L. O’Brien (2015), "Knowing When to Spend: Unintended Financial Consequences of Earmarking to Encourage Savings," Journal of Marketing 
Research, 53 (5), 790-803.

and Eldar Shafir (2012), "On Assets and Debt in the Psychology of Perceived Wealth," Psychological Science, 23 (1), 101-8.

Tay, Louis, Cassondra Batz, Scott Parrigon, and Lauren Kuykendall (2017), "Debt and Subjective Well-being: The Other Side of the Income-Happiness Coin," Journal of Happiness Studies, 18 (3), 903-37.

Taylor, Catherine A., Lauren Hamvas, Janet Rice, Denise L. Newman, and William DeJong (2011), "Perceived Social Norms, Expectations, and Attitudes toward Corporal Punishment among an Urban Community Sample of Parents," Journal of Urban Health, 88 (2), 254-69.

Thaler, Richard H. (1985), "Mental Accounting and Consumer Choice," Marketing Science, 4 (3), 199-214.

(2008), "Mental Accounting and Consumer Choice," Marketing Science, 27 (1), 15-25.

Thaler, Richard H. (1980), "Toward a Positive Theory of Consumer Choice," Journal of Economic Behavior and Organization, 1, 39-60.

Thomas, Manoj, Kalpesh Kaushik Desai, and Satheeshkumar Seenivasan (2011), "How Credit Card Payments Increase Unhealthy Food Purchases: Visceral Regulation of Vices," Journal of Consumer Research, 38 (1), 126-39.

Trump, Rebecca K., Stacey R. Finkelstein, and Paul M. Connell (2015), "I will Risk a Stranger's Money, But Not My Own or My Friend's Money: Effect of Proximity of the Money Source to the Self on Financial Risk-Taking," Marketing Letters, 26 (4), 501-12.

Tsosie, Claire and Erin El Issa (2019), "The 2018 American Household Credit Card Debt Study," NerdWallet, [available at https://www.nerdwallet.com/blog/average-credit-carddebt-household/].

Tully, Stephanie M. and Eesha Sharma (2018), "Context-Dependent Drivers of Discretionary Debt Decisions: Explaining Willingness to Borrow for Experiential Purchases," Journal of Consumer Research, 44 (5), 960-73.

Verhallen, Pieter, Elisabeth Brüggen, Thomas Post, and Gaby Odekerken-Schröder (2018), "Norms in Behavioral Interventions: Peer or Anchoring Effects?," SSRN Electric Journal.

Wager, Tor D., Lauren Y. Atlas, Martin A. Lindquist, Mathieu Roy, Choong-Wan Woo, and Ethan Kross (2013), “An fMRI-Based Neurologic Signature of Physical Pain,” The New England Journal of Medicine, 368, 1388-97.

Walters, Daniel, Carsten Erner, Craig Fox, Marc Scholten, Daniel Read, and Christopher Trepel (2016), "Debt Aversion: Anomalous in Theory, Advantageous in Practice," in Advances in Consumer Research, North American - Advances in Consumer Research Volume 44, eds. Page Moreau and Stefano Puntoni, Duluth, MN : Association for Consumer Research, 17984.

Wertenbroch, Klaus, Dilip Soman, and Joseph Nunes (2001), "Debt Aversion as Self-Control: Consumer Self-Management of Liquidity Constraints."

Williams, Fred O. (2018), "How Much is the Average Credit Card Debt in America?," [available at https://www.creditcards.com/credit-card-news/average-credit-card-debt.php].

Worthington, A. C. (2006), "Debt as a Source of Financial Stress in Australian Households," International Journal of Consumer Studies, 30 (January), 2-15.

Xu, Qian, Yuanji Zhou, Maolin Ye, and Xinyue Zhou (2012), "Perceived Social Support Reduces the Pain of Spending Money," Journal of Consumer Psychology, 25 (2), 219-30.

"Your Money, Your Goals: A Financial Empowerment Toolkit for Social Services Programs" 
(2015), Consumer Financial Protection Bureau, Retrieved from https://files.consumerfinance.gov/f/201407_cfpb_your-money-yourgoals_toolkit_english.pdf.

Zauberman, Gal, and John G. Jr. Lynch (2005), "Resource Slack and Propensity to Discount Delayed Investments of Time Versus Money," Journal of Experimental Psychology: General, 134 (1), 23-37.

Zellermayer, Ofer (1997), “The Pain of Paying," Dissertation Submitted to the Carnegie Melon University.

Zhu, Feng, and Xiaoquan (Michael) Zhang (2010), "Impact of Online Consumer Reviews on Sales: The Moderating Role of Product and Consumer Characteristics," Journal of Marketing, 74 (2), 133-48. 


\section{Appendices}

\section{Appendix A- Scenario Used in Essay 2, Study 1}

Imagine that:

Five months ago, you took out a loan to purchase a used car because your previous car did not look new and lustrous anymore and had a few small dents on it [was not reliable and safe anymore and was creating serious problems for you].

Your previous car had very low [high] mileage on it and was completely functional. You knew that you could continue driving this car without experiencing safety problems. However, you wanted to have a car that looks new and lustrous and you didn't like the appearance of your old car [You needed to have a reliable and secure car and you did not feel safe in your old car]. So, you decided to purchase a new car.

After searching and comparing the available cars on the market, you found a used car that you liked and was built in recent years at a dealership that you trusted. The new, used car was much more lustrous and attractive than your old car [The new, used car was much more reliable and safe than your old car]. You went to the dealership to purchase the car.

The car was priced at \$14,000. The dealership offered you a 4-year loan with an annual interest rate of $10 \%$ to purchase the car. Using this loan, you were able to purchase the car by paying $\$ 355$ every month for 4 years. You really wanted to buy this car, so you decided to use the loan and purchase the car.

Here's an overview of the loan you used to purchase the car. Please read this information carefully.

\begin{tabular}{|l|c|}
\hline Total amount of loan & $\$ 14,000$ \\
\hline Loan term in months & 48 months \\
\hline Interest rate & $10 \%$ \\
\hline Fixed monthly payments & $\$ 355$ \\
\hline Total interest paid by the end of the 48 months & $\$ 3,040$ \\
\hline
\end{tabular}

It's been five months since you used the loan and purchased the car. Remember that you bought this car because your old car did not look new and lustrous anymore and had a few 
small dents on it [Remember that you bought this car because your old car was not reliable and safe anymore and was creating serious problems for you].

So far, you've made all past payments of the loan on time. Today you have to make the fifth payment (\$355) towards this loan. You log in to the bank's website and make the fifth payment. You must make 43 more fixed monthly payments of $\$ 355$ to pay off this loan. 


\section{Appendix B- Scenario and Stimuli Used in Essay 2, Study 2}

Three months ago, you decided to purchase a new TV. When searching online, you found a highly rated big screen $8 K H D T V$ that was recently introduced to the market. This TV was built using the latest technologies in the market and was priced at $\$ 5400$. You liked the TV, so you decided to go to a store in your neighborhood and check it out.

At the store, you found out that the store offers a 36-months financing option with a 6\% annual interest rate to purchase any digital products. If you use the financing option to purchase the TV, you must make fixed monthly payments of \$164 for 36 months. You decided to take the financing option and purchase the TV using this loan.

When checking out at the store, the employee asked you to read the loan terms and sign the contract. Please take a few minutes to carefully read the loan information.

Loan Terms:

\begin{tabular}{|c|c|}
\hline The total amount of the loan & $\$ 5400$ \\
\hline Number of Payments & 36 monthly payments \\
\hline Annual interest rate & $6 \%$ \\
\hline $\begin{array}{c}\text { Monthly Payments (The amount you must pay every } \\
\text { month) }\end{array}$ & $\$ 164$ \\
\hline Total interest paid by the end of the three years & $\$ 504$ \\
\hline
\end{tabular}

Sign the contract by typing I agree in the following box.[text input]

Remember that you purchased the TV three months ago using the 36-month financing loan option. Every month you must log in to the store's website to make your payments.

So far you have made all of the three past payments in time. Today you must pay the 4th installment towards this loan. Before making the payment, you start browsing the internet and you find the following article on the website of the Association of Consumers and Bankers.

Please take a few minutes to read the article.

\section{[manipulation stimuli]}

After reading the article, you log in to the store's website and you make the \$164 payment for this month. 
[High social acceptability condition]

The Vast Majority of American Customers (90\%) Use Financing/Loan Options to Buy Digital Products.

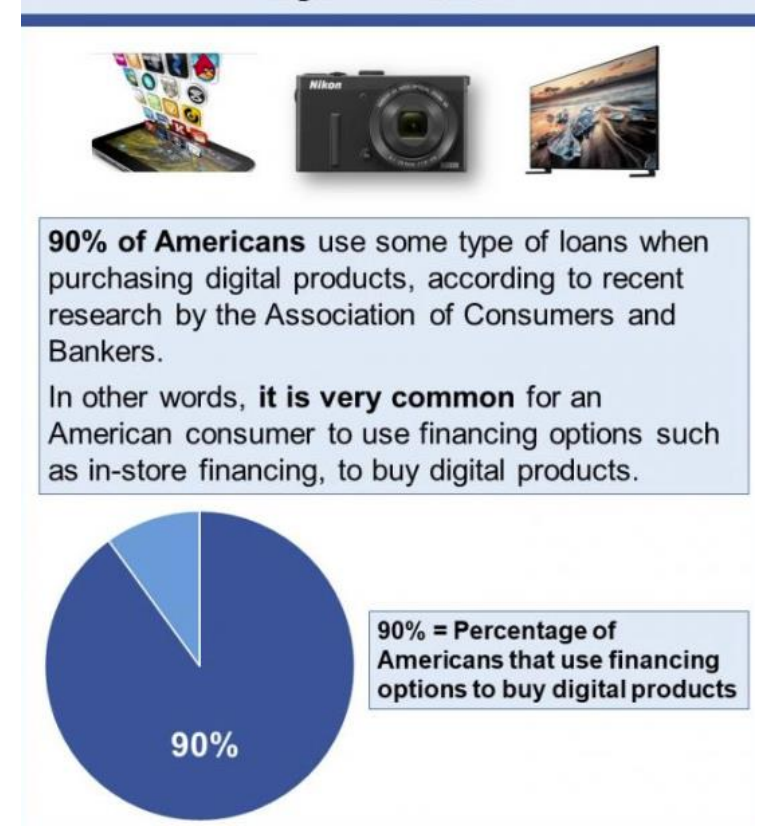

[Low social acceptability condition]

Very Few American Customers (10\%) Use Financing/Loan Options to Buy Digital Products.

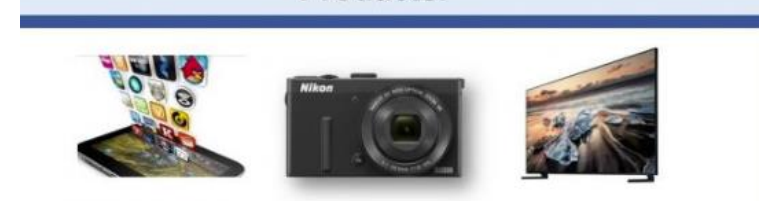

$10 \%$ of Americans use some type of loans when purchasing digital products, according to recent research by the Association of Consumers and Bankers.

In other words, it is very uncommon for an American consumer to use financing options such as in-store financing, to buy digital products.

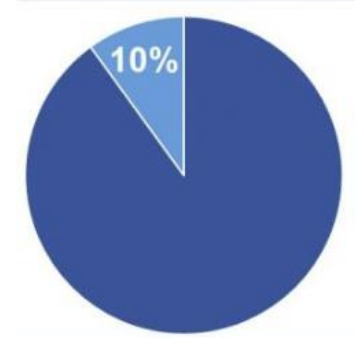

$10 \%=$ Percentage of Americans that use financing options to buy digital products 


\section{Appendix C- Scenario and Stimuli used in Essay 3, Study 1}

\section{Study Instructions}

In this survey, you will read a scenario in which you will be asked to imagine that you have borrowed a loan to purchase a product and then you will answer a few questions regarding that loan. After answering those questions, you will participate in a game that simulates loan repayment in real life.

Each round of the game represents one month of loan repayment. You will play the game for 7 rounds. The goal of this game is for you to make monthly financial decisions regarding how you want to repay the loan described in the scenario.

\section{Scenario}

Last month, you took out an auto loan to purchase a used car, which you use for your daily commute. The car was priced at \$7,900. You took a 48-month auto loan with an annual interest rate of $10 \%$ to purchase the car. Using this loan, you were able to purchase the car by paying fixed monthly payments of $\$ 200$ for 48 months. At this interest rate, you will pay $\underline{\$ 1,721}$ in interest by the end of the 48-month time period.

It has been almost a month since you bought this car using the loan. Today, you must make the first payment on this loan. Before you make the payment, you recall a recent experience you had with the car you just bought. Yesterday, you had trouble starting the car. After trying everything else, you had the car towed to a local mechanic. It turned out that your car's malfunction was caused by a broken starter, which the mechanic replaced immediately.

\section{[Negative benefits manipulation]}

After fixing the car, the mechanic told you that your car is an old model and has very high mileage on it. Since this car has been driven a lot, most of its crucial parts are very old and worn.

As a result, your car would not be safe to drive in the near future without replacing these costly parts. Worse yet, you are very likely to face regular costly repairs in the near future.

\section{[Low benefits manipulation]}

After fixing the car, the mechanic told you that your car is an old model and has very high mileage on it. Since this car has been driven a lot, most of its crucial parts are very old and worn.

Despite having the worn parts, your car would be perfectly safe to drive for a few more years without replacing these costly parts and you are unlikely to face regular costly repairs in the near future.

\section{[High benefits manipulation]}

After fixing the car, the mechanic told you that your car is an old model but it has very low mileage on it. Since this car has not been driven much, most of its crucial parts are very new and unworn. 
As a result, your car would be perfectly safe to drive for a very long time without replacing these costly parts. Better yet, you are unlikely to face regular costly repairs in the near future.

\section{Game Instructions}

Now that you've read the scenario you can play the loan repayment game.

You can read the instructions on the next page. You will be asked a few questions about the game instructions before playing the game. If you answer them incorrectly, you will leave the survey and will not get paid.

The goal of this game is for you to make monthly financial decisions regarding how to pay the loan described in the scenario. You will play this game for 7 rounds representing 7 months of loan repayment. In each round, you will be asked to imagine that after paying your bills and buying your necessities, you have $\$ 600$ left and you must decide how to allocate this money. You can use the $\$ 600$ to: 1) pay off the described loan, 2) put in savings, or 3) spend on something you like. In each round, after reading the loan statement, you will be asked to decide how much of this $\$ 600$ you would like to allocate to each of these three purposes. After playing each round, your loan balance will be recalculated based on the amount you decided to pay on the loan and then you will play the next round.

Remember that you borrowed a $\$ 7,900$ loan with a $10 \%$ annual interest rate to purchase the car. You must pay $\$ 200$ every month to pay off this loan in 48 months. Interest will be calculated monthly and will be added to your loan balance. If you don't pay the fixed monthly payment (\$200) each month, you will be charged a \$25 late payment fee, which will be added to your loan balance.

On the next page, you will be asked to answer a few questions about the game's instructions. If you answer any of them incorrectly, you will leave the survey and will not get paid. 


\section{Appendix D- Scenario and Stimuli Used in Essay 3, Study 2}

One year ago, you took out an auto loan to purchase a used car, which you currently use for your daily commute. The car was priced at $\$ 8,000$. You took a 48-month auto loan with an annual interest rate of $10 \%$ to purchase the car. Using this loan, you were able to purchase the car by paying fixed monthly payments of $\$ 202$ for 48 months. At this interest rate, you will pay \$1,696 in interest by the end of the 48-months time period.

It has been almost a year since you bought your car. Today, you must pay the 12th payment on this auto loan. Before you make the loan payment, you recall a recent experience you had with your car. Yesterday, you had trouble starting your car. After trying everything else, you had the car towed to a local mechanic. It turned out that your car's malfunction was caused by a broken starter, which the mechanic replaced immediately.

\section{[Negative benefits manipulation]}

After fixing the car, the mechanic told you that your car is an old model and has very high mileage on it. Since this car has been driven a lot, most of its crucial parts are very old and worn.

As a result, your car would not be safe to drive in the near future without replacing these costly parts. Worse yet, you are very likely to face regular costly repairs in the near future.

\section{[Low benefits manipulation]}

After fixing the car, the mechanic told you that your car is an old model and has very high mileage on it. Since this car has been driven a lot, most of its crucial parts are very old and worn.

Despite having the worn parts, your car would be perfectly safe to drive for a few more years without replacing these costly parts and you are unlikely to face regular costly repairs in the near future.

\section{[High benefits manipulation]}

After fixing the car, the mechanic told you that your car is an old model but it has very low mileage on it. Since this car has not been driven much, most of its crucial parts are very new and unworn.

As a result, your car would be perfectly safe to drive for a very long time without replacing these costly parts. Better yet, you are unlikely to face regular costly repairs in the near future.

\section{[No replacement manipulation]}

Recalling your experience with the mechanic made you think about your car situation. You knew that your car was an old model. However, you decided that you will NOT replace this car in the near future. After making this decision, you opened the bank's website and you made the 12th payment on the auto loan. 


\section{[Replacement manipulation]}

Recalling your experience with the mechanic made you think about your car situation. You knew that your car was an old model. So, you decided to replace this car in the near future. After making this decision, you opened the bank's website and you made the 12th payment on the auto loan. 